Journal of Engineering Sciences, Assiut University, Vol.35, No. 5, pp.1139-1199, Sep. 2007

\title{
SOME MAIN FACTORS AFFECTING EFFICIENCY OF EXTERNALLY BONDED PARTIALLY LATERAL WRAPPING CFRP OF AXIALLY SHORT STATIC LOADING PLAIN AND R.C COLUMNS
}

\section{Abdel Rahman Megahid, Khairy Hassan Abel Kareem, Omar Ahmed Farghal, and}

Civil Engineering Department, faculty of Engineering, Assiut University, Assiut, EGYPT

\section{Mahmoud Mohamed El-Taher}

Consulting Engineer, Supreme Council of Luxor, Luxor, EGYPT

(Received July $1^{\text {st }}, 2007$ Accepted July 20, 2007)

Plain and reinforcement concrete columns have an important function in the structural concept of many structures. Often, these columns are vulnerable to exceptional loads (such as impact, explosion or seismic loads), load increase (increasing use or change of function of structures, etc.) and degradation (corrosion of steel reinforcement, alkali silica reaction, etc.). On the other hand, confinement of concrete is an efficient technique to enhance the structural behavior of concrete members primarily subjected to compression. Since the introduction of Fiber Reinforced Polymer (FRP) as externally bonded reinforcement confinement by means of Carbon Fiber Reinforced Polymer (CFRP) wrapping has been of considerable interest for the upgrading of columns, piers, chimneys, etc. It may also be necessary to strengthen old RC structures a result of new code equipment or because of damage to the structure of environmental stresses.

The efficiency of this strengthening technique depends mainly upon the encountered parameters such as concrete strength, percentage of longitudinal reinforcement, volume of internal stirrup, shape and size of cross-section, volume of wrapped reinforcement and arrangements of wrapped sheets. Therefore, the herein work describes an experimental work of 37 columns to study the behavior of plain and reinforced concrete circular, square and rectangular short axially loaded unconfined and confined columns with externally CFRP wrapping reinforcement. The measured strains in axial direction were recorded at the different axial load levels for the different tested columns and plotted against the corresponding axial stresses comparing the axial stress-axial strain relations of the strengthened columns with that of non-strengthened columns. The program was planned to investigate the effect of size of cross section of columns, shape of cross section and percentage of longitudinal steel of columns, percentage of lateral steel (stirrups) and strengthening system of columns on the confined concrete behavior and the efficiency of such confinement in terms of the induced axial nominal stress, axial nominal strain, the initial modulus of elasticity and the modulus of toughness which represents the area under stress-strain curve and the percentage of increase of modulus of toughness. 
KEYWORDS: Carbon Fiber Reinforced Polymer (CFRP), wrapping, strengthening, efficiency, plain and reinforced short columns.

\section{1- INTRODUCTION}

Fiber reinforcement polymer (FRP) materials are composites which consist of organic or inorganic fibers embedded in matrix, the matrix sometimes referred to as binder, is a polymer resin, often with some fillers and additives of various natures.

Externally bonded Carbon Fiber Reinforced Polymer (CFRP) sheets are particularly suitable for strengthening and repairing of reinforced concrete structure elements due to the high axial strength compared to steel, low weight, excellent corrosion resistance and non susceptibility to a wide range of aggressive media, electromagnetic neutrality, excellent fatigue characteristics for CFRP, low axial coefficient of thermal expansion and very simple to be applied in a wide variety without any difficulties, which is considered from the principals when applying the alternative techniques e.g. steel plate technique. Moreover, CFRP sheets are very easy to be cut and wrapped in order to be applied as either closed stirrups or U-jacket strips $[1,2,3,4,5,6,7,8,9,10]$.

\section{Previous Works}

Mark et al. [11] carried out tests to investigate the size effect in axially loaded squaresection concrete prisms strengthened Using CFRP wrapping:. The percentage increase in peak axial strain achieved by wrapping is reduced slightly as the cross- sectional size was increased. The effect of size on the in increase in peak axial strain was not significant as its effect on the increase in strength. Reza et al. [12] carried out tests to study the effect of shape. They concluded that: the axial strength of circular columns strengthened with two layers of FRP increased by up to $106 \%$ than the case of square. The application of FRP wrap may not increase the axial strength of square columns. However, if the corners of the square columns are rounded appropriately, the axial strength and ductility of columns increase considerably. Where the axial strength of the square columns $\mathrm{C}$ (rounded edge $12 \mathrm{~mm}$ ) improved by up to $15 \%$ than the sharp edges, also the ductility has improved.

The aim of herein work is, from one hand to study the behavior of plain and reinforced concrete axially loaded short unconfined and confined columns with various shapes and sizes in terms of stress and strain characteristics. From the other hand, the aim is to evaluate their strength, ductility, stiffness as well as toughness showing the effect of both size and shape on such properties. At the same time showing how the efficiency of confinement and used technique is affected by same included parameters such as: type of column either plain or reinforced, \% of lateral reinforcement (stirrups), strengthening technique, shape and size of cross-section

\section{2- EXPERMENTAL PROGRAM}

\section{2-1 Test Specimens}

Tests of thirty-seven plain and reinforced short concrete columns with different sizes and shapes of cross-sections were constructed to study the included parameters under axial 
static loading. The concrete columns were divided into two main groups; eighteen plain concrete columns and nineteen reinforced concrete columns with different longitudinal and lateral reinforcements. The height for plain and reinforced concrete columns was $100 \mathrm{~cm}$. The experimental program was divided into seven groups (Groups $\boldsymbol{A}, \boldsymbol{B}, \boldsymbol{C}, \boldsymbol{D}$,

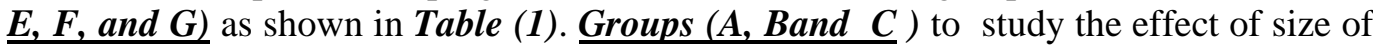
cross-section of plain concrete, $\operatorname{group}(\boldsymbol{D})$ to study the effect shape of cross- section of plain concrete column, group $(\boldsymbol{E})$ to study the effect shape of cross- section of reinforced concrete columns, group $(\boldsymbol{F})$ to study the effect size of cross- section of reinforced concrete columns and $\operatorname{group}(\boldsymbol{G})$ to study the effect of stirrup percentage and strengthening technique,

Table (1) Description of test specimens including the experimental program (Series 1) Group A, B, C and D (Plain Concrete Columns)

\begin{tabular}{|c|c|c|c|c|c|c|c|}
\hline Group & $\begin{array}{c}\text { Col. } \\
\text { designation }\end{array}$ & Constants & Parameter & Shape & $\begin{array}{l}\text { Cross- section } \\
\text { dimensions }\end{array}$ & $\begin{array}{c}\text { Strengthening } \\
\text { system }\end{array}$ & $\begin{array}{c}\% \text { of } \\
\text { confinement } \\
\left(\mu_{\mathrm{f}} \%\right)\end{array}$ \\
\hline \multirow{6}{*}{$\mathbf{A}$} & Ac $1-0$ & \multirow{6}{*}{ 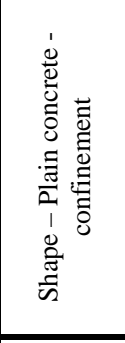 } & \multirow{18}{*}{ 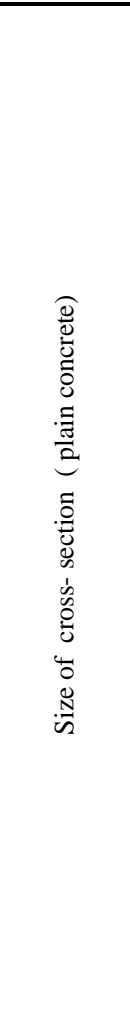 } & \multirow{6}{*}{ 营 } & $\mathrm{D}=12.50 \mathrm{~cm}$ & - & \\
\hline & Ac $1-1$ & & & & $\mathrm{D}=12.50 \mathrm{~cm}$ & $\begin{array}{c}1 \text { layer } 5 \text { strips } \\
\mathrm{b}_{\mathrm{f}}=55 \mathrm{~mm}\end{array}$ & 0.14 \\
\hline & Ac 2-0 & & & & $\mathrm{D}=15.00 \mathrm{~cm}$ & & \\
\hline & Ac 2-1 & & & & $\mathrm{D}=15.00 \mathrm{~cm}$ & $\begin{array}{c}1 \text { layer } 5 \text { strips } \\
\mathrm{b}_{\mathrm{f}}=66 \mathrm{~mm}\end{array}$ & 0.14 \\
\hline & Ac 3-0 & & & & $\mathrm{D}=17.00 \mathrm{~cm}$ & 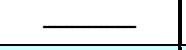 & \\
\hline & Ac 3-1 & & & & $\mathrm{D}=17.00 \mathrm{~cm}$ & $\begin{array}{c}1 \text { layer } 5 \text { strips } \\
\mathrm{b}_{\mathrm{f}}=75 \mathrm{~mm}\end{array}$ & 0.14 \\
\hline \multirow{6}{*}{ B } & Bs $1-0$ & \multirow{6}{*}{ 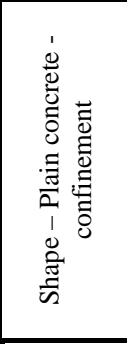 } & & \multirow{6}{*}{ 䒕 } & $\mathrm{B}=12.50 \mathrm{~cm}$ & 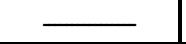 & \\
\hline & Bs $1-1$ & & & & $\mathrm{~B}=12.50 \mathrm{~cm}$ & $\begin{array}{c}1 \text { layer } 5 \text { strips } \\
b_{\mathrm{f}}=56 \mathrm{~mm}\end{array}$ & 0.14 \\
\hline & Bs 2-0 & & & & $\mathrm{B}=15.00 \mathrm{~cm}$ & - & \\
\hline & Bs $2-1$ & & & & $\mathrm{~B}=15.00 \mathrm{~cm}$ & $\begin{array}{c}1 \text { layer } 5 \text { strips } \\
b_{\mathrm{f}}=66 \mathrm{~mm}\end{array}$ & 0.14 \\
\hline & Bs 3-0 & & & & $\mathrm{B}=17.00 \mathrm{~cm}$ & - & \\
\hline & Bs 3-1 & & & & $\mathrm{B}=17.00 \mathrm{~cm}$ & $\begin{array}{c}1 \text { layer } 5 \text { strips } \\
\mathrm{b}_{\mathrm{f}}=75 \mathrm{~mm}\end{array}$ & 0.14 \\
\hline \multirow{6}{*}{ C } & Bs 2-0 & \multirow{6}{*}{ 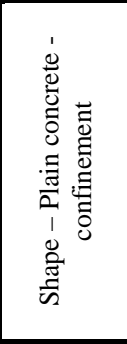 } & & \multirow{6}{*}{ 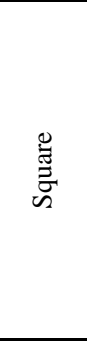 } & $15 \mathrm{~cm} \times 15 \mathrm{~cm}$ & 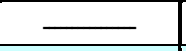 & \\
\hline & Bs $2-1$ & & & & $15 \mathrm{~cm} \times 15 \mathrm{~cm}$ & $\begin{array}{c}1 \text { layer } 5 \text { strips } \\
\mathrm{b}_{\mathrm{f}}=66 \mathrm{~mm}\end{array}$ & 0.14 \\
\hline & Cr 2-0 & & & & $15 \mathrm{~cm} \times 22.50 \mathrm{~cm}$ & & \\
\hline & Cr 2-1 & & & & $15 \mathrm{~cm} \times 22.50 \mathrm{~cm}$ & $\begin{array}{c}1 \text { layer } 5 \text { strips } \\
\mathrm{b}_{\mathrm{f}}=80 \mathrm{~mm}\end{array}$ & 0.14 \\
\hline & Cr 3-0 & & & & $15 \mathrm{~cm} \times 30.00 \mathrm{~cm}$ & $\ldots$ & \\
\hline & Cr 3-1 & & & & $15 \mathrm{~cm} \times 30.00 \mathrm{~cm}$ & $\begin{array}{c}1 \text { layer } 5 \text { strips } \\
\mathrm{b}_{\mathrm{f}}=88 \mathrm{~mm}\end{array}$ & 0.14 \\
\hline \multirow{6}{*}{ D } & Ac 3-0 & \multirow{6}{*}{ 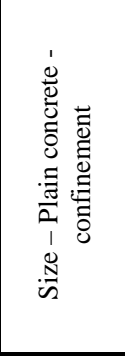 } & \multirow{6}{*}{ 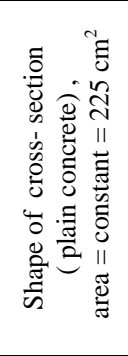 } & \multirow{6}{*}{ 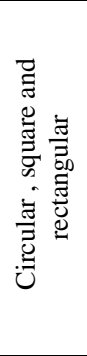 } & $\mathrm{D}=17.00 \mathrm{~cm}$ & 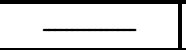 & \\
\hline & Ac 3-1 & & & & $\mathrm{D}=17.00 \mathrm{~cm}$ & $\begin{array}{c}\text { layer } 5 \text { strips } \\
\mathrm{b}_{\mathrm{f}}=75 \mathrm{~mm}\end{array}$ & 0.14 \\
\hline & Bs 2-0 & & & & $\mathrm{B}=15.00 \mathrm{~cm}$ & 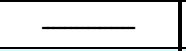 & \\
\hline & Bs $2-1$ & & & & $\mathrm{~B}=15.00 \mathrm{~cm}$ & $\begin{array}{c}1 \text { layer } 5 \text { strips } \\
\mathrm{b}_{\mathrm{f}}=66 \mathrm{~mm}\end{array}$ & 0.14 \\
\hline & Dr $1-0$ & & & & $\begin{array}{c}12.50 \mathrm{~cm} \times 18.00 \\
\mathrm{~cm}\end{array}$ & & \\
\hline & Dr 1-1 & & & & $\begin{array}{c}12.50 \mathrm{~cm} \times 18.00 \\
\mathrm{~cm}\end{array}$ & $\begin{array}{c}1 \text { layer 5strips } \\
\mathrm{b}_{\mathrm{f}}=66 \mathrm{~mm}\end{array}$ & 0.14 \\
\hline
\end{tabular}


(Series 2) Group E, F and G (Reinforced Concrete Columns)

\begin{tabular}{|c|c|c|c|c|c|c|c|c|c|}
\hline Group & $\begin{array}{c}\text { Col. } \\
\text { designation }\end{array}$ & Constants & Parameter & Shape & $\mid \begin{array}{c}\text { Cross- section } \\
\text { dimensions }\end{array}$ & $\begin{array}{c}\text { Longitudinal } \\
\text { steel }(\mu \%)\end{array}$ & $\begin{array}{l}\text { Lateral steel } \\
\qquad\left(\mu^{-} \%\right)\end{array}$ & $\begin{array}{c}\text { Strengthening } \\
\text { system }\end{array} \mid$ & $\begin{array}{c}\% \text { of } \\
\text { confinement } \\
\left(\mu_{\mathrm{f}} \%\right)\end{array}$ \\
\hline \multirow{6}{*}{$\mathbf{E}$} & Ec $1-0$ & \multirow{6}{*}{ 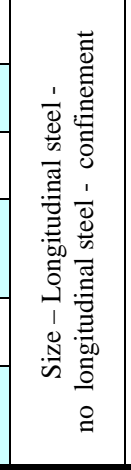 } & \multirow{6}{*}{ 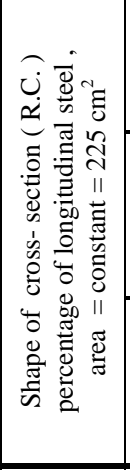 } & \multirow{2}{*}{ 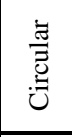 } & $\mathrm{D}=17.00 \mathrm{~cm}$ & \begin{tabular}{|c|}
$\mu=1.39 \%$ \\
$\mathrm{As}=4 \Phi 10$ \\
\end{tabular} & Ast = Zero & & \\
\hline & Ec 1-1 & & & & $\mathrm{D}=17.00 \mathrm{~cm}$ & $\begin{array}{l}\mu=1.39 \% \\
\text { As }=4 \Phi 10 \\
\end{array}$ & Ast $=$ Zero & $\begin{array}{c}1 \text { layer } 5 \text { strips } \\
\mathrm{b}_{\mathrm{f}}=75 \mathrm{~mm}\end{array}$ & 0.14 \\
\hline & Es $1-0$ & & & \multirow{2}{*}{ 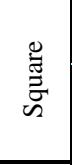 } & $\mathrm{B}=15.00 \mathrm{~cm}$ & $\begin{array}{l}\mu=1.39 \% \\
\text { As }=4 \Phi 10\end{array}$ & Ast = Zero & - & \\
\hline & Es $1-1$ & & & & $\mathrm{~B}=15.00 \mathrm{~cm}$ & $\begin{array}{l}\mu=1.39 \% \\
\text { As }=4 \Phi 10\end{array}$ & Ast $=$ Zero & $\begin{array}{c}1 \text { layer } 5 \\
\text { strips } \\
\mathrm{b}_{\mathrm{f}}=66 \mathrm{~mm}\end{array}$ & 0.14 \\
\hline & Er 1-0 & & & \multirow{2}{*}{ 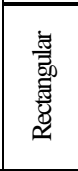 } & $\begin{array}{c}12.50 \mathrm{~cm} \mathrm{x} \\
18.00 \mathrm{~cm}\end{array}$ & $\begin{array}{l}\mu=1.39 \% \\
\text { As }=4 \Phi 10 \\
\end{array}$ & Ast = Zero & - & \\
\hline & Er 1-1 & & & & $\begin{array}{c}12.50 \mathrm{~cm} \mathrm{x} \\
18.00 \mathrm{~cm}\end{array}$ & $\begin{array}{c}\mu=1.39 \% \\
\text { As }=4 \Phi 10\end{array}$ & Ast $=$ Zero & $\begin{array}{c}1 \text { layer } 5 \\
\text { strips } \\
\mathrm{b}_{\mathrm{f}}=66 \mathrm{~mm}\end{array}$ & 0.14 \\
\hline \multirow{6}{*}{$\mathbf{F}$} & Fc 1-0 & \multirow{6}{*}{ 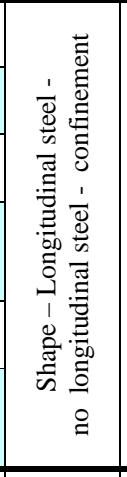 } & \multirow{6}{*}{ 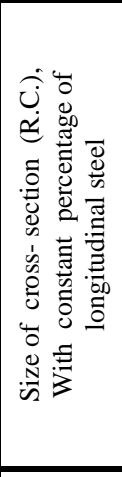 } & \multirow{2}{*}{ 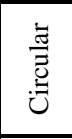 } & $\mathrm{D}=12.50 \mathrm{~cm}$ & \begin{tabular}{|c|}
$\mu=1.73 \%$ \\
As $=4 \Phi 8$
\end{tabular} & Ast = Zero & $\longrightarrow$ & \\
\hline & Fc 1-1 & & & & $\mathrm{D}=12.50 \mathrm{~cm}$ & $\begin{array}{c}\mu=1.73 \% \\
\text { As }=4 \Phi 8 \\
\end{array}$ & Ast $=$ Zero & $\begin{array}{c}1 \text { layer } 5 \text { strips } \\
\mathrm{b}_{\mathrm{f}}=55 \mathrm{~mm}\end{array}$ & 0.14 \\
\hline & Fe 2-0 & & & \multirow{2}{*}{ 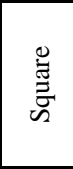 } & $\mathrm{D}=15.00 \mathrm{~cm}$ & $\begin{array}{c}\mu=1.73 \% \\
\text { As }=6 \Phi 8\end{array}$ & Ast $=$ Zero & 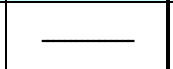 & \\
\hline & Fc 2-1 & & & & $\mathrm{D}=15.00 \mathrm{~cm}$ & $\begin{array}{c}\mu=1.73 \% \\
\text { As }=6 \Phi 8\end{array}$ & Ast $=$ Zero & $\begin{array}{c}1 \text { layer } 5 \\
\text { strips } \\
\mathrm{b}_{\mathrm{f}}=66 \mathrm{~mm}\end{array}$ & 0.14 \\
\hline & Fc 3-0 & & & \multirow{2}{*}{ 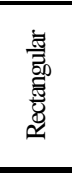 } & $\mathrm{D}=17.00 \mathrm{~cm}$ & $\begin{array}{c}\mu=1.73 \% \\
\text { As }=5 \Phi 10\end{array}$ & Ast $=$ Zero & & \\
\hline & Fc 3-1 & & & & $\mathrm{D}=17.00 \mathrm{~cm}$ & $\begin{array}{l}\mu=1.73 \% \\
\text { As }=5 \Phi 10 \\
\end{array}$ & Ast $=$ Zero & $\begin{array}{c}1 \text { layer } 5 \\
\text { strips } \\
\mathrm{b}_{\mathrm{f}}=75 \mathrm{~mm}\end{array}$ & 0.14 \\
\hline \multirow{9}{*}{$\mathbf{G}$} & Fc3-0 & \multirow{9}{*}{ 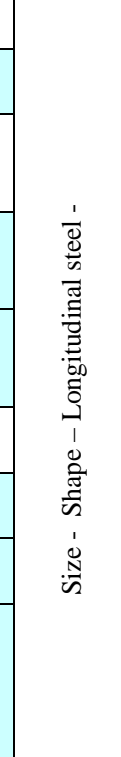 } & \multirow{9}{*}{ 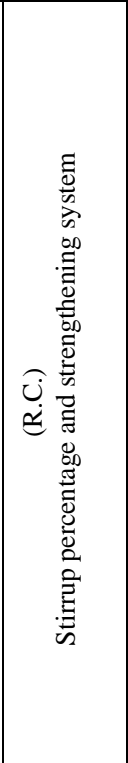 } & \multirow{9}{*}{ 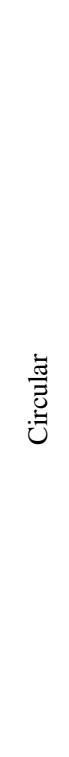 } & \multirow{9}{*}{$\mathrm{D}=17.00 \mathrm{~cm}$} & \multirow{9}{*}{$\begin{array}{c}\mu=1.73 \% \\
\text { As }=5 \Phi 10\end{array}$} & $\mu^{\prime}=0.00 \%$ & $\longrightarrow$ & \\
\hline & Fc3-1 & & & & & & $\mu^{\prime}=0.00 \%$ & $\begin{array}{c}\text { layer } 5 \text { strips } \\
b_{\mathrm{f}}=75 \mathrm{~mm}\end{array}$ & 0.14 \\
\hline & Gc $1-0$ & & & & & & $\begin{array}{c}\mu^{`}=0.33 \% \text { St. } \\
1 \varnothing 6 \mathrm{~mm} \\
@ 17.5 \mathrm{~cm} \\
\end{array}$ & & \\
\hline & Gc $1-1$ & & & & & & $\begin{array}{c}\mu^{\prime}=0.33 \% \text { St. } \\
1 \varnothing 6 \mathrm{~mm} \\
@ 17.50 \mathrm{~cm} \\
\end{array}$ & $\begin{array}{c}\text { layer } 5 \text { strips } \\
b_{\mathrm{f}}=75 \mathrm{~mm}\end{array}$ & 0.14 \\
\hline & Gc $1-2$ & & & & & & $\begin{array}{c}\mu^{`}=0.33 \% \text { St. } \\
1 \varnothing 6 \mathrm{~mm} \\
@ 17.50 \mathrm{~cm} \\
\end{array}$ & $\begin{array}{c}2 \text { layers } 5 \\
\text { strips } \\
\mathrm{b}_{\mathrm{f}}=75 \mathrm{~mm} \\
\end{array}$ & 0.28 \\
\hline & Gc $1-3$ & & & & & & \begin{tabular}{|l|}
$\mu^{`}=0.58 \%$ St. \\
$1 \emptyset 6 \mathrm{~mm} @ 10 \mathrm{~cm}$
\end{tabular} & & \\
\hline & Gc $1-4$ & & & & & & $\begin{array}{l}\mu^{\prime}=0.58 \% \mathrm{St} . \\
1 \emptyset 6 \mathrm{~mm} @ 10 \mathrm{~cm} \\
\end{array}$ & $\begin{array}{c}\text { layer } 5 \text { strips } \\
\mathrm{b}_{\mathrm{f}}=75 \mathrm{~mm}\end{array}$ & 0.14 \\
\hline & Gc $1-5$ & & & & & & \begin{tabular}{|l|}
$\mu^{\prime}=0.58 \%$ St. \\
$1 \varnothing 6 \mathrm{~mm} @ 10 \mathrm{~cm}$ \\
\end{tabular} & $\begin{array}{c}\text { 1ayers 5 strips } \\
\mathrm{b}_{\mathrm{f}}=75 \mathrm{~mm}\end{array}$ & 0.28 \\
\hline & Gc $1-6$ & & & & & & $\mu^{\prime}=0.00 \%$ & $\begin{array}{c}2 \text { layers } 5 \\
\text { strips } \\
b_{\mathrm{f}}=75 \mathrm{~mm}\end{array}$ & 0.28 \\
\hline
\end{tabular}


$\mu=(\mathrm{As} / \mathrm{Ac}) \times 100 \quad$ and $\quad \mu^{\prime}=(\mathrm{Vst} / \mathrm{Vc}) \times 100$ Where

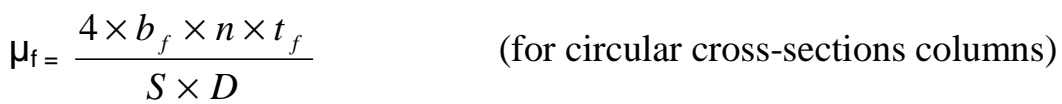

$\mu_{\mathrm{f}}=\frac{(b+t) \times 2 \times b_{f} \times t_{f} \times n}{b \times t \times S} \quad$ (for Rectangular square cross-sections)

Where,

$\mu=$ Percentage of longitudinal steel reinforcement, $\mu^{`}=$ the percentage of lateral steel (stirrups), $\mu_{\mathrm{f}}=$ the percentage of confinement, $\mathrm{A}_{\mathrm{s}}=$ cross-sectional area of longitudinal steel reinforcement, $\mathrm{Ac}=$ cross-sectional area of concrete, $\mathrm{V}_{\mathrm{st}}=$ volume of lateral steel reinforcement, $\mathrm{V}_{\mathrm{C}}=$ volume of concrete, $\mathrm{b}_{\mathrm{f}}=$ total width of the bounded CFRP , $\mathrm{t}_{\mathrm{f}}=$ CFRP thickness, $\mathrm{n}=$ number of layer of CFRP, $\mathrm{b}, \mathrm{t}=$ dimension of column cross-section and $\mathrm{S}=$ centre to centre spacing of the CFRP.(for examples see Fig. (1) to Fig. (3).

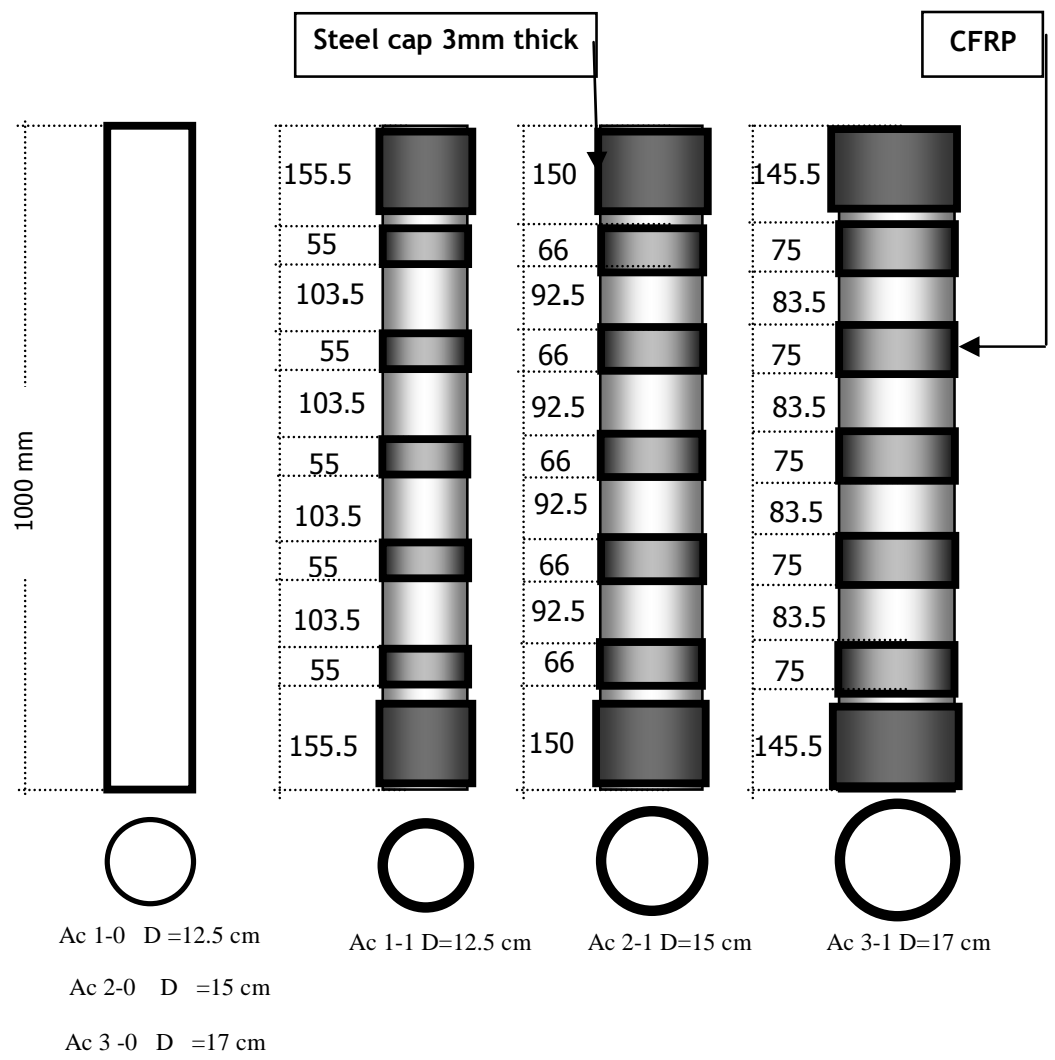

Fig. (1) Plain concrete columns - circular sections $\left(\mu=0.00 \%\right.$ and $\left.\mu^{-}=0.00 \%\right)$ Group A 


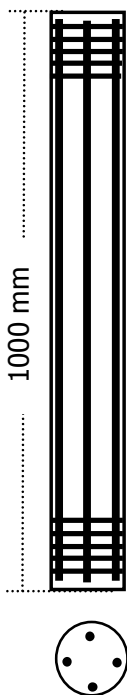

Fc 1-0 D=12.5 cm Fc $2-0 \mathrm{D}=15 \mathrm{~cm}$ Fc $3-0 \mathrm{D}=17 \mathrm{~cm}$

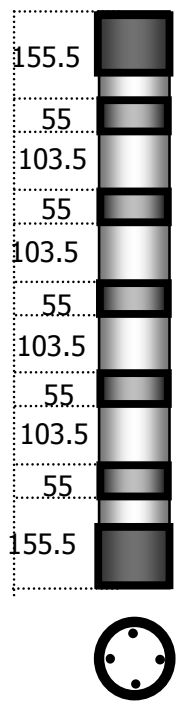

Fc $1-1 \mathrm{D}=12.5 \mathrm{~cm}$ (1 layer)

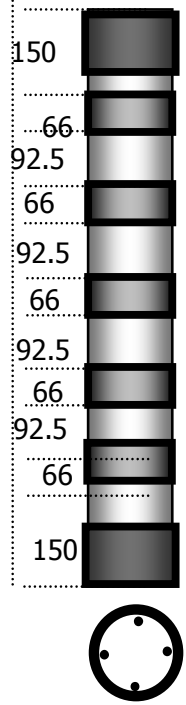

Fc 2-1 D=15 cm (1 layer)

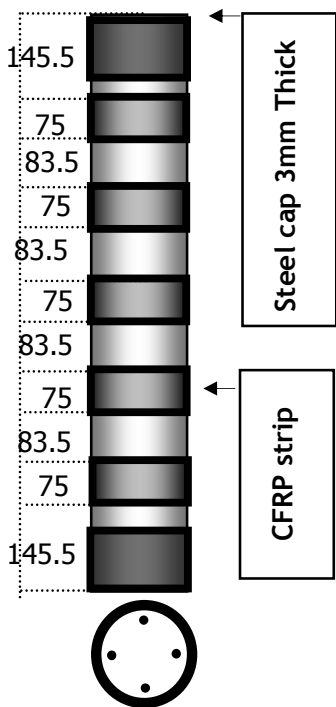

Fc 3-1 D=17 cm (1 layer)

Fig. (2) Reinforced concrete columns - circular sections $\left(\mu=1.73 \%\right.$ and $\left.\mu^{-}=0.00 \%\right)$ Group F

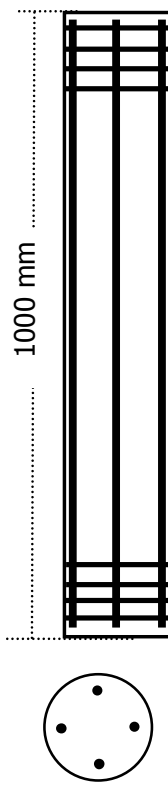

Fc 3-0 $\mu^{-}=0.00 \%$
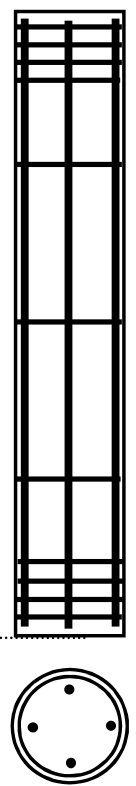

Gc $1-0$ $\mu^{-}=0.33 \%$


Gc 1-3 $\mu^{-}=0.58 \%$

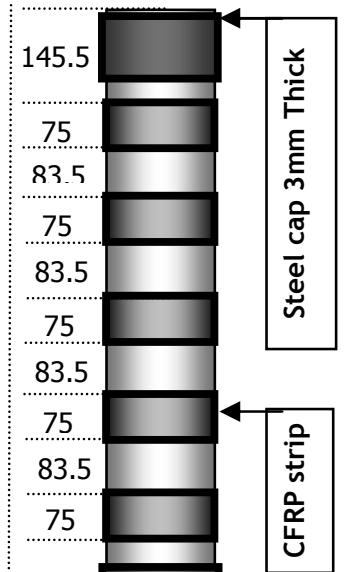

145.5

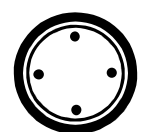

Fc 3-1 $\mu^{-}=0.00 \% \quad 1$ layer Gc $1-1 \mu^{-}=0.33 \% \quad 1$ layer Gc $1-2 \mu^{-}=0.33 \% \quad 2$ layers Gc $1-4 \mu^{-}=0.58 \% \quad 1$ layer Gc $1-5 \mu^{-}=0.58 \% \quad 2$ layers Gc $1-6 \mu^{-}=0.00 \% 2$ layers

Fig. (3) Reinforced concrete columns - circular sections $(\mathrm{D}=17 \mathrm{~cm}$ and $\mu=1.73 \%)$ Group $\mathbf{G}$ 


\section{2-2 Materials and Concrete Mix Proportion}

All columns were casted from concrete having the same strength, therefore concrete mix design was done to give cube strength of about $200 \mathrm{~kg} / \mathrm{cm}^{2}$ after 28 days using the following materials:

- Ordinary Portland cement.

- $\quad$ Sand (fineness modulus $=3.50$, specific gravity $=2.6$ and unit weight of 1.6 $\left.\mathrm{t} / \mathrm{m}^{3}\right)$.

- Gravel (20 mm maximum nominal size, fineness modulus $=6.75$, specific gravity $=2.65$ and unit weight of $1.6 \mathrm{t} / \mathrm{m}^{3}$ ).

- No additives were incorporated in concrete.

The concrete mix proportions by weight for $1 \mathrm{~m}^{3}$ are given in Table (2). High tensile steel deformed bars of grade 36/52 and diameter $10 \mathrm{~mm}$ were used as longitudinal steel, and diameter $8 \mathrm{~mm}$ mild steel plain bars of grade 24/35 were used for longitudinal steel for columns (F 1 1-0), ( F c 1-1), (Fc 2-0), and (F 2 2-1), while mild steel plain bars of grade 24/35 and diameter $6 \mathrm{~mm}$ were used for stirrups.

The composite strengthening system used in this study comprised of four basic components namely: primer, putty, saturant, and CFRP sheets under a commercial of Sika Wrap Hex-230 [4] ,[13]. Such CFRP sheet is available in rolled sheet of $0.13 \mathrm{~mm}$ effective thickness and $300 \mathrm{~mm}$ width.. Some mechanical properties of CFRP are shown in Table (3).

Table (2) Concrete mix proportions

\begin{tabular}{|c|c|c|c|}
\hline $\begin{array}{c}\text { Cement } \\
\left(\mathrm{kg} / \mathrm{m}^{3}\right)\end{array}$ & $\begin{array}{c}\text { Fine aggregate } \\
\left(\mathrm{kg} / \mathrm{m}^{3}\right)\end{array}$ & $\begin{array}{c}\text { Coarse aggregate } \\
\left(\mathrm{kg} / \mathrm{m}^{3}\right)\end{array}$ & $\begin{array}{c}\text { Water } \\
\left(\mathrm{liter} / \mathrm{m}^{3}\right)\end{array}$ \\
\hline 350 & 567 & 1267.54 & 192.5 \\
\hline
\end{tabular}

Table (3) Mechanical properties of CFRP [4],[13]

\begin{tabular}{|c|c|c|c|c|}
\hline $\begin{array}{c}\text { Tensile } \\
\text { strength } \\
\left(\mathrm{kg} / \mathrm{cm}^{2}\right)\end{array}$ & $\begin{array}{c}\text { Modulus of } \\
\text { Elasticity } \\
\left(\mathrm{kg} / \mathrm{cm}^{2}\right)\end{array}$ & $\begin{array}{c}\text { Ultimate } \\
\text { strain }\end{array}$ & $\begin{array}{c}\text { Thickness } \\
(\mathrm{mm})\end{array}$ & $\begin{array}{c}\text { Weight of } \\
\text { CFRP } \\
\left(\mathrm{g} / \mathrm{m}^{2}\right)\end{array}$ \\
\hline 35500 & 2400000 & $1.4 \%$ & 0.13 & 200 \\
\hline
\end{tabular}

\section{2-3 Instrumentation}

Universal testing machine of (500 ton) capacity was used mainly in testing the columns. The deformation of the tested columns were measured using two mechanical dial gauges having an accuracy of 0.01 inch, were placed at the moving head of the machine, two similar, were placed in the middle part of the columns. The distance between dial gauges was $20 \mathrm{~cm}$ to measure the vertical strain of concrete column. Also, the induced strain in concrete and CFRP was measured by means of an electrical strain gauges of 10 $\mathrm{mm}$. gauge length. The reading of dial and strain gauges were recorded, each load incremented by 4 ton up to the failure of the column. 


\section{3- TEST RESULTS}

\section{3-1 With Respect to Failure Mode of Tested Columns:}

During tests, three failure mechanisms of failure were observed as follows:

Photos from (1) to (6) show some examples for the different modes of failure for both tested plain and reinforced concrete columns.

The first mechanism: was due to shear failure, in non-strengthened columns which is referred as control plain concrete columns, failure governed by sudden crushing of the unconfined plain concrete columns, and the columns finally separated into two cones for circular plain concrete columns. Failure was governed by shear failure between the medium third to the upper third for all columns. This mechanism was observed in case of reference columns (Ac1-0), (Ac 2-0), (Ac 3-0), (Bs 1-0), (Bs2-0), (Bs 3-0), (Dr 10), (Ec1-0), (Es 1-0), (Er 1-0), (Fc1-0), (Fc2-0) and (Fc 3-0).

The second mechanism: was due to both rapture of one of CFRP strips located at the middle third and also located at the upper or the lower third accompanied with delamination of concrete cover along the whole premiter of that strips and a complete concrete crushing at that zone simultaneously.. This mechanism was observed in case of strengthened columns with a number of CFRP strips of one ply (Ac1-1), (Ac 2-1), (Ac 3-1), (Bs 1-1), (Bs 2-1), (Bs 3-1), (Cr 2-1), (Cr 3-1), (Dr 1-1), (Ec 1-1), (Es 1-1), (Er 11), (Fc 1-1), ( Fc 2-1), (Fc3-1), (Gc 1-1), (Gc 1-3) and (Gc 1-4) For non - circular columns the CFRP failed near the corners.

The third mechanism: was due to concrete crushing at unconfined zone between CFRP strips. This mechanism was observed in case of columns strengthened with a number of CFRP strips of two plies (Gc 1-2), (Gc 1-5) and (Gc 1-6), see Photos (3-1) to (3-37) where modes of failure for both unconfined and confined plain and reinforced concrete columns as shown for different sizes and shapes.
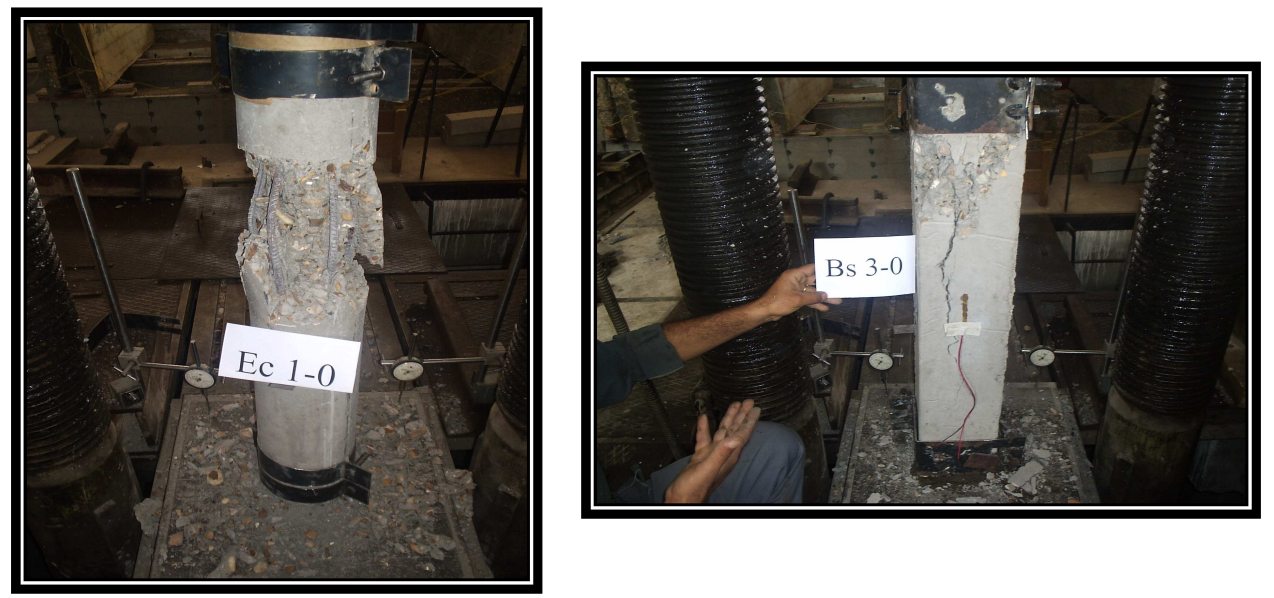

Photo (1) Final failure mode (Bs 3-0). $\quad$ Photo (2) Final failure mode (Es 1-0). (The first mechanism) 

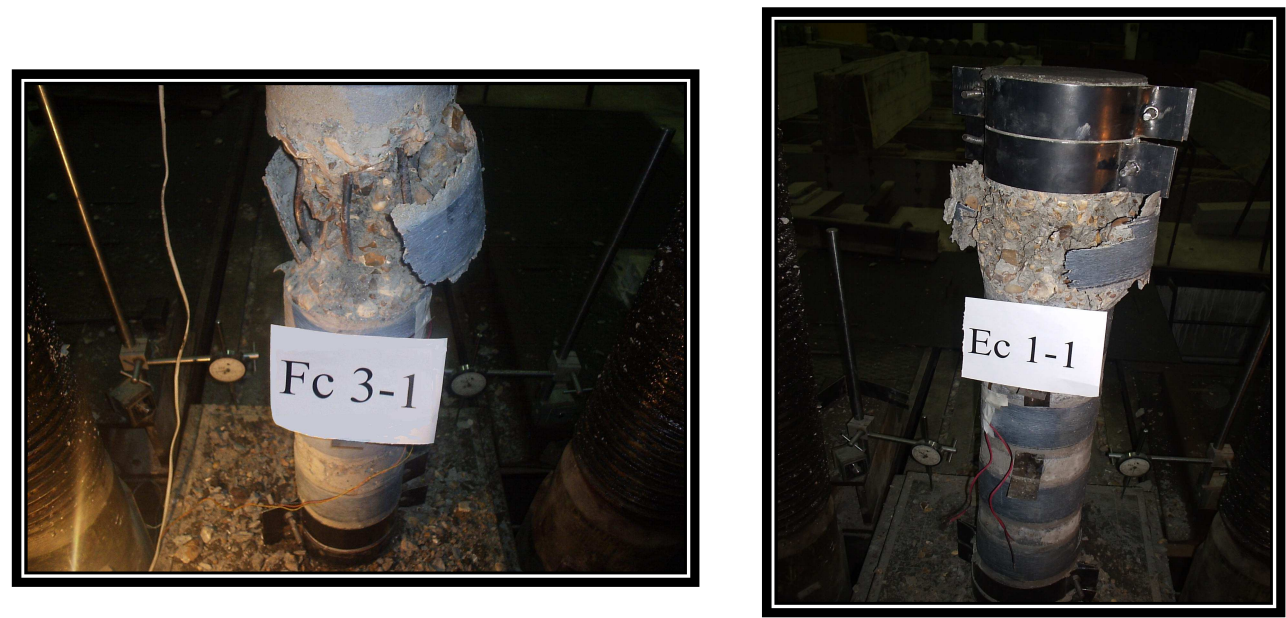

Photo (3) Final failure mode (Bs 3-0) $\quad$ Photo (4) Final failure mode (Ec 1-1).

(The second mechanism)
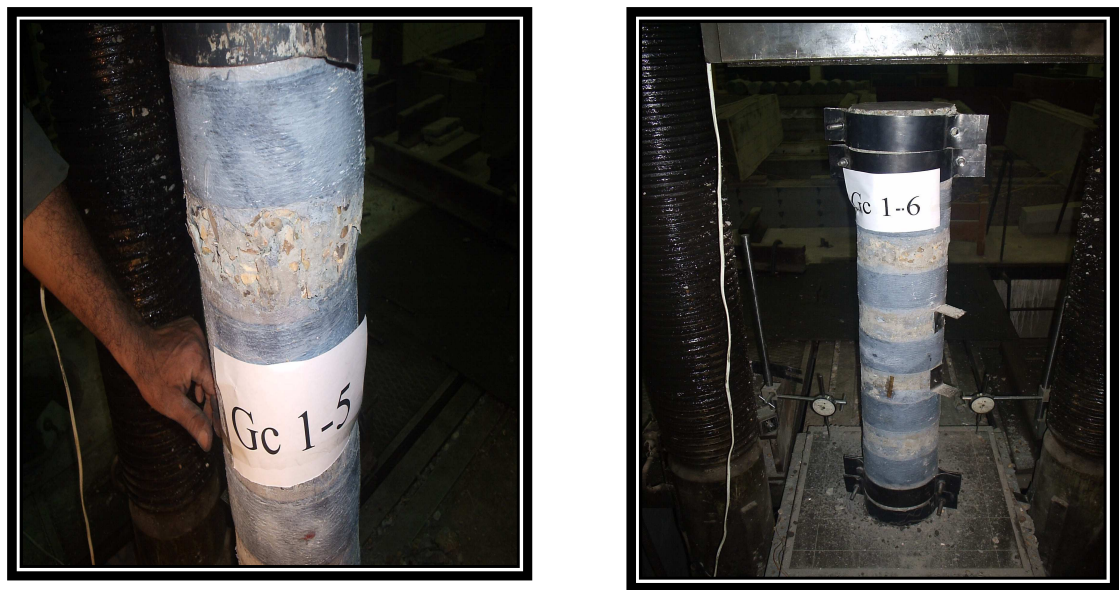

Photo (5) Final failure mode (GC 1-5) Photo (6) Final failure mode (GC 1-6) (The third mechanism)

\section{3-2 With Respect to the Axial Nominal Stress - Axial Nominal Strain Relationship of Tested Columns :}

The axial nominal stress defined by the applied load over the gross area = P/A ( $\mathrm{kg} /$ $\mathrm{cm}^{2}$ ), the axial nominal strain define by the change in height (deformation ) over the overall height of the column $\varepsilon=\Delta \ell / \ell(\mathrm{cm} / \mathrm{cm})$ for all tested columns are evaluated during the testing of each column up to failure. Figures (4) to (5) show the relationship between the axial nominal stress and axial nominal strain for all tested groups of columns either plain or reinforced. 
Based on these relationships the values of max. axial load, the max. nominal axial stress, the max. Nominal strain, modulus of elasticity as well as the modulus of toughness for all tested columns are tabulated in Tables (4) and (5).

Table (4) The values of axial nominal stresses and nominal strains as well as the different values of efficiencies for plain concrete columns

\begin{tabular}{|c|c|c|c|c|c|c|c|c|c|c|}
\hline Oें & 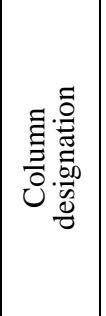 & 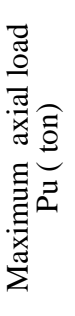 & 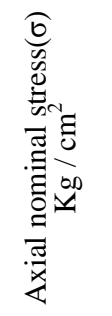 & 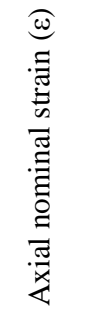 & 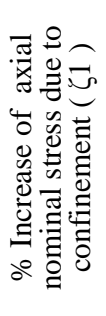 & 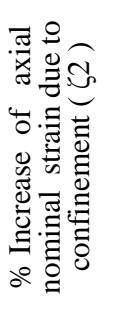 & 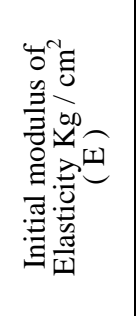 & 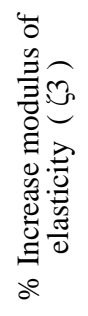 & 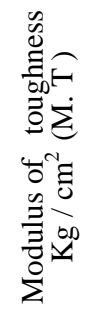 & 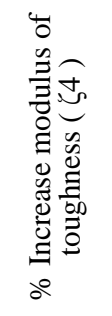 \\
\hline \multirow{6}{*}{ A } & Ac 1-0 & 20 & 163.05 & 0.0023 & \multirow{2}{*}{105} & \multirow{2}{*}{386.95} & $1.80 \times 10^{5}$ & \multirow{2}{*}{38.88} & 0.2597 & \multirow{2}{*}{1059.14} \\
\hline & Ac 1-1 & 41 & 334.26 & 0.0112 & & & $2.50 \times 10^{5}$ & & 3.0103 & \\
\hline & Ac 2-0 & 27 & 152.86 & 0.0021 & \multirow{2}{*}{92.59} & \multirow{2}{*}{352.38} & $1.75 \times 10^{5}$ & \multirow{2}{*}{37.14} & 0.2328 & \multirow{2}{*}{799.70} \\
\hline & Ac 2-1 & 52 & 294.40 & 0.0095 & & & $2.40 \times 10^{5}$ & & 2.0945 & \\
\hline & Ac 3-0 & 33 & 145.46 & 0.00195 & \multirow{2}{*}{75.75} & \multirow{2}{*}{305.12} & $1.70 \times 10^{5}$ & \multirow{2}{*}{32.35} & 0.1961 & \multirow{2}{*}{690.72} \\
\hline & Ac 3-1 & 58 & 255.67 & 0.0079 & & & $2.25 \times 10^{5}$ & & 1.5506 & \\
\hline \multirow{6}{*}{ B } & Bs 1-0 & 24 & 153.6 & 0.0020 & \multirow{2}{*}{75} & \multirow{2}{*}{345} & $1.70 \times 10^{5}$ & \multirow{2}{*}{29.41} & 0.2157 & \multirow{2}{*}{745.99} \\
\hline & Bs 1-1 & 42 & 268.8 & 0.0089 & & & $2.2 \times 10^{5}$ & & 1.8248 & \\
\hline & Bs 2-0 & 33 & 146.66 & 0.0018 & \multirow{2}{*}{57.57} & \multirow{2}{*}{305.55} & $1.70 \times 10^{5}$ & \multirow{2}{*}{26.47} & 0.1722 & \multirow{2}{*}{695.58} \\
\hline & Bs 2-1 & 52 & 231.11 & 0.0073 & & & $2.15 \times 10^{5}$ & & 1.3700 & \\
\hline & Bs 3-0 & 41 & 141.86 & 0.0016 & \multirow{2}{*}{48.78} & \multirow{2}{*}{260.06} & $1.65 \times 10^{5}$ & \multirow{2}{*}{24.24} & 0.1581 & \multirow{2}{*}{589.18} \\
\hline & Bs 3-1 & 61 & 211.14 & .00577 & & & $2.05 \times 10^{5}$ & & 1.0896 & \\
\hline \multirow{6}{*}{ C } & Bs 2-0 & 33 & 146.66 & 0.0018 & \multirow{2}{*}{57.57} & \multirow{2}{*}{305.55} & $1.7 \times 10^{5}$ & 26,17 & 0.1722 & 88 \\
\hline & Bs 2-1 & 52 & 231.11 & 0.0073 & & & $2.15 \times 10^{5}$ & 20.41 & 1.3700 & (1) \\
\hline & Cr 2-0 & 49 & 145.18 & 0.0017 & & & $1.7 \times 10^{5}$ & & 0.1660 & \\
\hline & Cr 2-1 & 75 & 222.22 & 0.0062 & 53.00 & 204.10 & $2.10 \times 10^{5}$ & 2.0 .52 & 1.1486 & נינ. \\
\hline & Cr 3-0 & 64 & 142.22 & 0.00165 & & & $1.65 \times 10^{5}$ & & 0.1423 & \\
\hline & Cr 3-1 & 88 & 195.55 & 0.0051 & (5). & 207.90 & 2. $0 \times 10^{5}$ & 1.21 & 0.8617 & (J) \\
\hline & Ac 3-0 & 33 & 145.46 & 0.00195 & 7 & & $1.7 \times 10^{5}$ & & 0.1961 & \\
\hline & Ac 3-1 & 58 & 255.67 & 0.0079 & 10.10 & 50.00 & $2.25 \times 10^{5}$ & 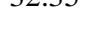 & 1.5506 & 070.12 \\
\hline Г & Bs 2-0 & 33 & 146.66 & 0.0018 & & & $1.7 \times 10^{5}$ & & 0.1722 & \\
\hline & Bs 2-1 & 52 & 231.11 & 0.0073 & I & SU.J5 & $2.15 \times 10^{5}$ & 20.41 & 1.3700 & 0 \\
\hline & Dr 1-0 & 33 & 145.46 & 0.0018 & & & $1.65 \times 10^{5}$ & & 0.1623 & \\
\hline & Dr 1-1 & 46 & 204.44 & 0.0070 & (2.1. & 200.00 & $2.05 \times 10^{5}$ & 2.21 & 1.1788 & 20.0 \\
\hline
\end{tabular}


Table (5) The values of axial nominal stresses and nominal strains as well as the different values of efficiencies for reinforced concrete columns

\begin{tabular}{|c|c|c|c|c|c|c|c|c|c|c|}
\hline 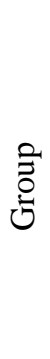 & 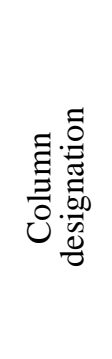 & 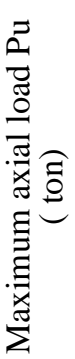 & 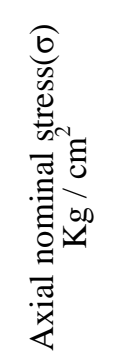 & 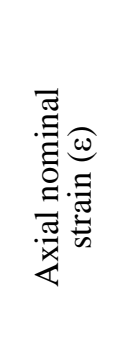 & 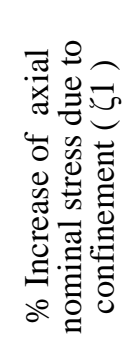 & 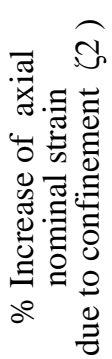 & 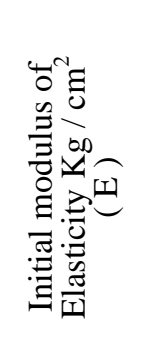 & 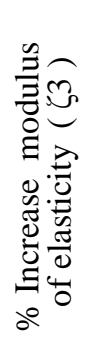 & 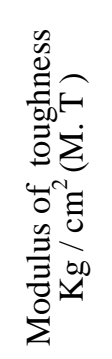 & 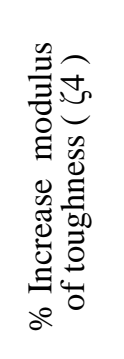 \\
\hline \multirow{6}{*}{$\mathbf{E}$} & Ec 1-0 & 43 & 189.54 & 0.0020 & \multirow{2}{*}{67.44} & \multirow{2}{*}{315} & $2.00 \times 10^{5}$ & \multirow{2}{*}{25.00} & 0.2693 & \multirow[t]{2}{*}{676.90} \\
\hline & Ec $1-1$ & 72 & 317.36 & 0.0083 & & & $2.50 \times 10^{5}$ & & 2.0922 & \\
\hline & Es 1-0 & 43 & 191.11 & 0.0020 & \multirow{2}{*}{53.48} & \multirow{2}{*}{290} & $2.00 \times 10^{5}$ & \multirow{2}{*}{20.00} & 0.2622 & \multirow{2}{*}{602.32} \\
\hline & Es 1-1 & 66 & 293.33 & 0.0078 & & & $2.40 \times 10^{5}$ & & 1.8415 & \\
\hline & Er 1-0 & 43 & 191.11 & 0.00196 & \multirow{2}{*}{37.21} & \multirow{2}{*}{277.50} & $1.95 \times 10^{5}$ & \multirow{2}{*}{15.38} & 0.2570 & \multirow{2}{*}{508.36} \\
\hline & Er 1-1 & 59 & 262.22 & 0.0074 & & & $2.25 \times 10^{5}$ & & 1.5635 & \\
\hline \multirow{6}{*}{$\mathbf{F}$} & Fc $1-0$ & 24 & 195.66 & 0.0025 & \multirow{2}{*}{91.66} & \multirow{2}{*}{376} & $2.0 \times 10^{5}$ & \multirow{2}{*}{25.50} & 0.3522 & \multirow{2}{*}{909.71} \\
\hline & Fc 1-1 & 46 & 375.03 & 0.0119 & & & $2.51 \times 10^{5}$ & & 3.5562 & \\
\hline & Fc 2-0 & 33 & 186.23 & 0.00228 & \multirow{2}{*}{75.75} & \multirow{2}{*}{338.59} & $2.00 \times 10^{5}$ & \multirow{2}{*}{22.50} & 0.3064 & \multirow{2}{*}{694.54} \\
\hline & Fc 2-1 & 58 & 328.37 & 0.0100 & & & $2.45 \times 10^{5}$ & & 2.4345 & \\
\hline & Fc 3-0 & 38 & 167.50 & 0.0022 & \multirow{2}{*}{65.79} & \multirow{2}{*}{277.27} & $1.90 \times 10^{5}$ & \multirow{2}{*}{21.05} & 0.2617 & \multirow{2}{*}{572.94} \\
\hline & Fc 3-1 & 63 & 277.71 & 0.0083 & & & $2.30 \times 10^{5}$ & & 1.7611 & \\
\hline \multirow{9}{*}{ G } & Fc3-0 & 38 & 167.50 & 0.0022 & \multirow{2}{*}{65.79} & \multirow{2}{*}{277.27} & $1.90 \times 10^{5}$ & \multirow{2}{*}{21.05} & 0.2617 & \multirow{2}{*}{572.94} \\
\hline & Fc3-1 & 63 & 277.71 & 0.0083 & & & $2.30 \times 10^{5}$ & & 1.7611 & \\
\hline & Gc 1-0 & 48 & 211.57 & 0.0026 & & & $2.05 \times 10^{5}$ & & 0.4985 & \\
\hline & Gc 1-1 & 76 & 335.00 & 0.0125 & 50.53 & 500.11 & $2.55 \times 10^{5}$ & 1.93 & 3.2144 & 01 \\
\hline & Gc 1-2 & 90 & 396.71 & 0.0165 & 87.50 & 534.61 & $2.76 \times 10^{5}$ & 34.63 & 4.9605 & 895.08 \\
\hline & Gc 1-3 & 56 & 246.85 & .0029 & & & $2.20 \times 10^{5}$ & & 0.7900 & \\
\hline & Gc 1-4 & 85 & 374.67 & 0.0162 & 31.10 & 450.02 & $2.70 \times 10^{5}$ & 2.12 & 4.4537 & 405.10 \\
\hline & Gc 1-5 & 100 & 440.79 & 0.0195 & 78.57 & 572.41 & $2.97 \times 10^{5}$ & 35.00 & 6.1943 & 684.08 \\
\hline & Gc 1-6 & 82 & 361.44 & 0.0130 & $\begin{array}{c}115.78 \\
(\mathrm{Fc} 3-0 \\
\text { reference } \\
\text { column ) }\end{array}$ & 490.91 & $2.55 \times 10^{5}$ & 34.21 & 3.5407 & 1227.59 \\
\hline
\end{tabular}




\section{4- ANALYSIS AND DISCUSSION OF TEST RESULTS}

The aim of this analysis and discussions is to demonstrate the effect of main parameters that affecting the efficiency of externally bonded (CFRP) strengthening reinforced concrete axially load short concrete columns namely:

- With respect to plain concrete columns: the effect of size and shape of crosssection are considered.

- With respect to reinforced concrete columns: the effect of the following parameters are considered.

1- $\quad$ Shape and size of cross- section

2- $\quad$ The percentage of longitudinal steel.

3- The percentage of lateral reinforcements (stirrups).

4- $\quad$ Strengthening technique.

The efficiencies are evaluated by calculating the following items for the strengthened columns compared with that without strengthening:

- Strength efficiency $\left(\zeta_{1}\right)$ which is represented by the percentage of increase of axial nominal stress .

- Ductility efficiency ( $\zeta 2$ ) which is represented by the percentage of increase of axial nominal strain .

- Stiffness efficiency ( $\zeta 3$ ) which is represented by the percentage of increase of modulus of elasticity.

- Absorbed energy efficiency $\left(\zeta_{4}\right)$ measured by the percentage of increase of the modulus of toughness, see Table (4) and Table (5) .

\section{4-1 With Respect to Plain Concrete Axially Loaded Columns}

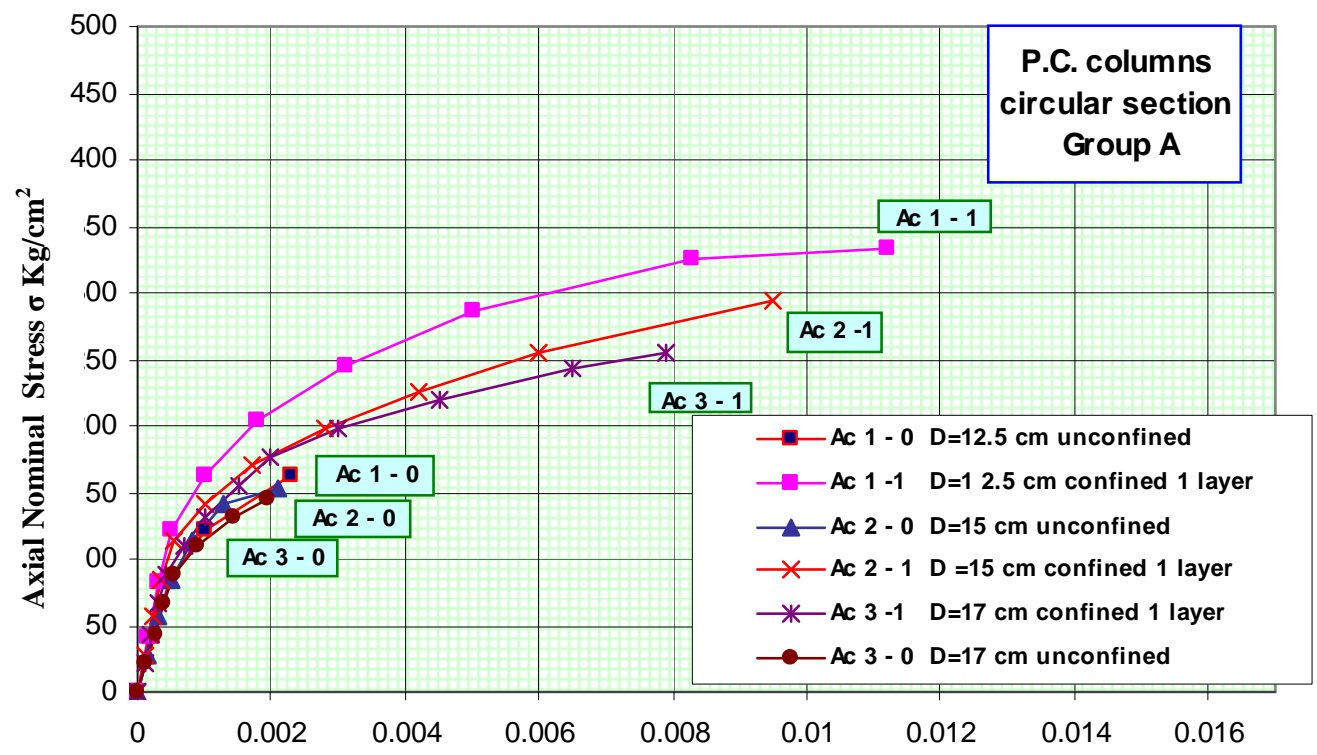

Axial Nominal Strain $(\varepsilon)$

Fig. (4) Comparison between axial nominal stress $(\sigma)$ and axial nominal strain $(\varepsilon)$ for both unconfined and confined circular P.C. columns (Group A) 


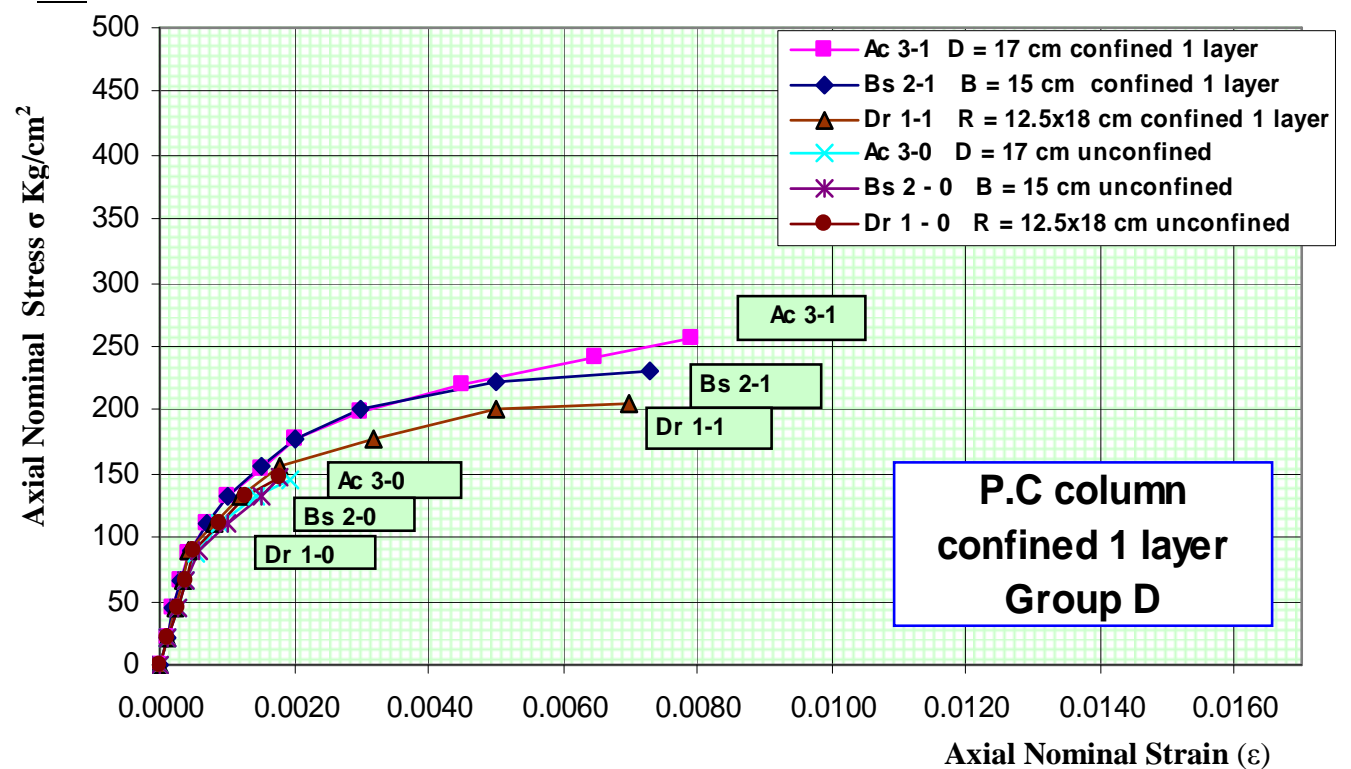

Fig. (5) Comparison between axial nominal stress $(\sigma)$ and axial nominal strain $(\varepsilon)$ for both unconfined and confined circular, square and rectangular P.C. columns with constant area $=225 \mathrm{~cm}^{2} \quad$ (Group D)

\section{4-1-1 Effect of Size of Cross-Section:}

This effect mainly depends on the shape of cross-section as follow:

\section{4-1-1-1 For Circular Plain Concrete Columns (Group A).}

Figures (6) to (9) show the relationships between the maximum nominal stress $(\sigma)$, the maximum nominal strain $(\mathcal{E})$, the value of modulus of elasticity as well as the modulus of toughness (M.T) and corresponding column diameter (D) for both unconfined and confined with one layer plain concrete columns.

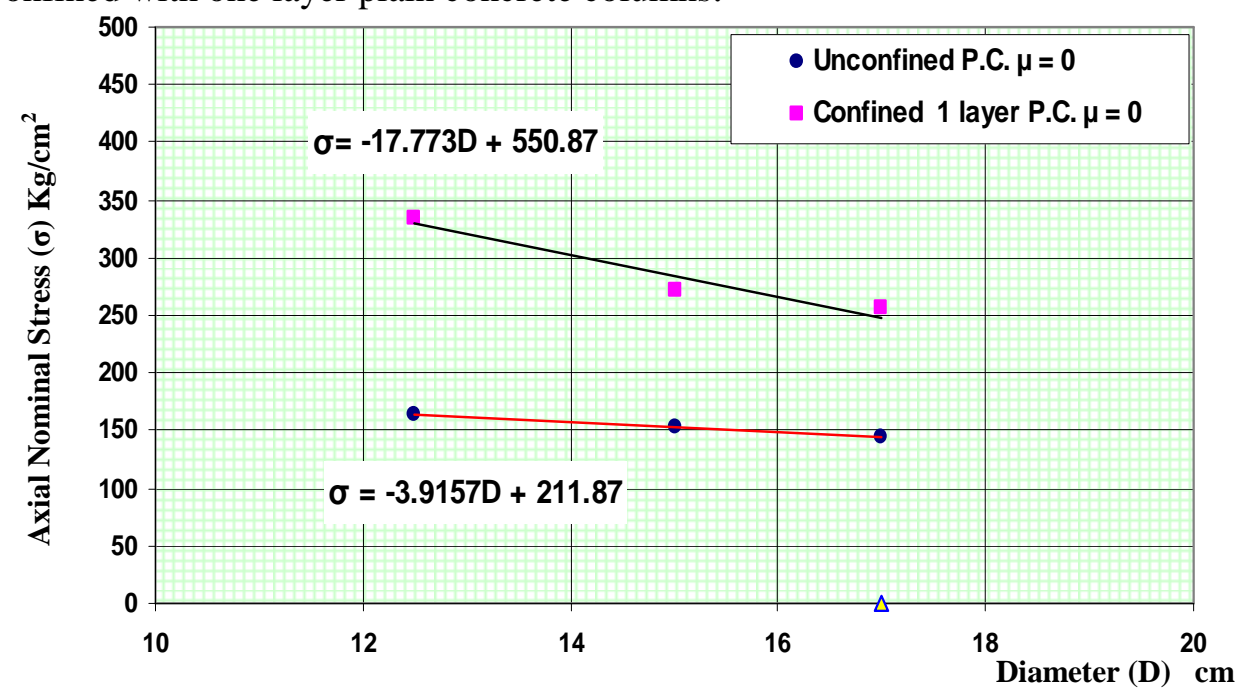

Fig. (6) Relation between axial nominal stress $(\sigma)$ and diameters) of P.C columns (D) (Group A) 


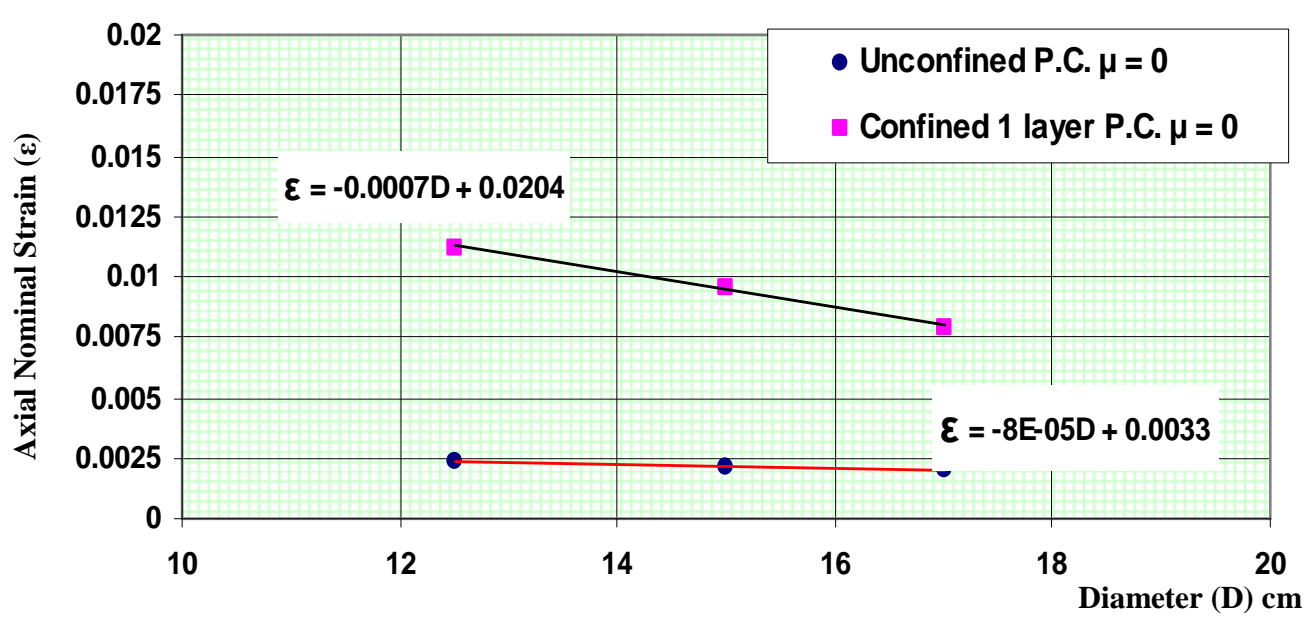

Fig. (7) Relation between nominal axial strain $(\mathcal{E}$ ) and diameters) of P.C columns (D) (Group A)

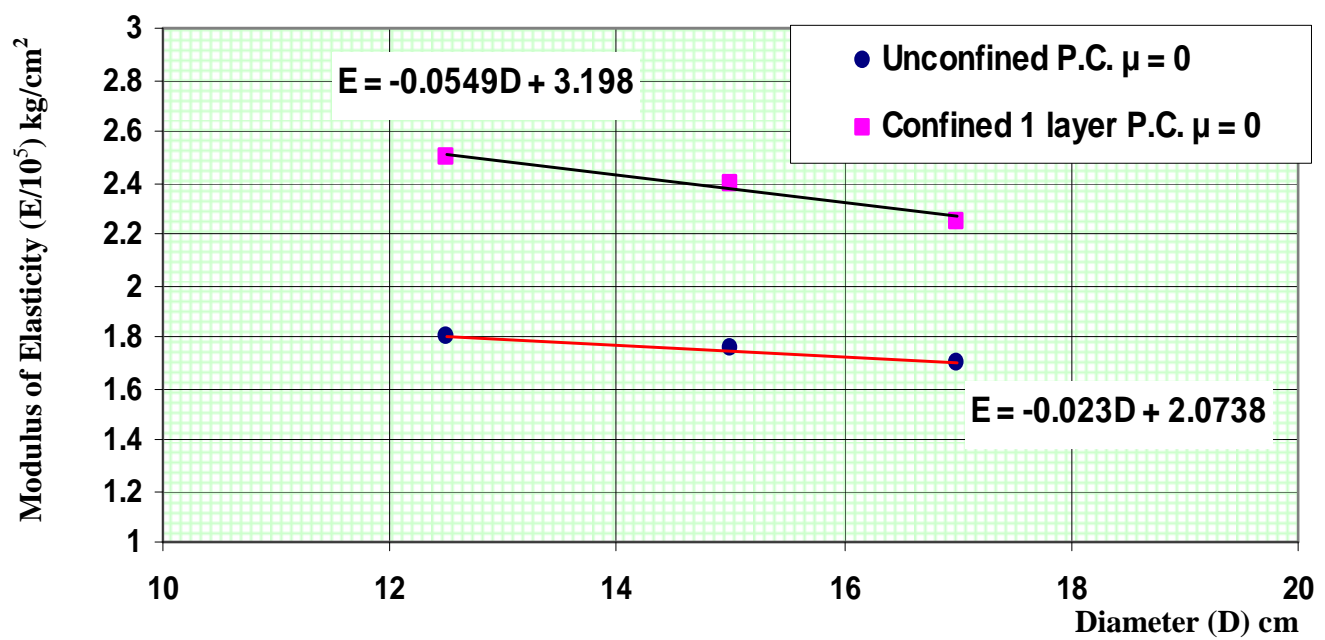

Fig. (8) Relation between modulus of elasticity (E) and diameters) of P.C columns (D) (Group A)

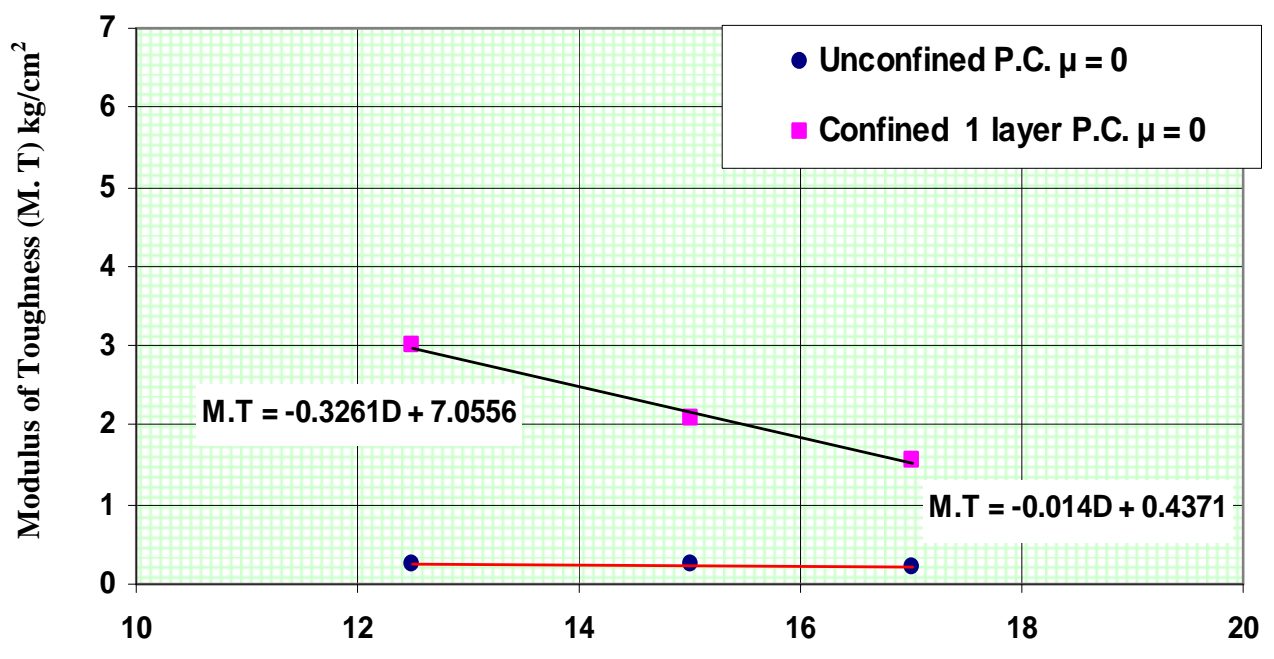

Diameter (D) cm

Fig. (9) Relation between modulus of toughness (M.T) and diameters of P.C columns (D) (Group A) 


\section{From Point of View of Strength:}

The Figs indicate that the strength usually decreased by increasing the size of circular column which represented by the following equations:

$\sigma=211.87-3.92 \mathrm{D}$

$\sigma=550.87-17.773 \mathrm{D}$
( for unconfined plain concrete) (for confined one layer plain concrete )

where $(\sigma)$ in $\mathrm{kg} / \mathrm{cm}^{2}$ and (D) in cms.

The above relationship can be rewritten in terms of the used cube compressive strength ( grade of concrete C 200 as follows :

$\frac{\sigma}{f_{\text {cube }}}=1.059-0.0196 \mathrm{D}$
$\frac{\sigma}{f_{\text {cube }}}=2.754-0.0888 \mathrm{D}$

( for unconfined plain concrete)

(for confined one layer plain concrete )

On the light of equations (4) and (5) for example for a standard dimension diameter of cylinder of $15 \mathrm{~cm}$, these equations led to the values:

$\frac{\sigma}{f_{\text {cube }}}=0.77$

( for unconfined plain concrete)

$\frac{\sigma}{f_{\text {cube }}}=1.42$

(for confined one layer plain concrete )

Figure (10) shows the relation between the strength efficiency $(\zeta 1)$ against the diameter (D) of specimen of plain concrete.

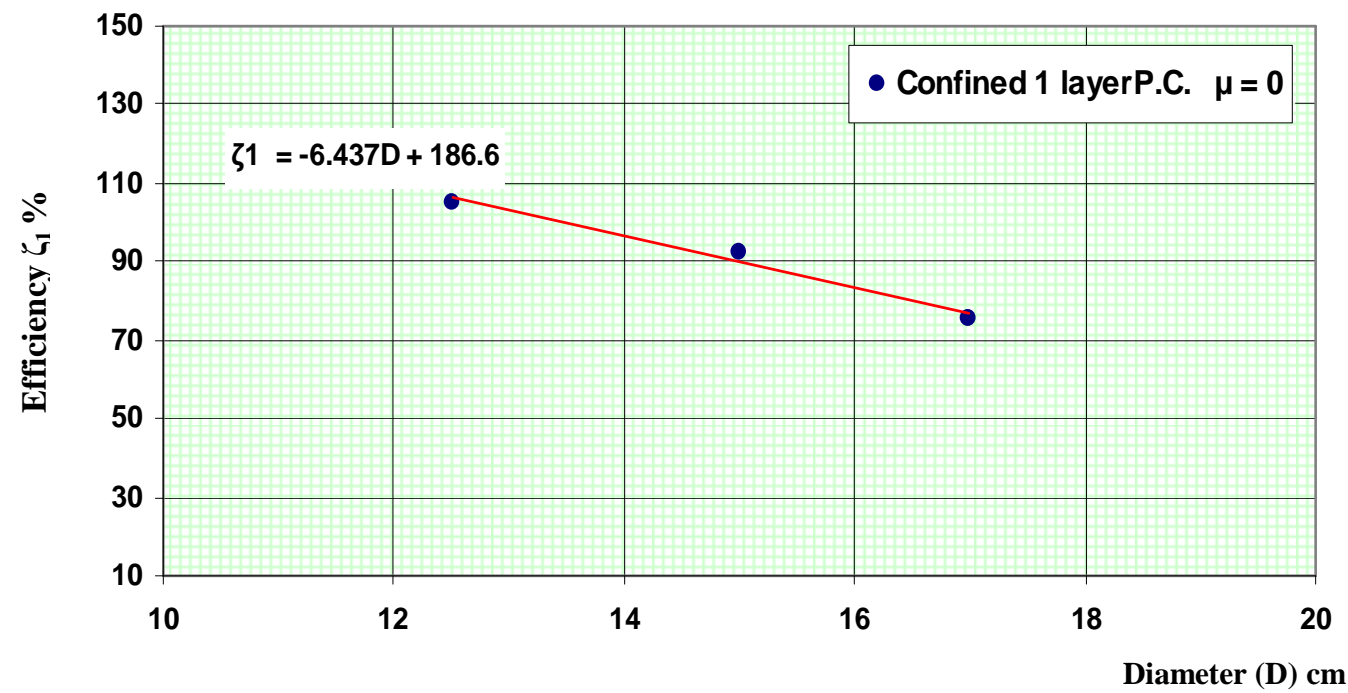

Fig. (10) Relation between efficiency ( $\zeta 1)$ and diameters of P.C columns (D) (Group A ) 
This relation indicates that the efficiency $(\zeta 1)$ decreases by the increase of column diameter (D) and can be best represented by the following relation:

$\zeta_{1}=186.60-6.437 \mathrm{D}$............(6) ( for circular plain concrete confined 1 layer)

From the above equation (6) it is seen that the value of $(\zeta 1)$ equals zero when the diameter (D) is approximately equals $30 \mathrm{~cm}$. This means that the strength efficiency or the percentage of increase in strength due to confinement of plain concrete vanishes when (D) is higher than $30 \mathrm{~cm}$.

\section{From Point of View of Strain:}

The relation between the induced axial strain with respect to the diameter of column is given as follows:

$\mathcal{E}_{(\mathrm{cm} / \mathrm{cm})=0.0033-8 \times 10-5 \quad \mathrm{D} \ldots \ldots \ldots \ldots . .(7) \quad(\text { for unconfined plain concrete) }}$

$\mathcal{E}(\mathrm{cm} / \mathrm{cm})=0.0204-0.0007 \mathrm{D} \ldots \ldots \ldots \ldots(8)$ (for confined one layer plain concrete )

where $(\mathcal{E})$ is the max. strain and (D) is the diameter of circular column in (cms). It is clear that the maxi. induced axial strains for confined plain concrete is considerably higher than that for unconfined concrete and mainly depends on the size of the crosssection .Concerning the ductility coefficient $\left(\zeta_{2}\right)$, Fig. (11) shows the relation between its value against the diameter for both unconfined and confined with one layer plain concrete circular column.

The relation can best be fitted by the following equation:

$\zeta_{2}=615.24-18.006 \mathrm{D} \ldots \ldots \ldots \ldots . . .(9)$ for circular plain concrete confined 1 layer)

Again, it is obvious that the ductility coefficient $\left(\zeta_{2}\right)$ decreases with the increase of (D) and vanishes when (D) equals $(34.0 \mathrm{~cm})$ i.e more or less bigger than $30 \mathrm{~cm}$ as strength efficiency $(\zeta 1)$.

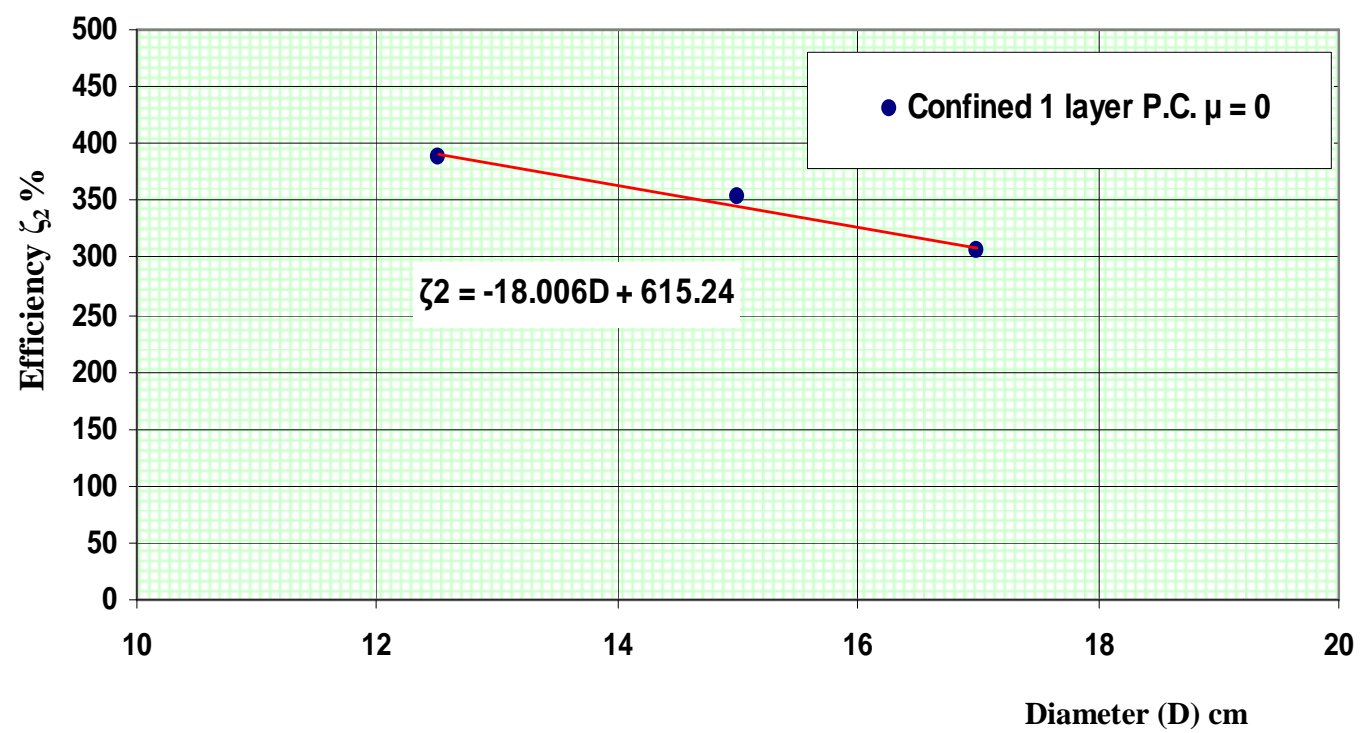

Fig. (11) Relation of efficiency $\left(\zeta_{2}\right)$ and diameters of P.C columns (D) 


\section{From Point of View of Stiffness:}

The relation between the modulus of elasticity of concrete as a function in (D)of column is given by :

$\mathrm{E}=2.0738 \times 10^{5}-0.023 \mathrm{D}$

( for unconfined plain concrete)

$\mathrm{E}=3.198 \times 10^{5}-0.0549 \mathrm{D}$

(for confined one layer plain concrete )

where (E) in $\mathrm{kg} / \mathrm{cm}^{2}$ and (D) in $\mathrm{cms}$.

The above relationships can be rewritten in terms of the used cube modulus of elasticity ( grade of concrete C 200) as follow :

$\frac{E}{\text { E grade }}=1.0479-1.1622 \times 10^{-7}$

( for unconfined reinforced concrete)

$\frac{E}{\text { E grade }}=1.6159-2.7741 \times 10^{-7} \mathrm{D}$

(13) ( for confined 1 layer reinforced concrete)

where $E$ grade $=14000 \sqrt{F c_{\text {cube }}}=14000 \sqrt{200}=1.979 \times 10^{5} \mathrm{~kg} / \mathrm{cm}^{2}$.

Concerning Fig. (12) shows the relation between $\left(\zeta_{3}\right)$ value and the diameter (D) for confined with one layer plain concrete circular column. This relation can be written by the following equation:

$\zeta_{3}=57.189-1.4202 \mathrm{D} \ldots \ldots \ldots \ldots . .(14)$ ( for confined 1 layer plain circular) column )

From the above equation (14) it is seen that the value of ( $\zeta 3)$ equals zero when (D) is approximately equals $40 \mathrm{~cm}$. This means that the stiffness efficiency of plain circular concrete column due to confinement vanishes when (D) $=40 \mathrm{~cm}$.

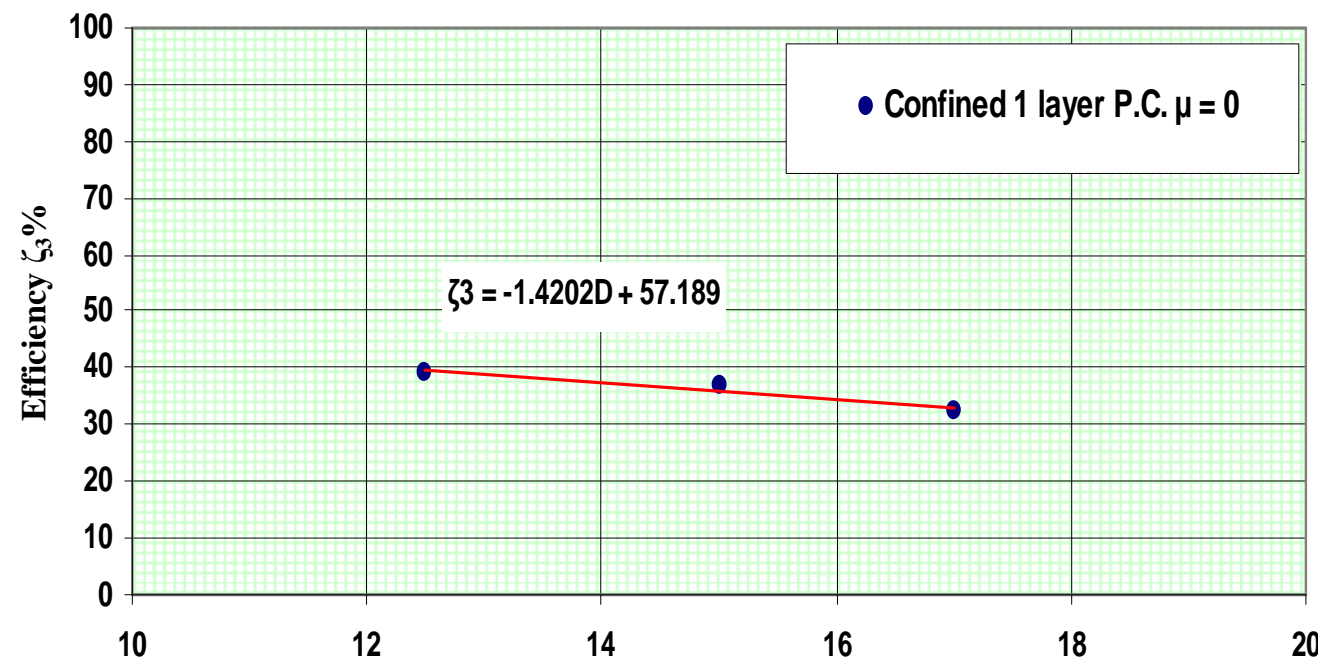

Diameter (D) cm

Fig. (12) Relation of efficiency ( $\zeta 3$ ) and diameters of P.C columns ( D) (Group A ) 


\section{From Point of View of Total Absorbed Energy:}

The calculated modulus of toughness as varied by the diameter of column can be given by :
M.T $=0.4371-0.014 \mathrm{D}$
( for unconfined plain concrete)
M.T $=7.0556-0.3261$
(for confined one layer plain concrete )

where (M.T) in $\mathrm{kg} / \mathrm{cm}^{2}$ and (D) in cms.

Again it is clear that the value of ( M.T ) for plain confined with one layer is higher than that for unconfined plain concrete, and both values decreases with the increase of diameter (D), Fig. (13) shows how this efficiency $\left(\zeta_{4}\right)$, decreases with the increase of diameter (D), which is represented by the following equation:

$$
\zeta_{4}=2077.6-82.769 \mathrm{D} \ldots \ldots . . .(17) \quad \text { (for plain circular column ) }
$$

Also this equation shows that the value of the efficiency $\left(\zeta_{4}\right)$ decreases with the increase of diameter ( $\mathrm{D}$ ) of column. At the same time this decrease vanishes when $\mathrm{D}=$ $25 \mathrm{~cm}$, i.e there is no increase in modulus of toughness ( M.T ) due to confined of plain concrete with one layer beyond $\mathrm{D}=25 \mathrm{~cm}$.

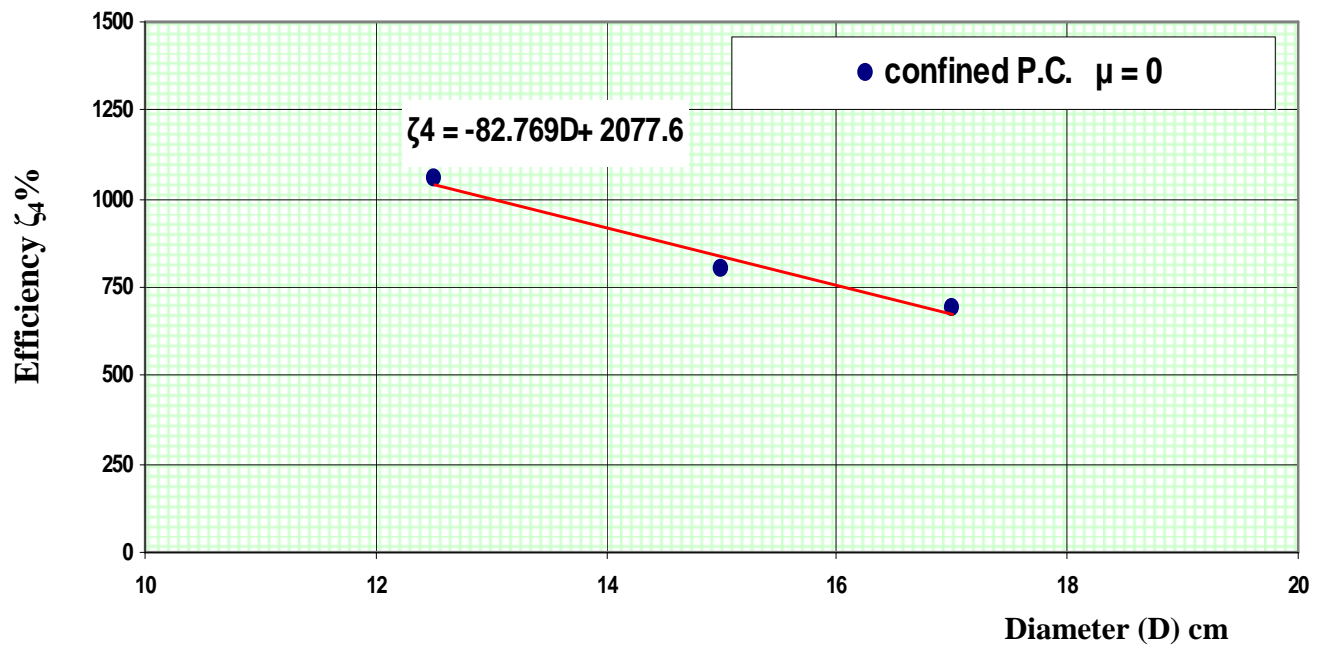

Fig. (13) Relation between efficiency $\left(\zeta_{4}\right)$ and diameters of plain circular concrete columns( D) ( Group A)

\section{4-1-1-2 For Square Plain Concrete Columns (Group B):}

The values of the max. induced nominal stresses, max. nominal strains, modulus of elasticity as well as modulus of toughness of such columns are given in Table (4)as well as in Fig. (14) to (17) which show the relationships between the max. nominal stress $(\boldsymbol{\sigma})$. the max. nominal strain $(\mathcal{E})$, the value of modulus of elasticity as well as the modulus of toughness (M.T) and corresponding column side cross-section (B) for both unconfined and confined with one layer plain concrete columns. 


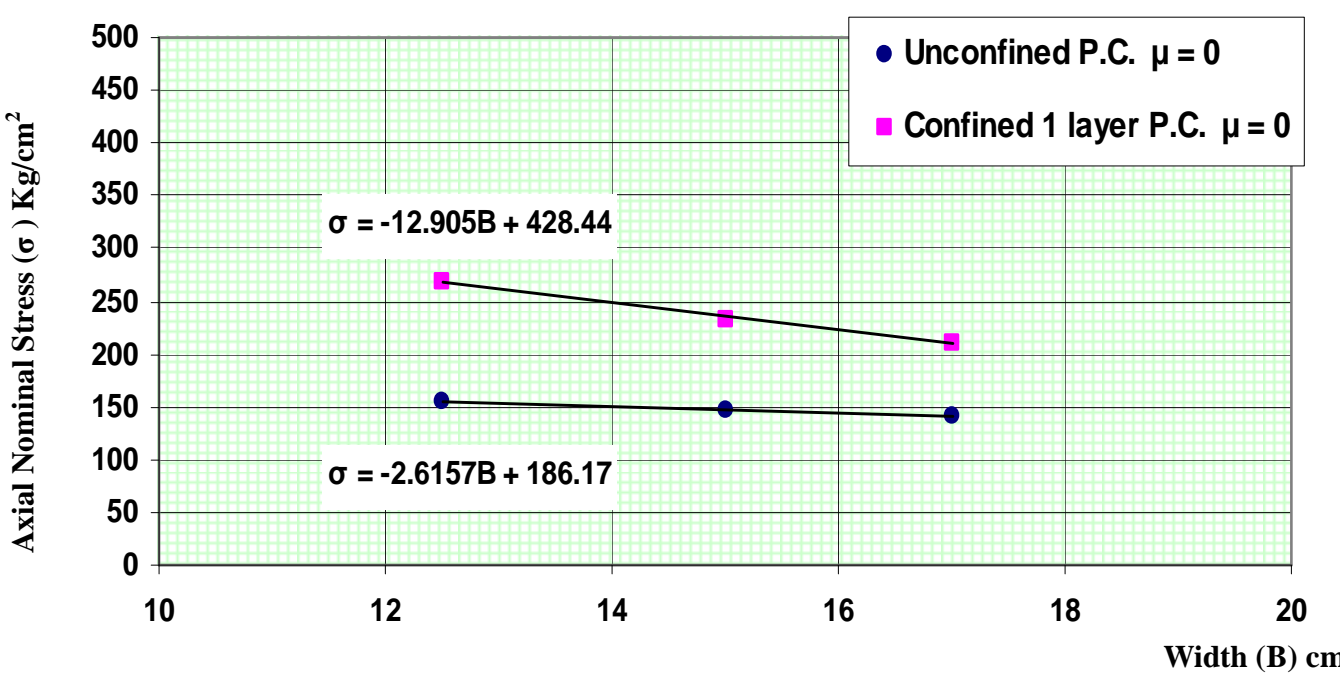

Fig. (14) Relation between axial nominal stress $(\sigma)$ and width of P.C square columns (B) (Group B)

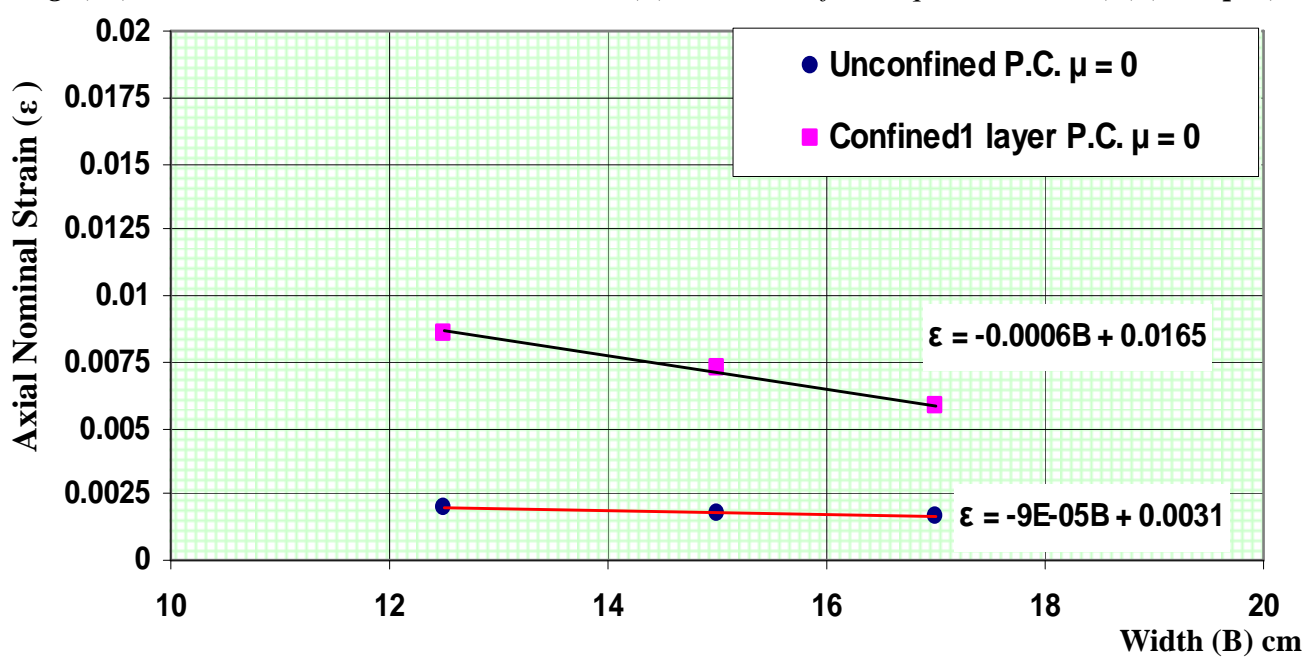

Fig. (15) Relation between axial nominal strain $(\mathcal{E})$ and width of P.C square columns (B) (Group B)

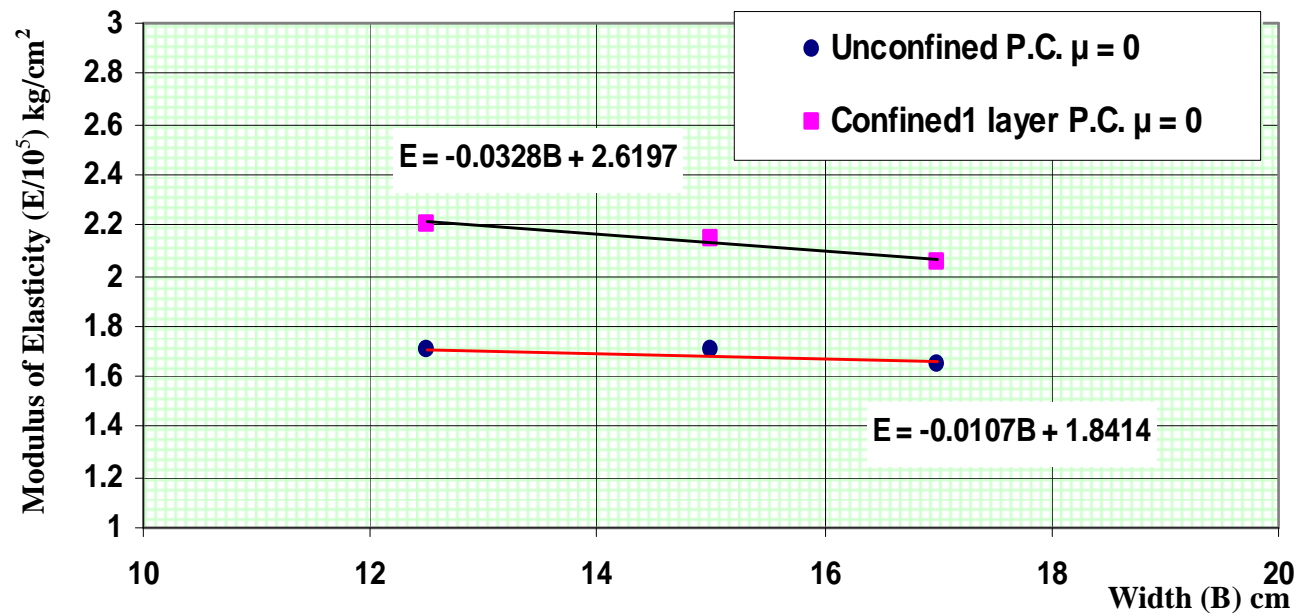

Fig. (16) Relation between modulus of elasticity (E) and width of P.C square columns (B) (Group B) 


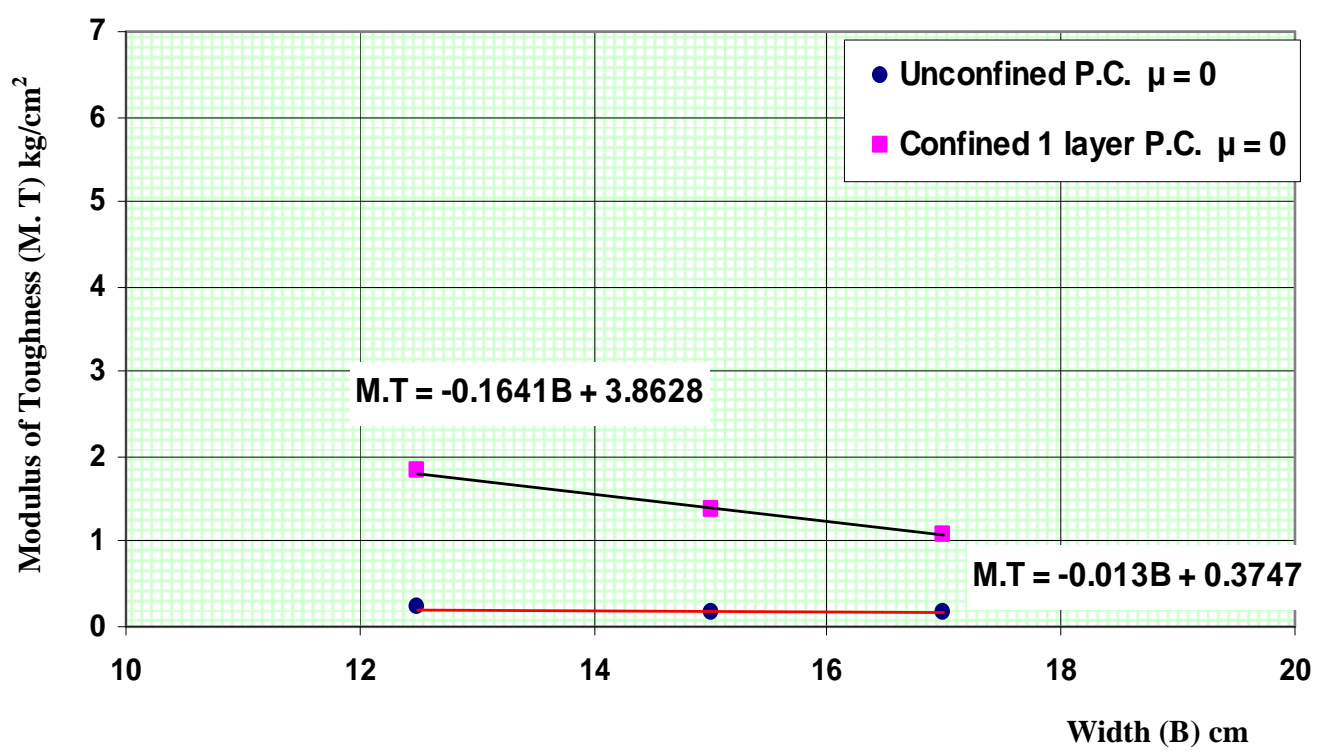

Fig. (17) Relation between modulus of toughness (M.T) and width of plain square concrete columns (B)

(Group B)

As a general rule, as the side (B) increases all the above values decreases for both unconfined and confined plain concrete. It is interesting to note that the rate of decrease for the case of unconfined plain concrete is smaller than that for case of confined 1 layer plain concrete. The relations between such properties and side dimension can be represented as follows:

\section{From Point of View of Strength :}

$$
\begin{aligned}
& \sigma=186.17-2.6157 \text { B } \\
& \text { ( for unconfined plain concrete) } \\
& \sigma=428.44-12.905 \mathrm{~B} \\
& \frac{\sigma}{f_{\text {cube }}}=0.93-0.0131 B \\
& \text { ( for unconfined plain concrete) } \\
& \frac{\sigma}{f_{\text {cube }}}=2.142-0.0645 B \\
& \text { (for confined one layer plain concrete) }
\end{aligned}
$$

To declare how the confinement affects the induced maxi. stress (strength) take for e.g. $\mathrm{B}=25 \mathrm{~cm}$, hence

$$
\begin{aligned}
& \frac{\sigma}{f_{\text {cube }}}=0.734
\end{aligned}
$$

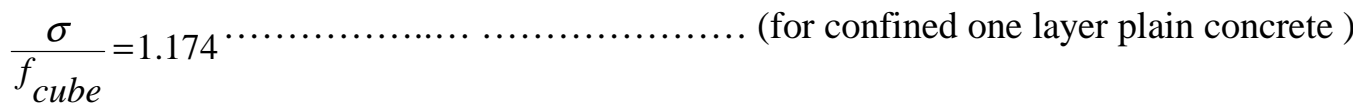




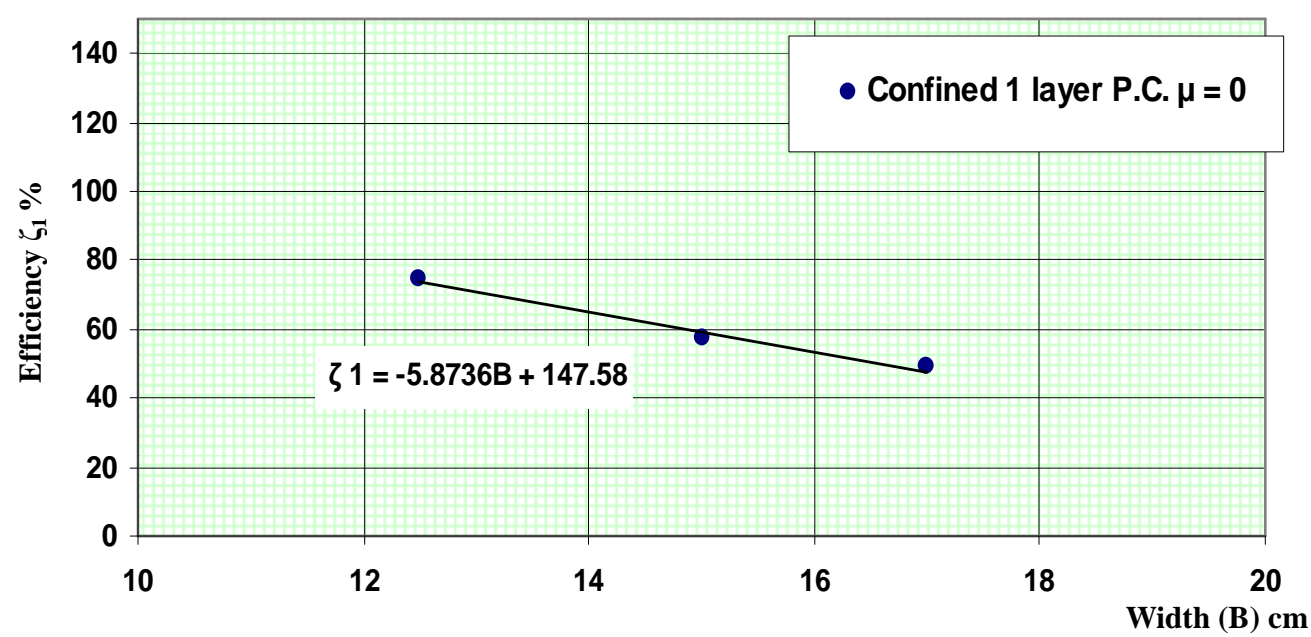

Fig. (18) Relation between efficiency $\left(\zeta_{1}\right)$ and width of plain square concrete columns (B) (Group B)

Concerning the efficiency values of strength ( $\zeta 1$ ), Fig. ( 18) shows how such value of $(\zeta 1)$ decreases with the increase of side ( B ) and can be represented by the equation :

$\zeta_{1}=147.58-5.8736 \mathrm{~B}$

..(22) (for square plain concrete confined 1 layer)

It is obvious that the value of ( $\zeta 1$ ) equals zero when the value of (B) equals $25 \mathrm{~cm}$. This means that, there is no increase in strength of plain concrete due to confinement beyond a side dimension of cross- section (B) bigger than $25 \mathrm{~cm}$.

\section{From Point of View of Strain:}

$\mathcal{E}=0.0031-9 \times 10^{-5} \mathrm{~B}$

( for unconfined plain concrete)

$\mathcal{E}=0.0165-0.0006 \mathrm{~B}$ (for confined one layer plain concrete)

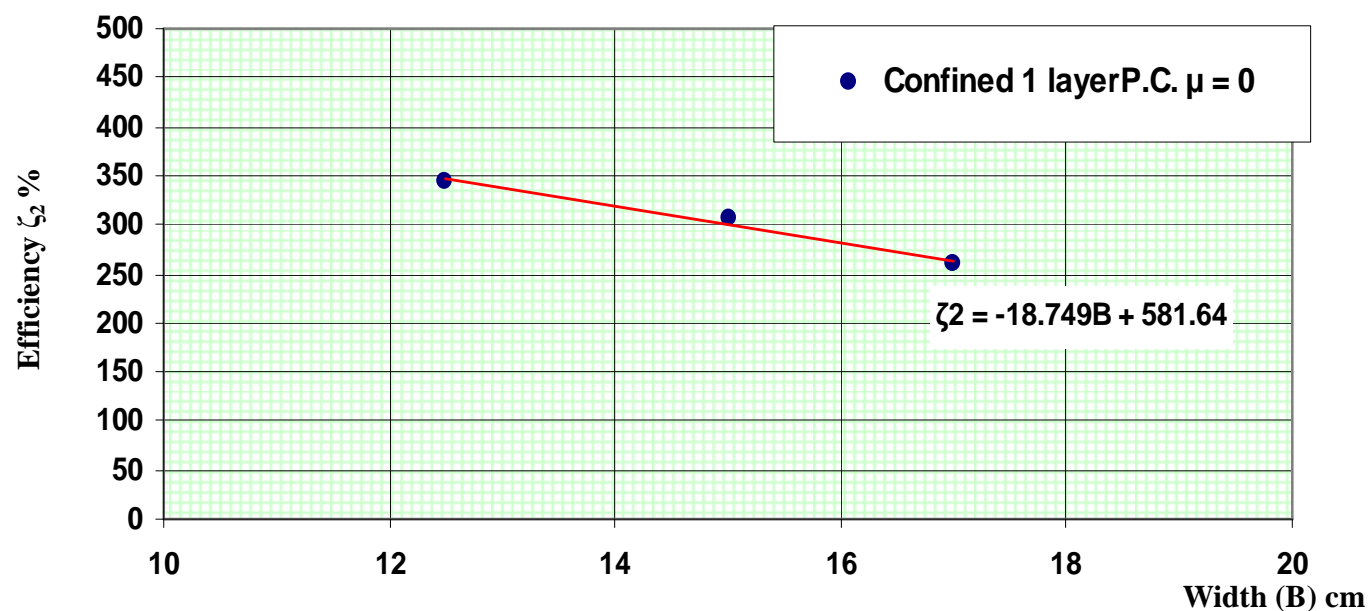

Fig. (19) Relation between efficiency $\left(\zeta_{2}\right)$ and width of P.C square columns (B) (Group B) 
From the point of view of ductility efficiency $\left(\zeta_{2}\right)$, the relation between $\left(\zeta_{2}\right)$ and the side dimension (B), Fig ( 19 ) can be represented by:
$\zeta_{2}=581.64-18.749 \mathrm{~B}$
( for square plain concrete confined 1 layer)

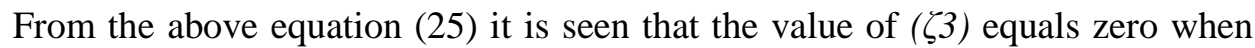
(B) is approximately equals $(\mathrm{B}=38 \mathrm{~cm})$. This means that the ductility efficiency of plain square concrete column vanishes when $(B)=38 \mathrm{~cm}$.

\section{From Point of View of Stiffness:}

$\mathrm{E}=1.8414 \times 10^{5}-0.0107 \mathrm{~B}$

$\mathrm{E}=2.6197 \times 10^{5}-0.0328 \mathrm{~B}$

( for unconfined plain concrete) (for confined one layer plain concrete )

The above relationships can be rewritten in terms of the used cube modulus of elasticity ( grade of concrete C 200) as follow:

$\frac{E}{\text { E grade }}=0.930-5.406 \times 10^{-8} \mathrm{~B}$

( for unconfined reinforced concrete)

$\frac{E}{E \text { grade }}=1.3237-1.6574 \times 10^{-7} \mathrm{~B}$

( for confined 1 layer reinforced concrete)

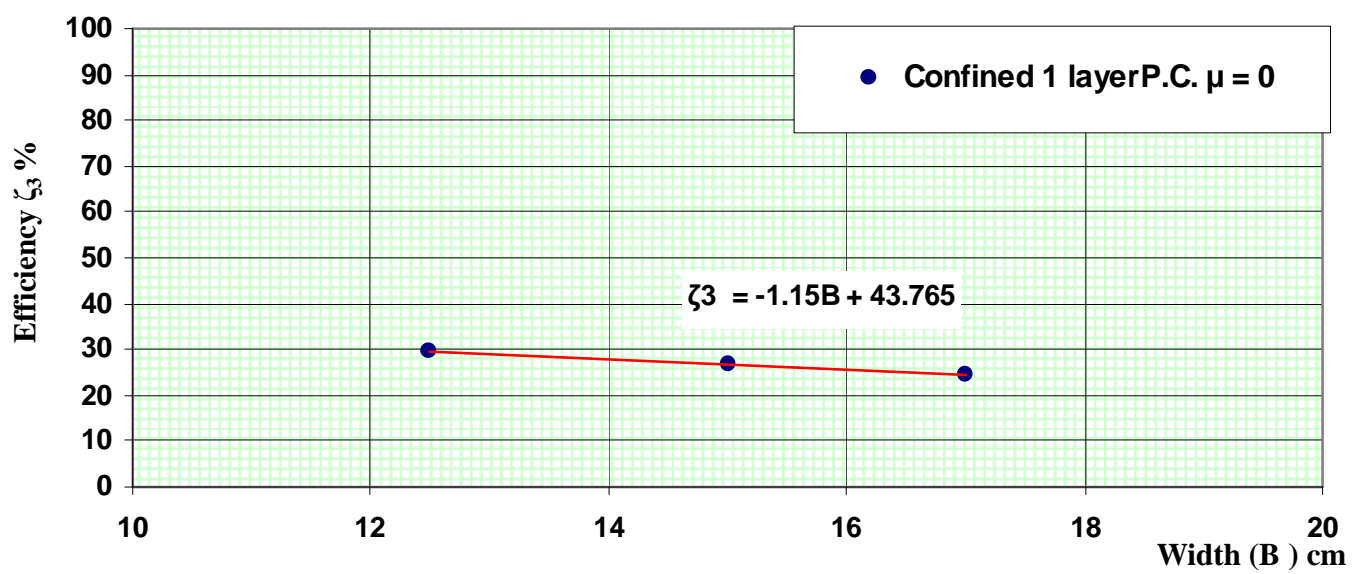

Fig. (20) Relation between efficiency $\left(\zeta_{3}\right)$ and width of plain square Concrete columns (B) (Group B)

Figure (20) shows the relation between $\left(\zeta_{3}\right)$ value and the dimension (B) for confined with one layer plain concrete square column. This relation can be written by the following equation:

$\zeta_{3}=43.765-1.15 \mathrm{~B}$

( for confined 1 layer plain square column )

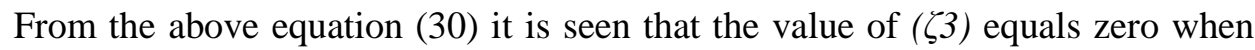
(B)is approximately equals $38 \mathrm{~cm}$. This means that the stiffness efficiency of plain square concrete column vanishes when $\mathrm{B} \geq 38 \mathrm{~cm}$.

\section{From Point of View of total Absorbed Energy:}

M.T $=0.3747-0.013 \mathrm{~B}$

M.T $=3.8628-0.1641 \mathrm{~B}$

( for unconfined plain concrete)

(for confined one layer plain concrete )

Where (M.T) in $\mathrm{kg} / \mathrm{cm}^{2}$ and (B) in $\mathrm{cms}$. 
From Fig. (21), the values of the efficiency $\left(\zeta_{4}\right)$ measured by modulus of toughness, decreases with the increase of (B) value and the relation can be best represented by the equation:
$\zeta_{4}=1184.90-34.245 \mathrm{~B}$
( for square plain concrete confined 1 layer) Again it is clear that the efficiency of energy absorption vanishes when the value of B is more than approximately $35 \mathrm{~cm}$.

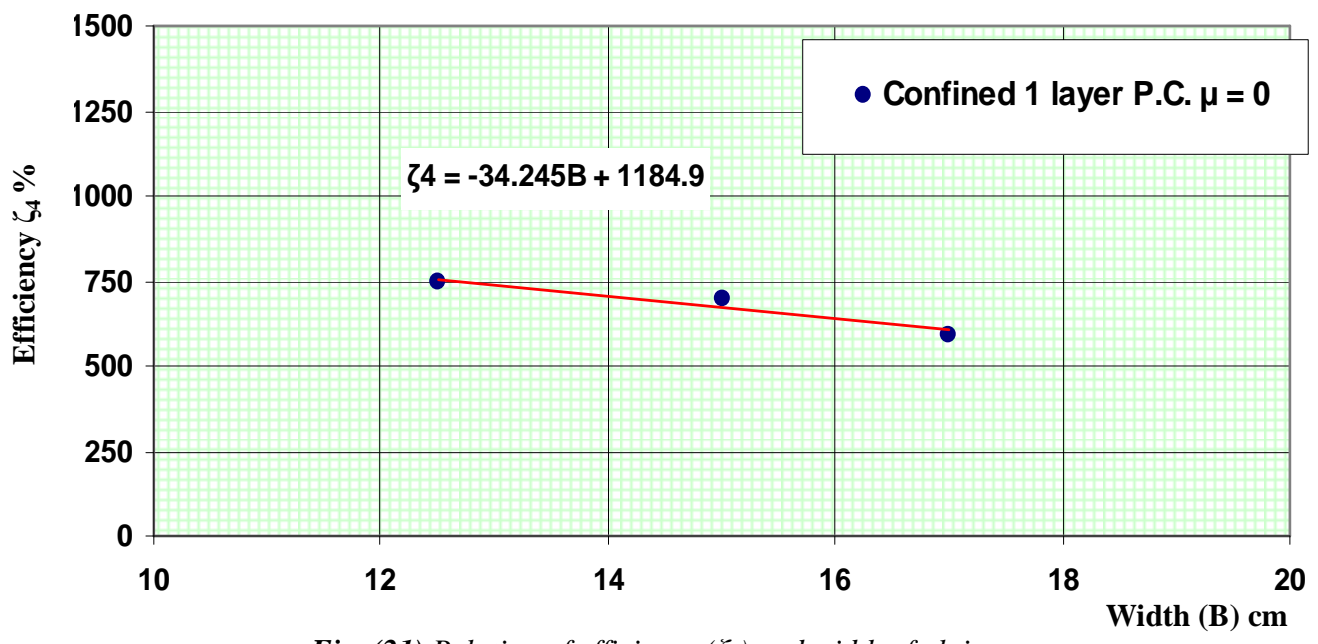

Fig. (21) Relation of efficiency $\left(\zeta_{4}\right)$ and width of plain square concrete columns (B) (Group B)

\section{4-1-1-3 For Rectangular Plain Concrete Columns (Group C):}

All the previous values are plotted against the corresponding value of $(\mathrm{t} / \mathrm{b})$ as shown in Figs. (22) to (25).



Fig. (22) Relation between axial nominal stress $(\sigma)$ and $(t / b)$ ratio for P.C rectangular columns (Group $\boldsymbol{C})$ 


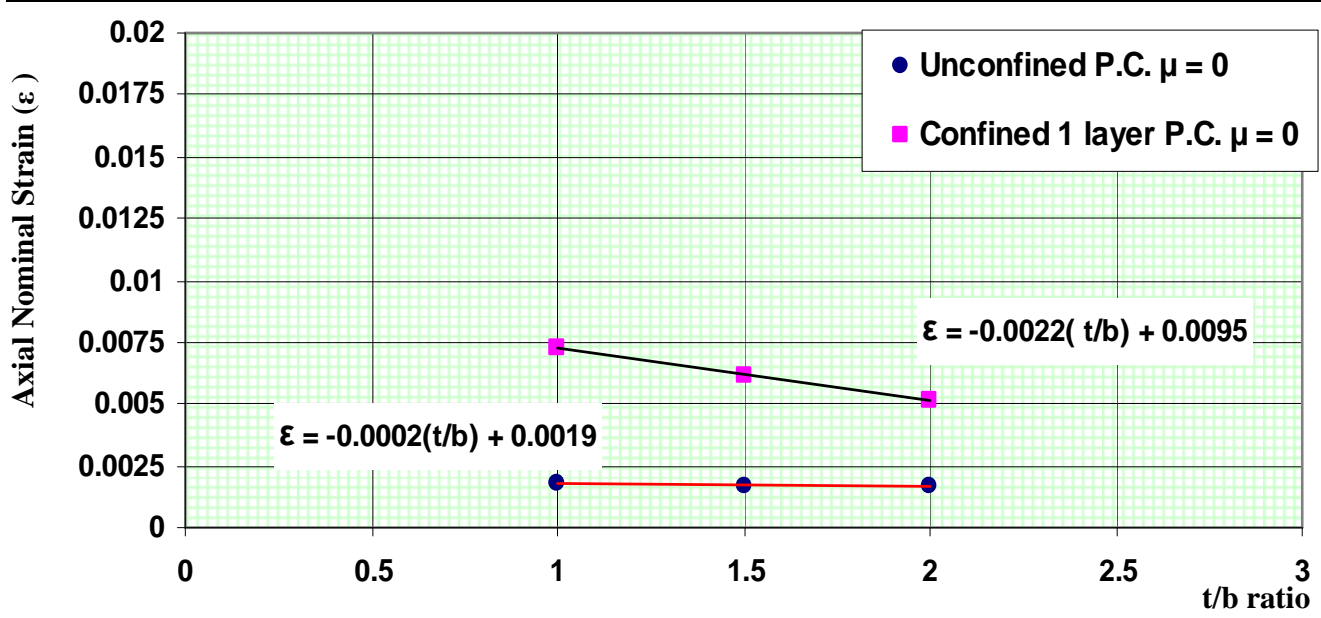

Fig. (23) Relation of axial nominal strain $(\mathcal{E})$ and $(t / b)$ ratio for P.C rectangular columns (Group $\boldsymbol{C}$ )

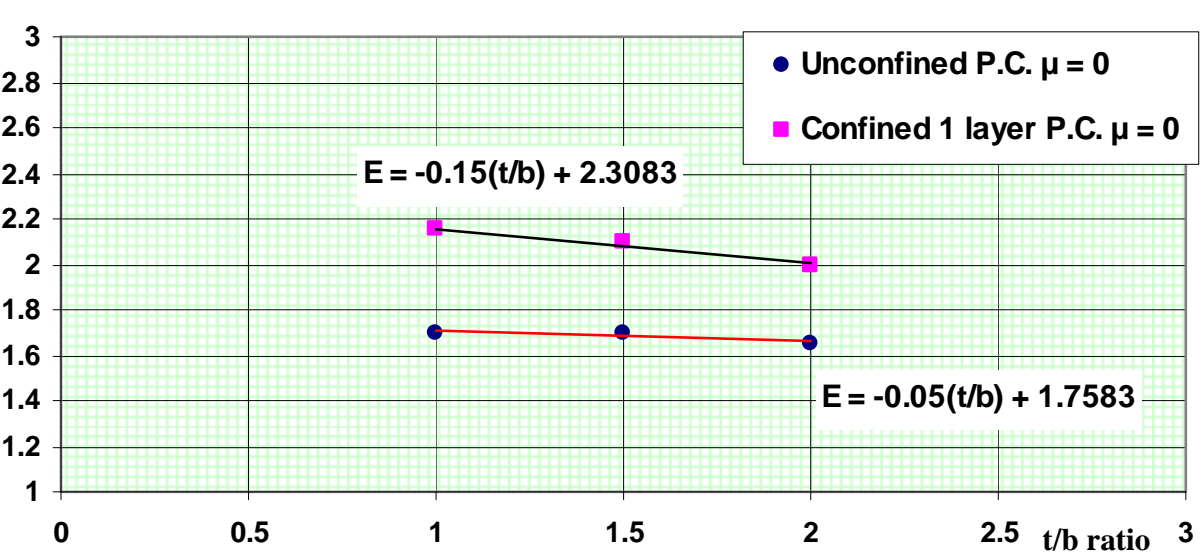

Fig. (24) Relation of modulus of elasticity $(E)$ and $(t / b)$ ratio for P.C rectangular columns (Group $\boldsymbol{C}$ )

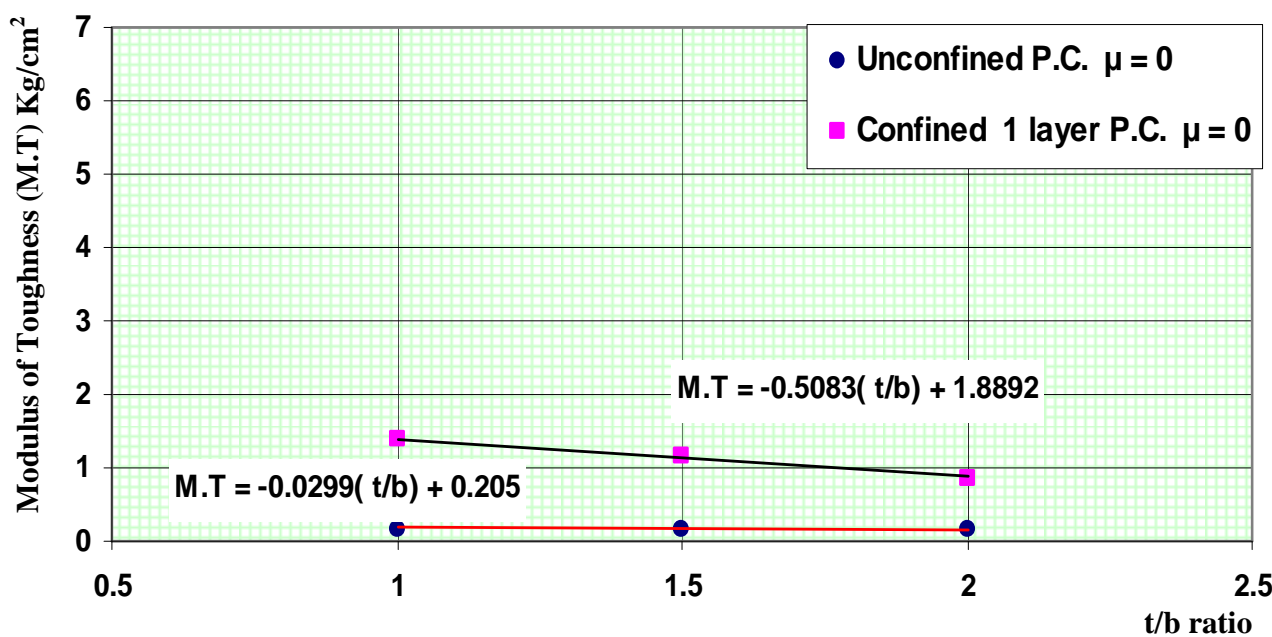

Fig. (25) Relation of modulus of toughness (M.T) and (t/b) ratio for plain rectangular concrete columns (Group C) 
Again all the above properties decrease by increasing the value of $(\mathrm{t} / \mathrm{b})$ ( volume or size of specimen) for both unconfined and confined plain concrete. Also the rate of decrease is higher for confined one layer plain concrete columns rather than for unconfined one.

\section{From Point of View of Strength:}

$\sigma=152.34-4.44(t / b)$

( for unconfined plain concrete)

$\sigma=296.63-35.56(t / b)$

By comparing these stresses by the grade of used concrete (C 200), hence

$\frac{\sigma}{f_{\text {cube }}}=0.7617-0.0222(t / b)$

$\frac{\sigma}{f_{\text {cube }}}=1.483-0.178(t / b)$

( for unconfined plain concrete)

Figure (26) shows the relations between this value of $\left(\zeta_{1}\right)$ and $(\mathrm{t} / \mathrm{b})$ ratio is a straight line one in the form:

$\zeta_{1}=79.482-20.07(t / b)$

(for confined one layer plain concrete )

Equation (38) reflects that the value of $\zeta_{1}$ vanishes when $(\mathrm{t} / \mathrm{b})$ equals approximately (4.0).

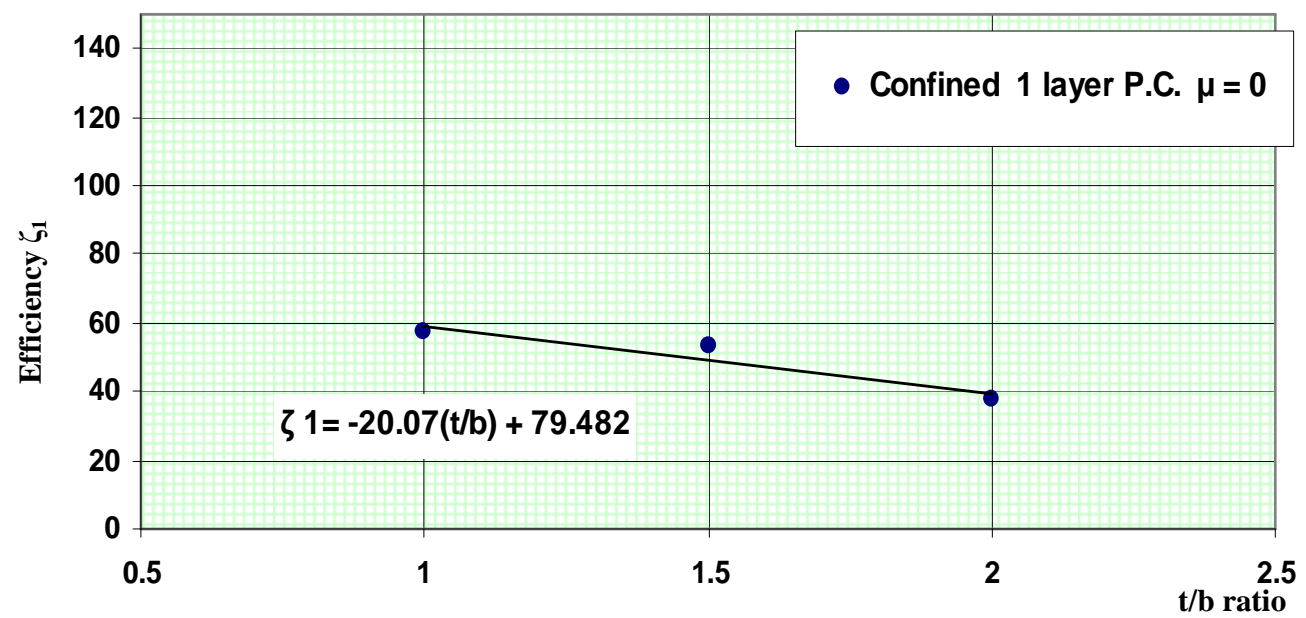

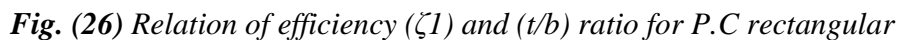
columns (Group C)

\section{From Point of View of Strain:}

$\mathcal{E}=0.0019-0.0002(t / b) \ldots \ldots . .(39)$

$\mathcal{E}=0.0095-0.0022(t / b)$

( for unconfined plain concrete)

The value of the strain efficiency $\left(\zeta_{2}\right)$ can be written in the following form as shown in Fig. (27)

$\zeta_{2}=404.47-96.46(t / b)$ (41) (for confined one layer plain concrete ) 
Also the above equation illustrates that the value $\left(\zeta_{2}\right)$ vanishes when the ratio $(\mathrm{t} / \mathrm{b})$ equals $(4.0)$, i.e the same value as strength efficiency.

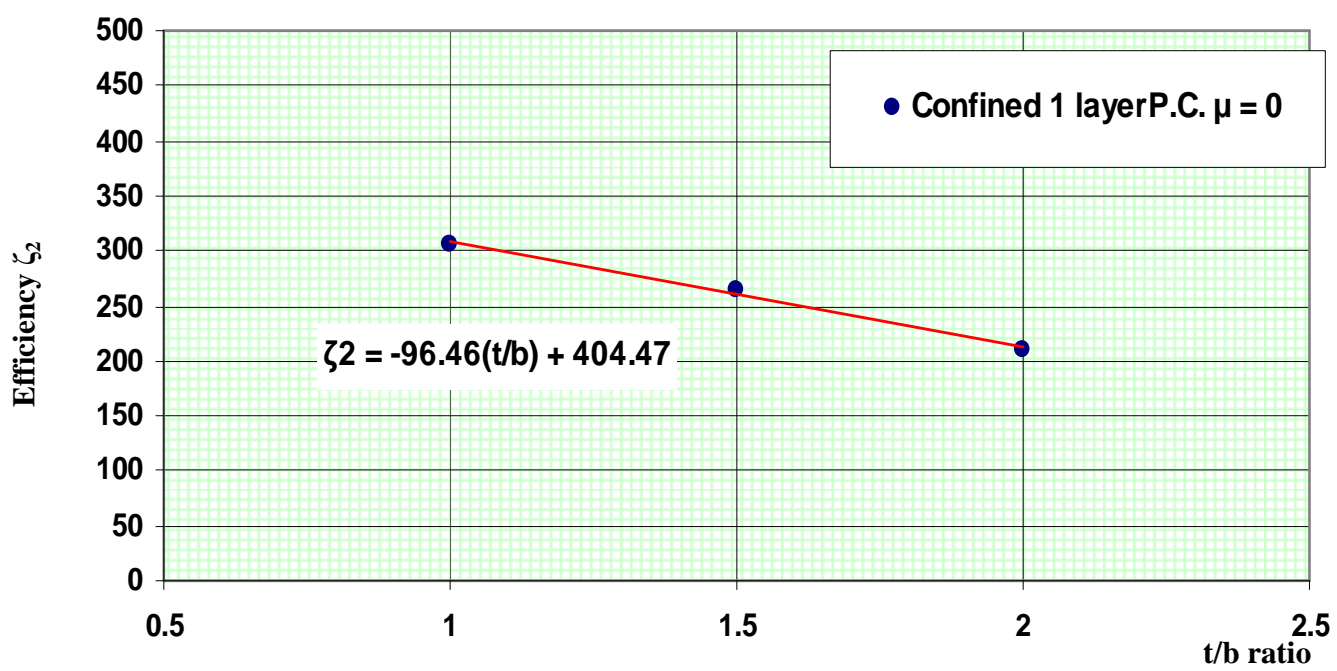

Fig. (27) Relation of efficiency $\left(\zeta_{2}\right)$ and $(t / b)$ ratio for P.C rectangular columns (Group C)

\section{From Point of View of Stiffness :}

$\mathrm{E}=1.7583 \times 10^{5}-0.05(\mathrm{t} / \mathrm{b})$

$\mathrm{E}=2.3083 \times 10^{5}-0.15(\mathrm{t} / \mathrm{b})$

( for unconfined plain concrete) (for confined one layer plain concrete )

The above relationships can be rewritten in terms of the used cube modulus of elasticity (grade of concrete C 200) as follow:

$\frac{E}{E \text { grade }}=0.888-2.52 \times 10^{-7}(\mathrm{t} / \mathrm{b})$.

(for unconfined reinforced concrete)

$\frac{E}{E \text { grade }}=1.1663-7.579 \times 10^{-7}(\mathrm{t} / \mathrm{b})$

(for confined 1 layer reinforced concrete)

Figure (28) shows the relation between $\left(\zeta_{3}\right)$ value and plain concrete rectangular columns of cross- sections. This relation can be written by the following equation:

$\zeta_{3}=31.623-5.26(\mathrm{t} / \mathrm{b}) \ldots(46)($ for confined 1 layer plain rectangular column $)$


$(t / b)$ ratio is approximately equals (6). This means that the stiffness efficiency of plain rectangular concrete column vanishes when $(\mathrm{t} / \mathrm{b})$ ratio $=(6)$.

\section{From Point of View of total Absorbed Energy:}

M.T $=0.205-0.0299(t / b)$

$\mathrm{M} . \mathrm{T}=1.8892-0.5083(t / b)$
( for unconfined plain concrete)

(48) (for confined one layer plain concrete ) 


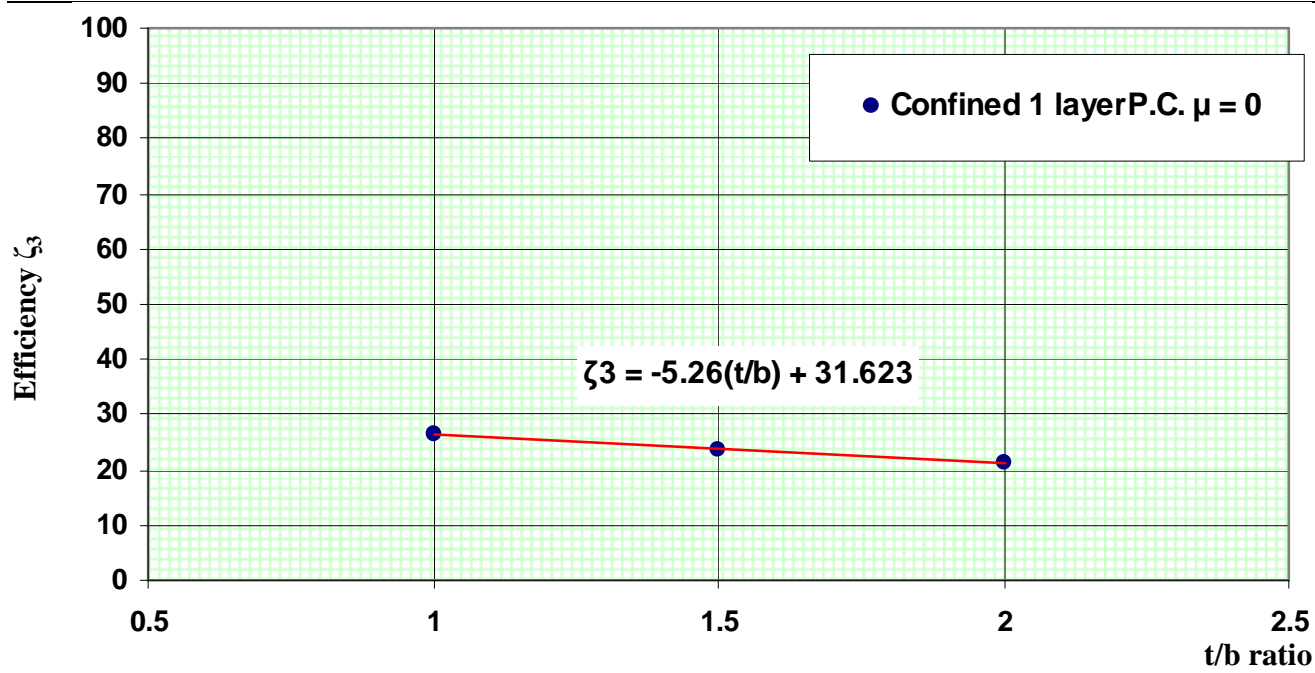

Fig. (28) Relation of efficiency $\left(\zeta_{3}\right)$ and $(t / b)$ ratio for P.C rectangular columns (Group $C)$

The relation between $\left(\zeta_{4}\right)$ and the $(\mathrm{t} / \mathrm{b})$ ratio is given by the following equation, see Fig. (29):

$\zeta_{4}=882.73-190.03(t / b) \ldots \ldots . . .(49)$ (for confined one layer plain concrete )

On the light of equation (49), it is clear that the efficiency $\left(\zeta_{4}\right)$ equals zero when $(\mathrm{t} / \mathrm{b})$ ratio equals $(4.65)$.

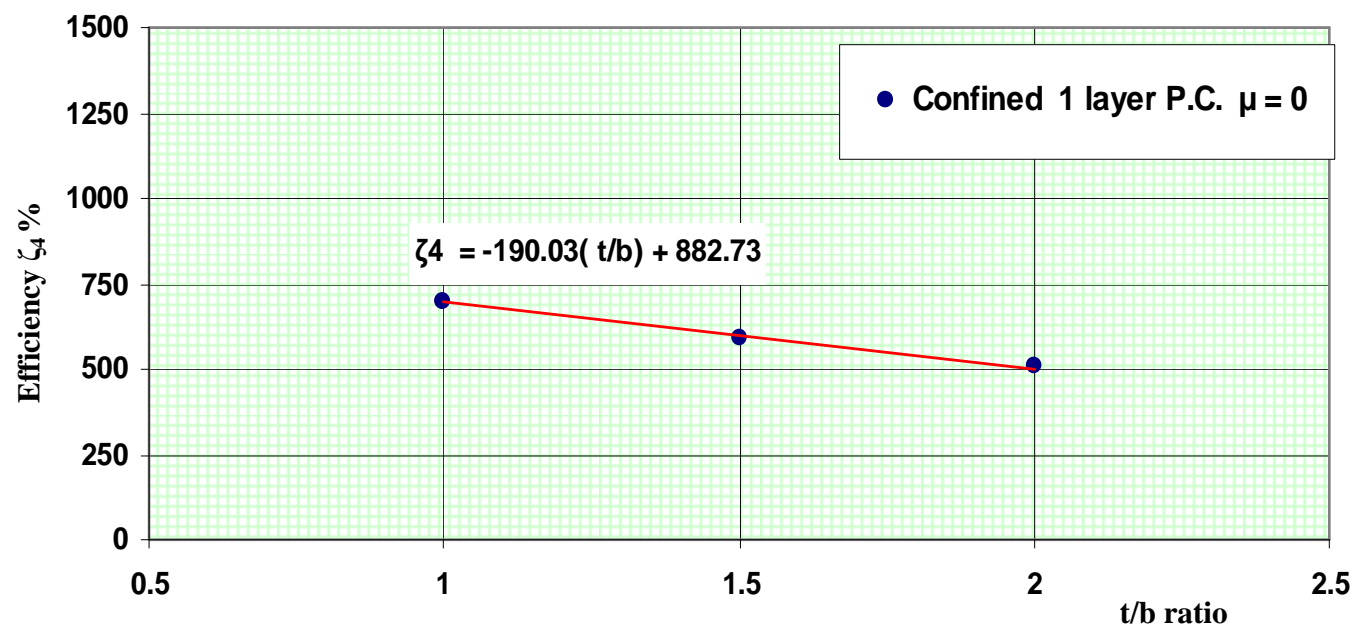

Fig. (29) Relation of efficiency $\left(\zeta_{4}\right)$ and $(t / b)$ ratio for plain rectangular concrete columns (Group $\mathrm{C}$ )

\section{4-1-2 Effect of Shape of Cross Section :}

For the effect of shape of cross - sections, the obtained values of axial stress, axial strain, and modulus of elasticity and modulus of toughness for columns having different shapes (group D) and constant area are shown in Figs. (30) to (33). 


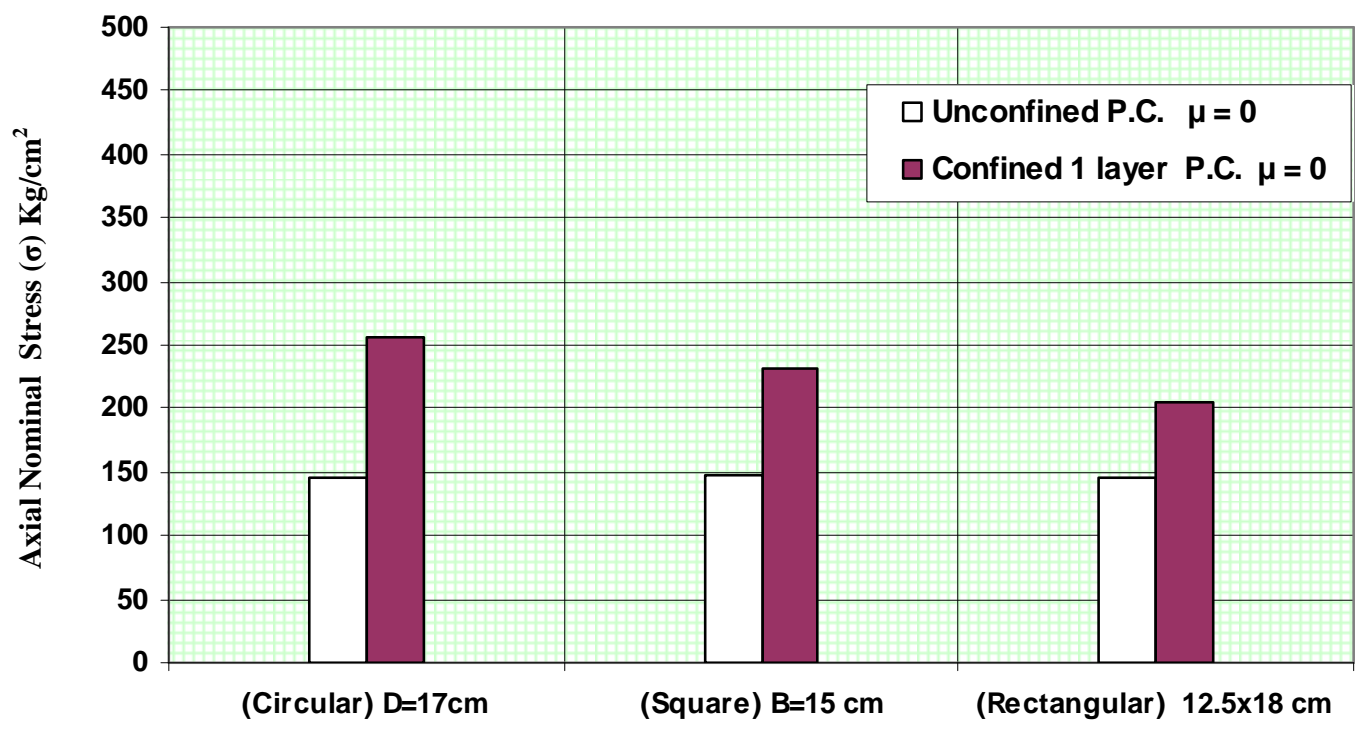

Shape of cross-section

Fig. (30) Comparison between axial nominal stress $(\sigma)$ and shape of cross-section P.C columns (Group D)

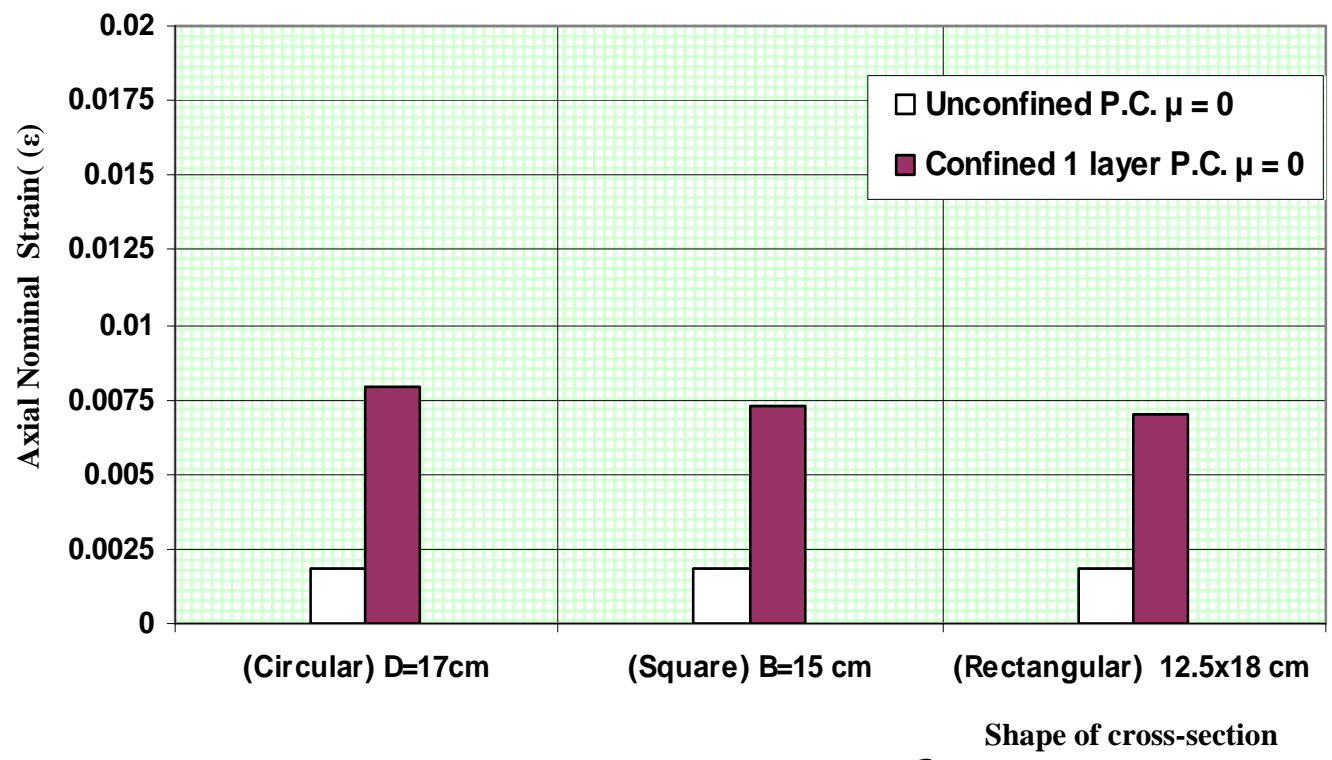

Fig. (31)Comparison between axial nominal strain $(\mathcal{E})$ and shape of cross-section P.C columns (Group D) 

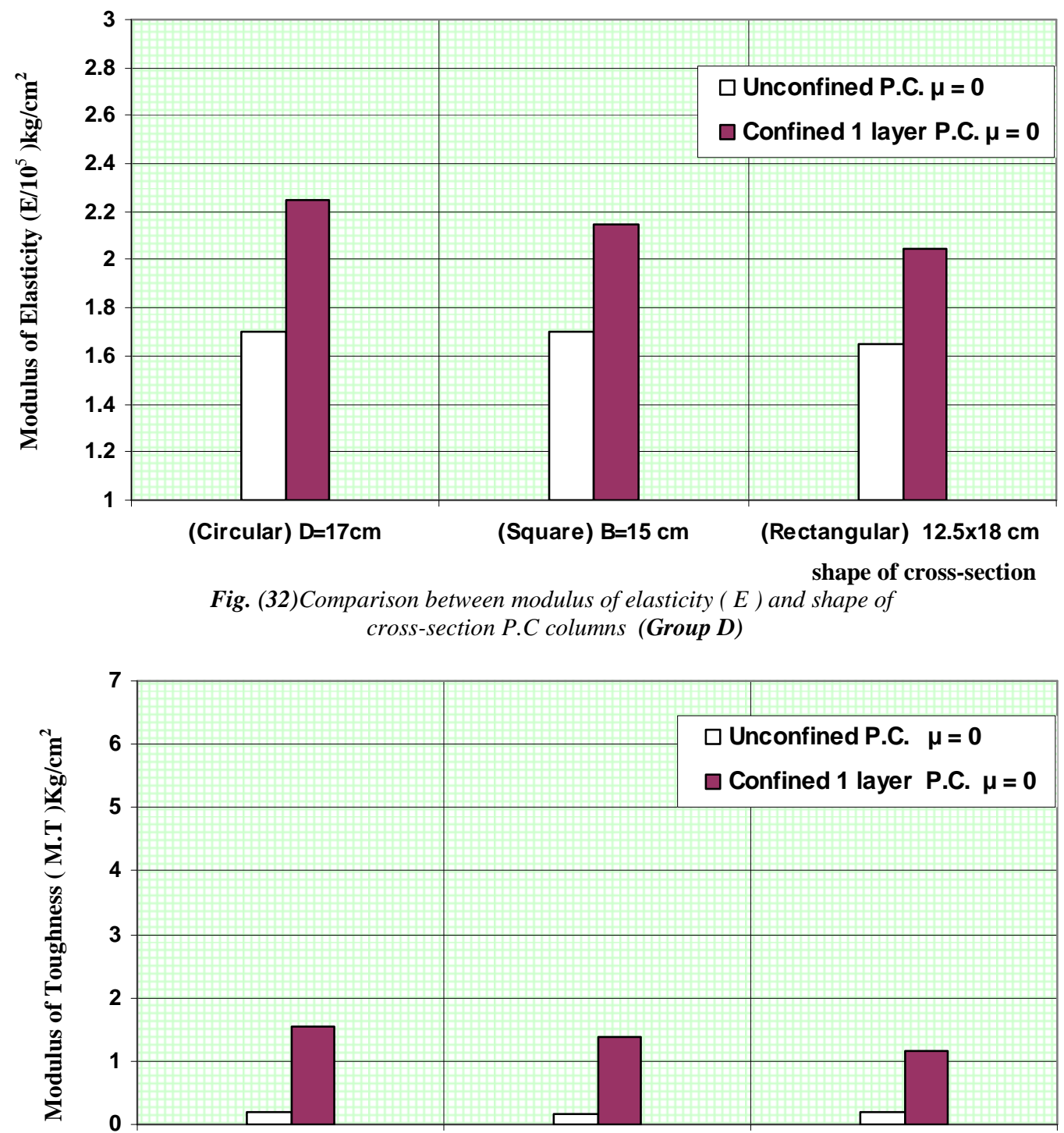

(Circular) $\mathrm{D}=17 \mathrm{~cm}$

(Square) $B=15 \mathrm{~cm}$

(Rectangular) $12.5 \times 18 \mathrm{~cm}$

shape of cross-section

Fig. (33) Comparison between modulus of toughness (M.T) and shape of cross-section P.C columns (Group D)

Also, these properties are higher for confined one layer plain concrete columns rather than that for unconfined plain concrete, as shown in these Figs. It is obvious that the value of these properties are higher for circular confined one layer plain concrete than both square and rectangular confined one layer, at the same time these properties are higher for square confined one layer plain concrete than rectangular confined one layer plain concrete. Table(4) as well as Fig.(34) to Fig.(37) give the values of efficiencies $\left(\zeta_{1}\right),\left(\zeta_{2}\right),\left(\zeta_{3}\right)$ and $\left(\zeta_{4}\right)$ where all the efficiencies varied according to the shape of cross-section. 


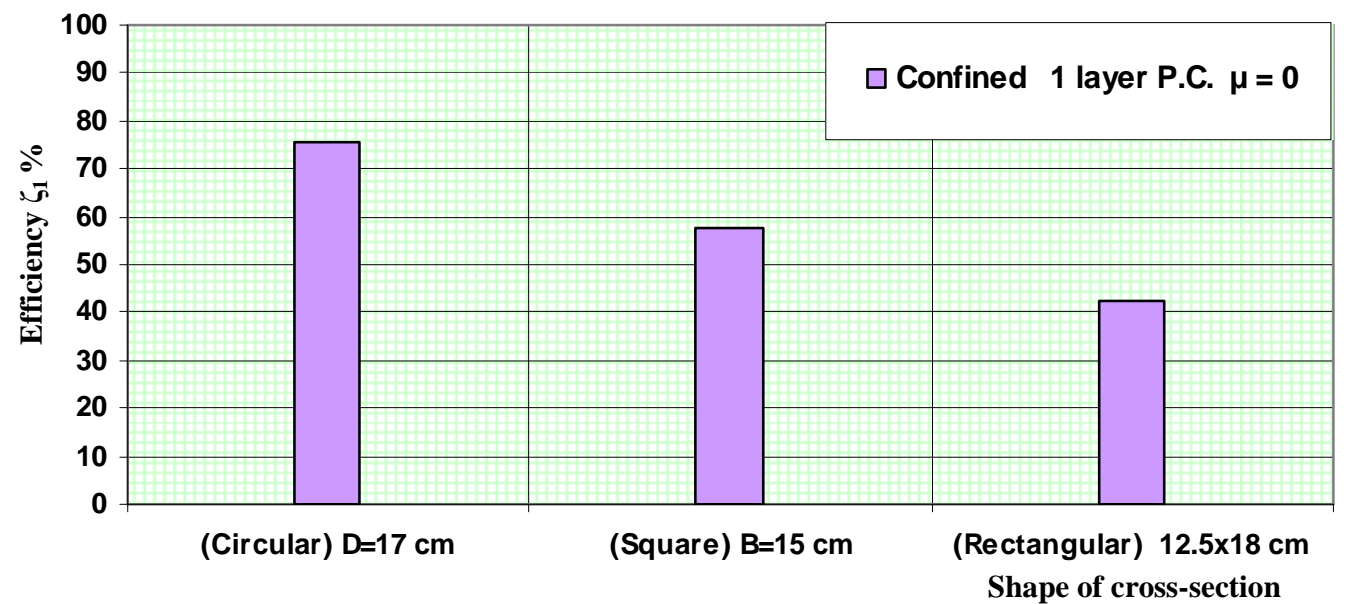

Fig. (34)Comparison between Efficiency $\left(\zeta_{1}\right)$ and shape of

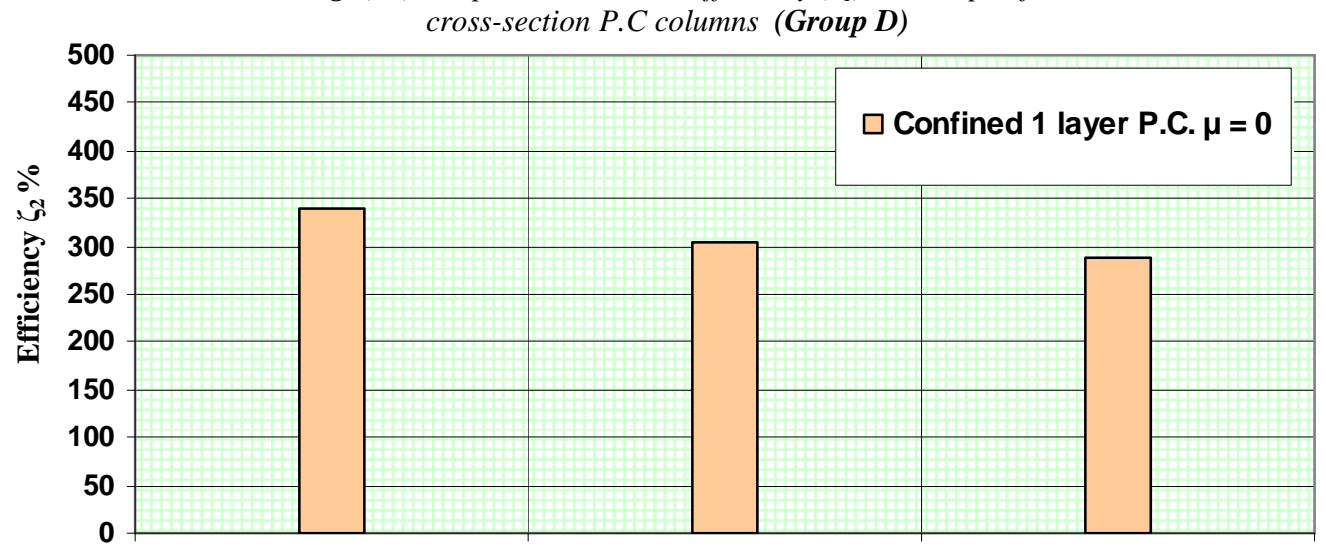

(Circular) $\mathrm{D}=\mathbf{1 7 \mathrm { cm }}$

(Square) $B=15 \mathrm{~cm}$

(Rectangular) $12.5 \times 18 \mathrm{~cm}$

Shape of cross-section

Fig. (35) Comparison between efficiency $\left(\zeta_{2}\right)$ and shape of cross-section P.C columns (Group D)

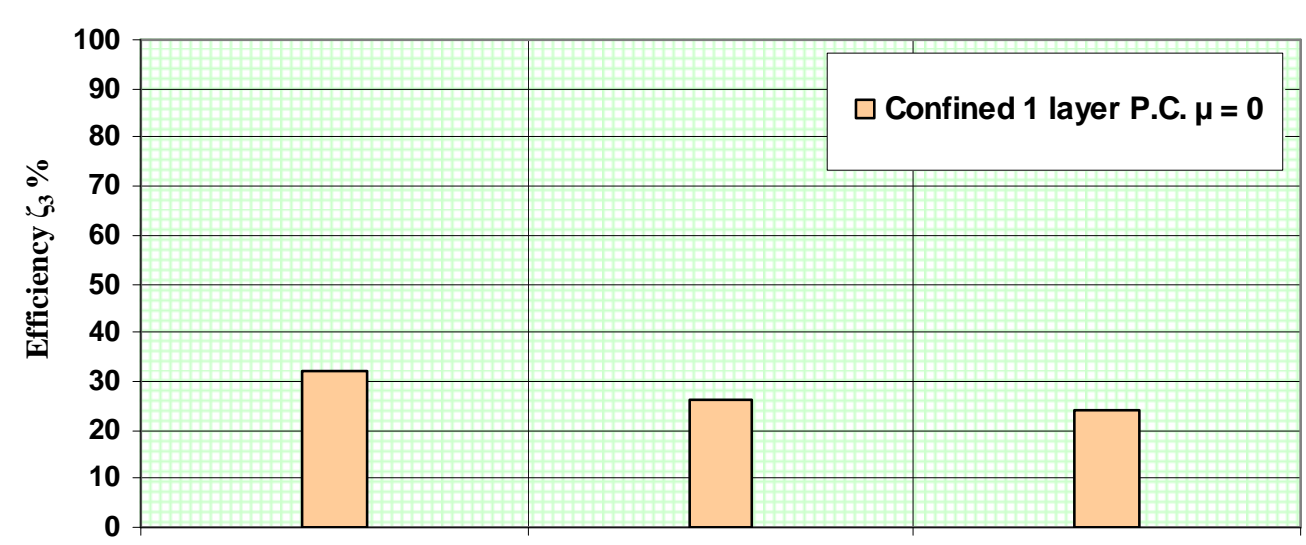

(Circular) $\mathrm{D}=\mathbf{1 7 \mathrm { cm }}$

(Square) $B=15 \mathrm{~cm}$

(Rectangular) $12.5 \times 18 \mathrm{~cm}$

Fig. (36) Comparison between efficiency $\left(\zeta_{3}\right)$ and shape of

shape of cross-section cross-section P.C columns (Group D) 


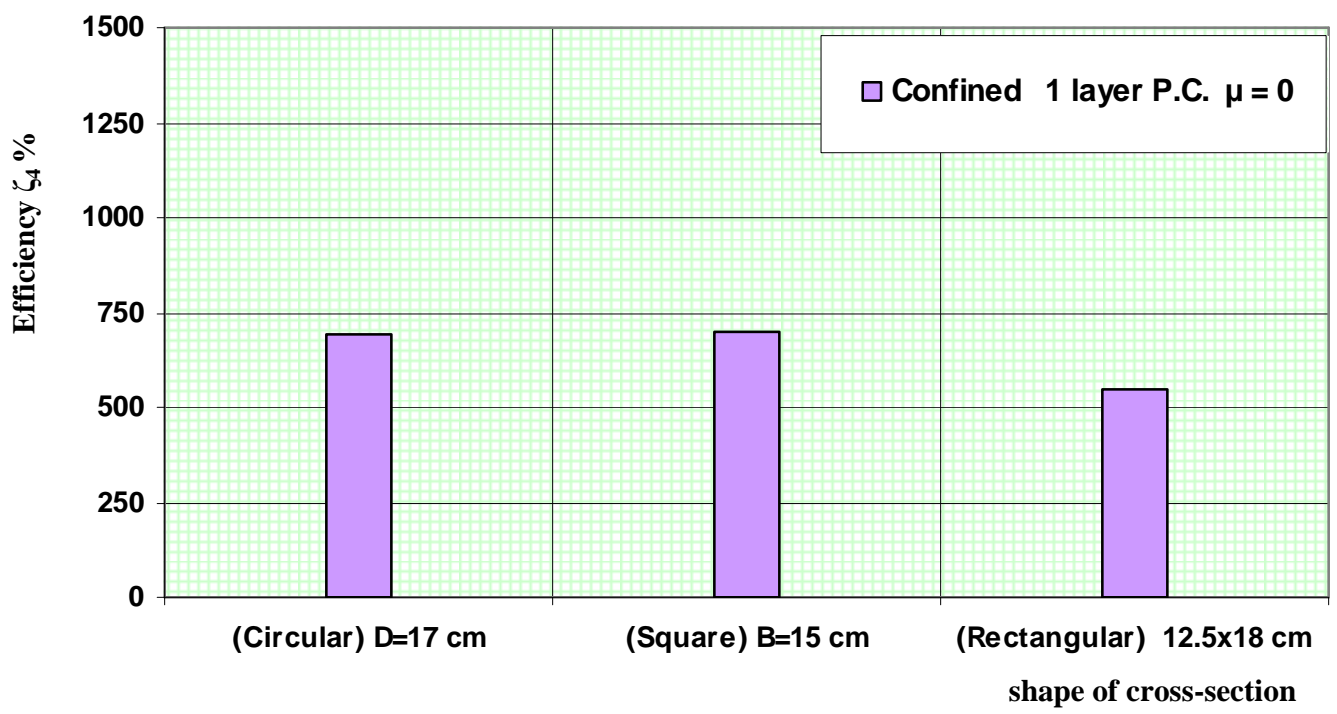

Fig. (37) Comparison between efficiency $\left(\zeta_{4}\right)$ and shape of cross-section P.C columns (Group D)

\section{4-2 With Respect to Reinforced Concrete Axially Loaded Columns:}

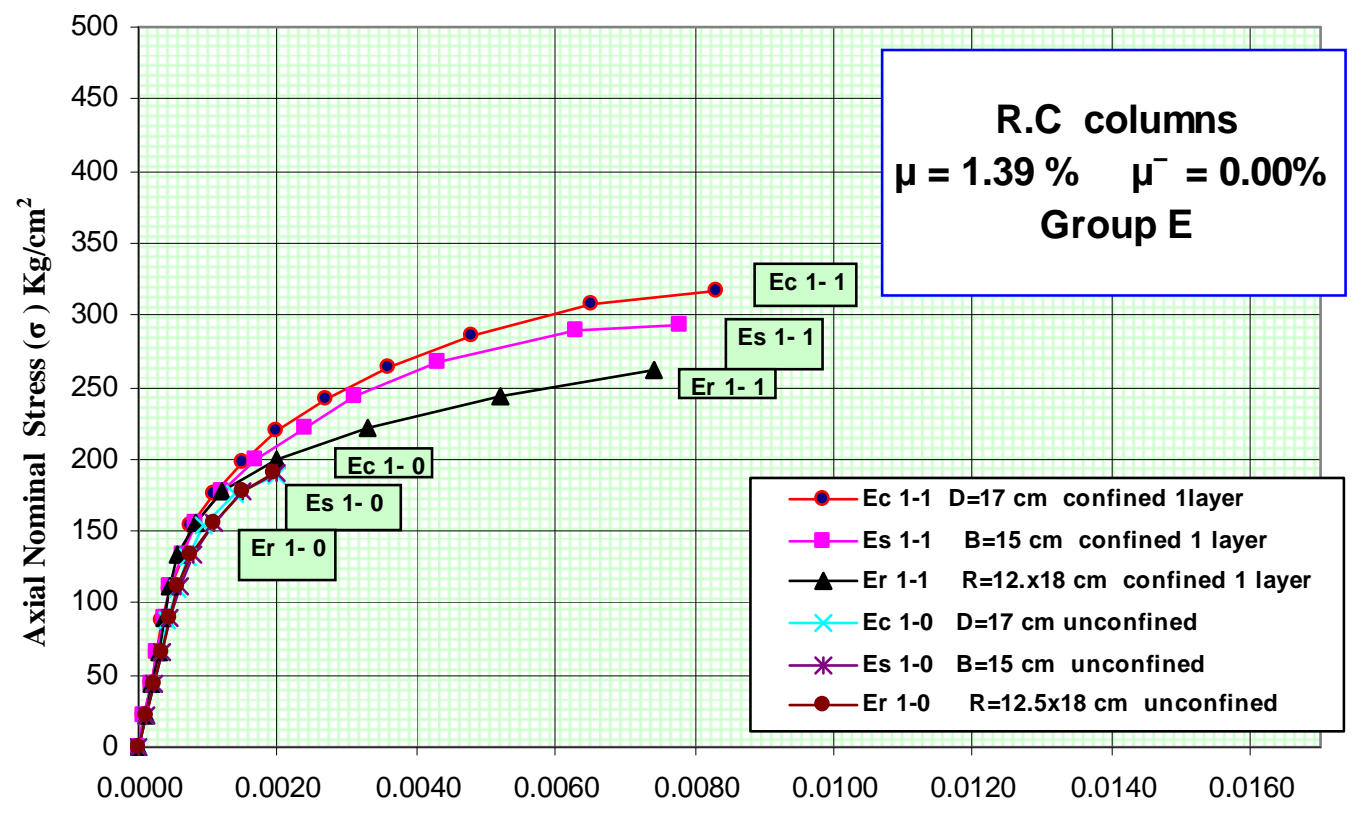

Axial Nominal Strain $(\varepsilon)$

Fig. (38) Comparison between axial nominal stress $(\sigma)$ and axial nominal strain $(\varepsilon)$ for both unconfined and confined circular, square and rectangular R.C. columns with longitudinal steel, $A=225 \mathrm{~cm}^{2}$ (Group E) 


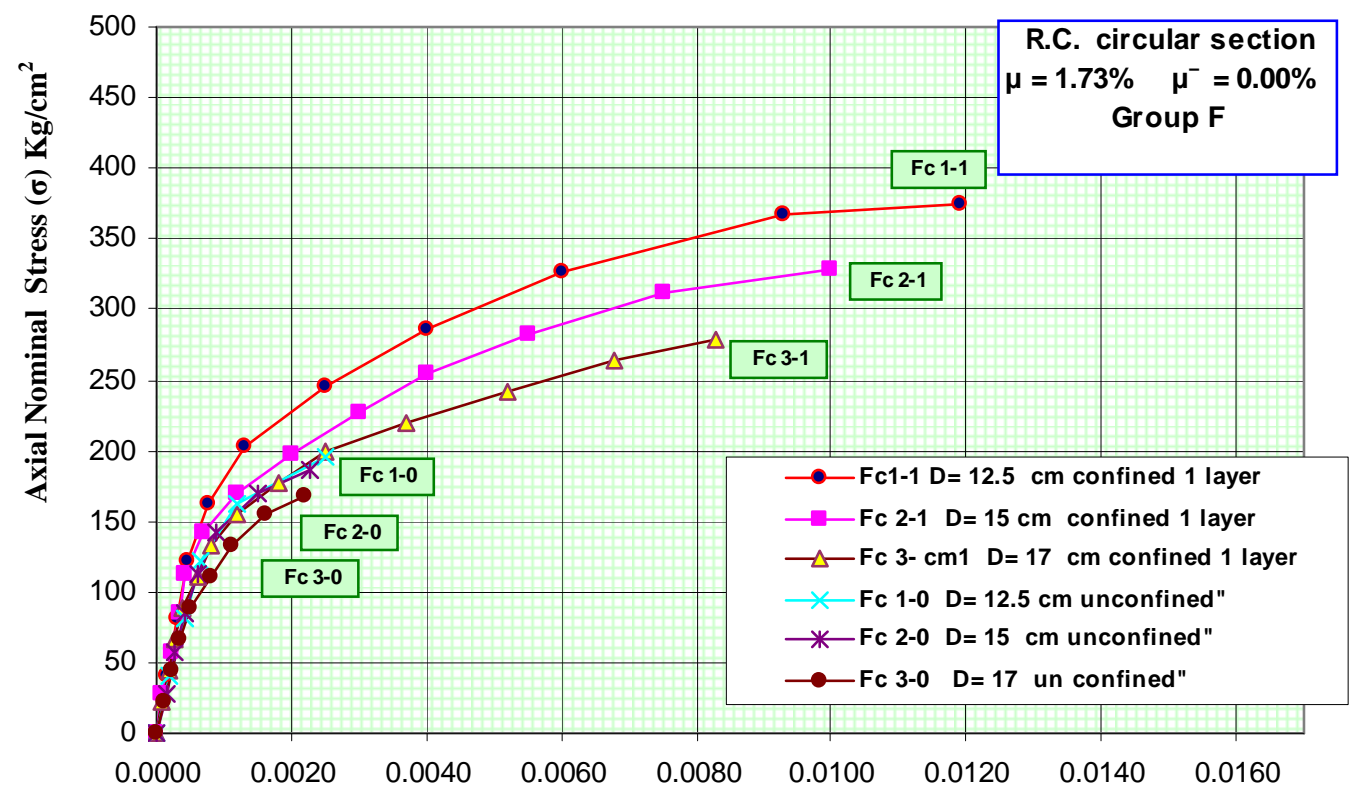

Axial Nominal Strain $(\varepsilon)$

Fig. (39) Comparison between axial nominal stress $(\sigma)$ and axial strain $(\varepsilon)$ for confined circular columns with longitudinal steel and different size (Group F)

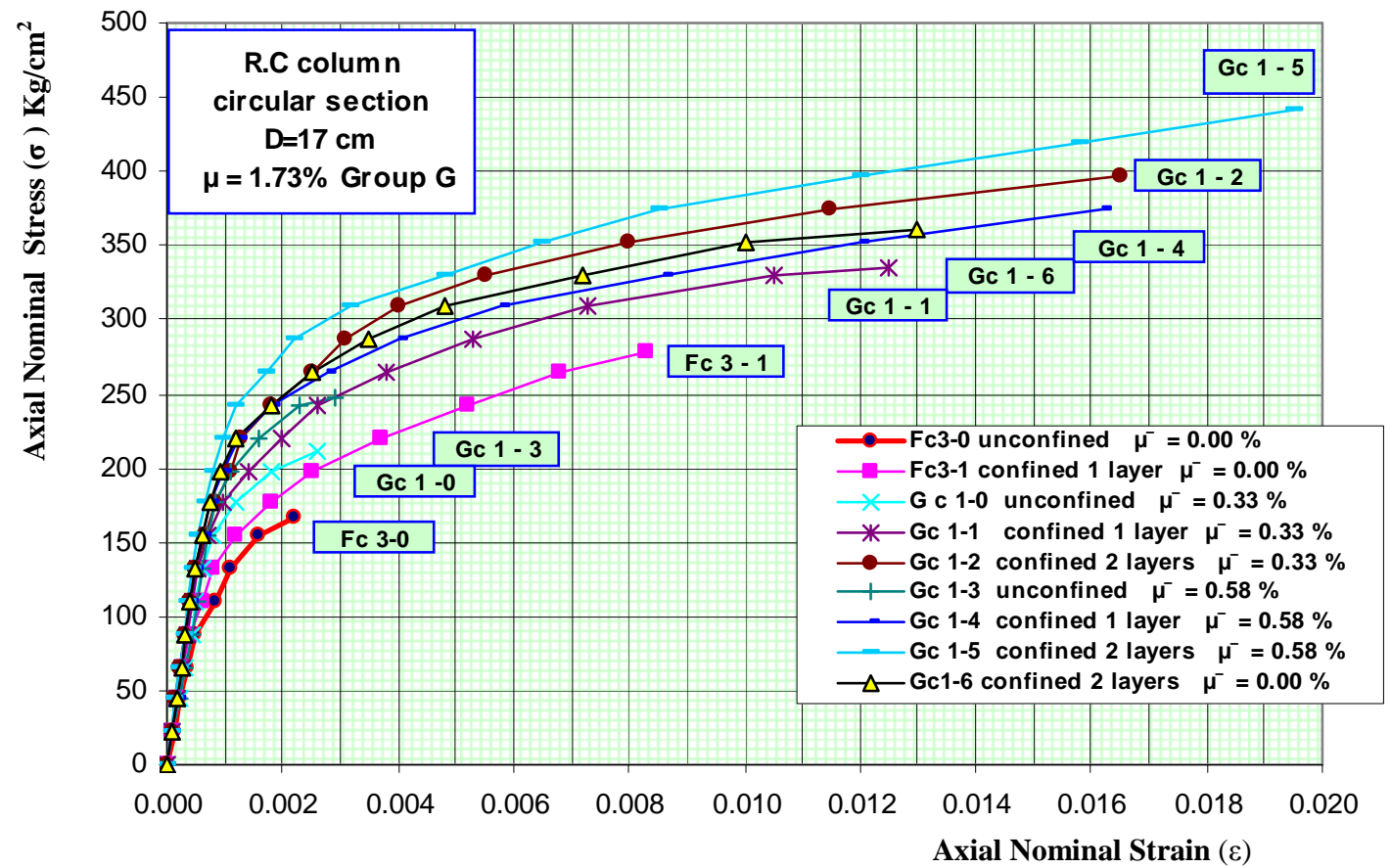

Fig. (40) Comparison between axial nominal stress $(\sigma)$ and axial nominal strain $(\varepsilon)$ for both confined and unconfined circular columns with longitudinal steel and different percentage of lateral steel (Group $\boldsymbol{G})$ 


\section{4-2-1 Effect of Shape and Size of Cross-Section :}

Figure (38) shows the relationship between axial nominal stress - nominal strain for different shapes of circular, square and rectangular concrete columns for unconfined and confined one layer reinforced concrete columns of constant cross sectional area of $225 \mathrm{~cm}^{2}$ with longitudinal steel $\mu=1.39 \%$ and no lateral steel $\mu^{-}=0.00 \%$. The obtained values of axial stress, axial strain, modulus of elasticity and modulus of toughness for such columns are shown in Figs. (41) to (44) for such sections.

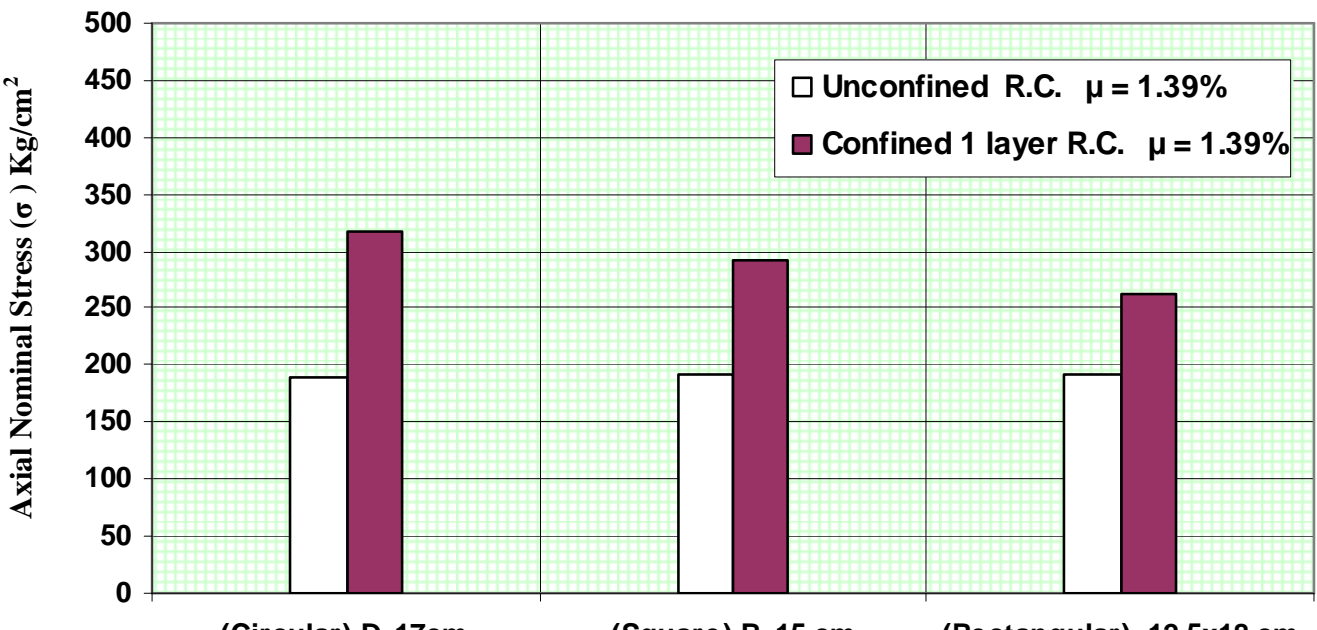

(Circular) D=17cm

(Square) $B=15 \mathrm{~cm}$

(Rectangular) $12.5 \times 18 \mathrm{~cm}$

Shape of cross-section

Fig. (41) Comparison between axial nominal stress $(\sigma)$ and shape of cross-section for R.C columns (Group E)

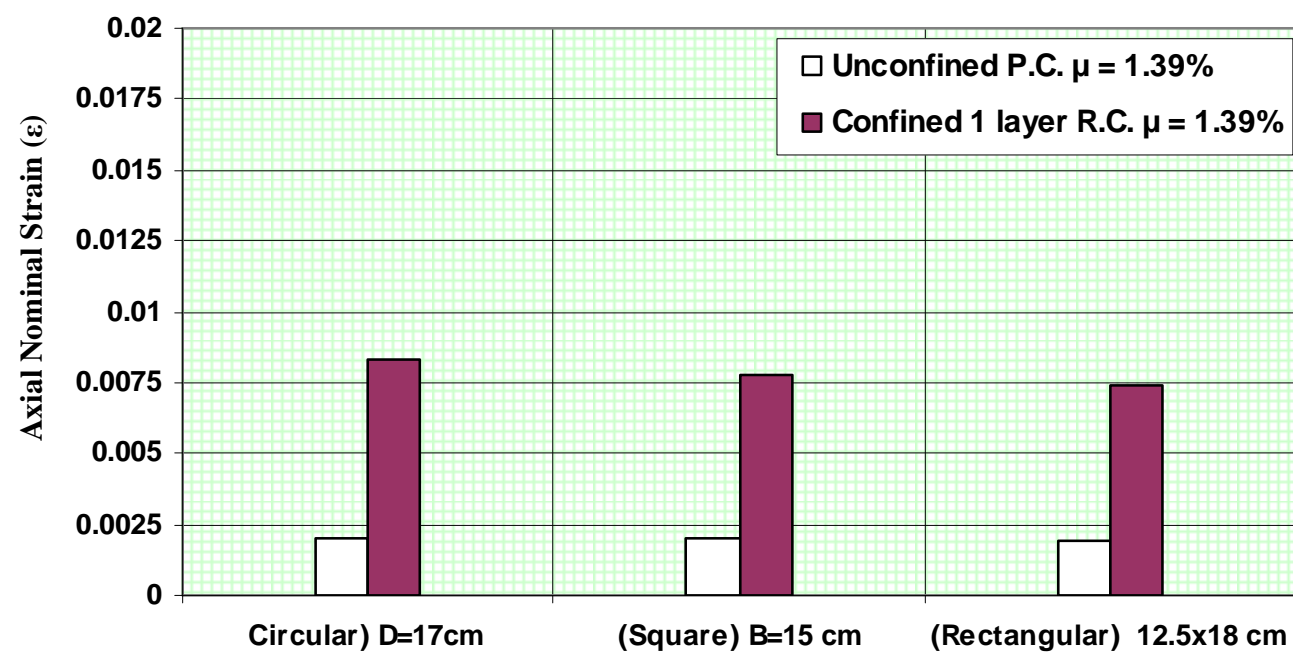

Shape of cross-section

Fig. (42) Comparison between axial nominal strain $(\mathcal{E})$ and shape of cross-section for R.C columns (Group E) 


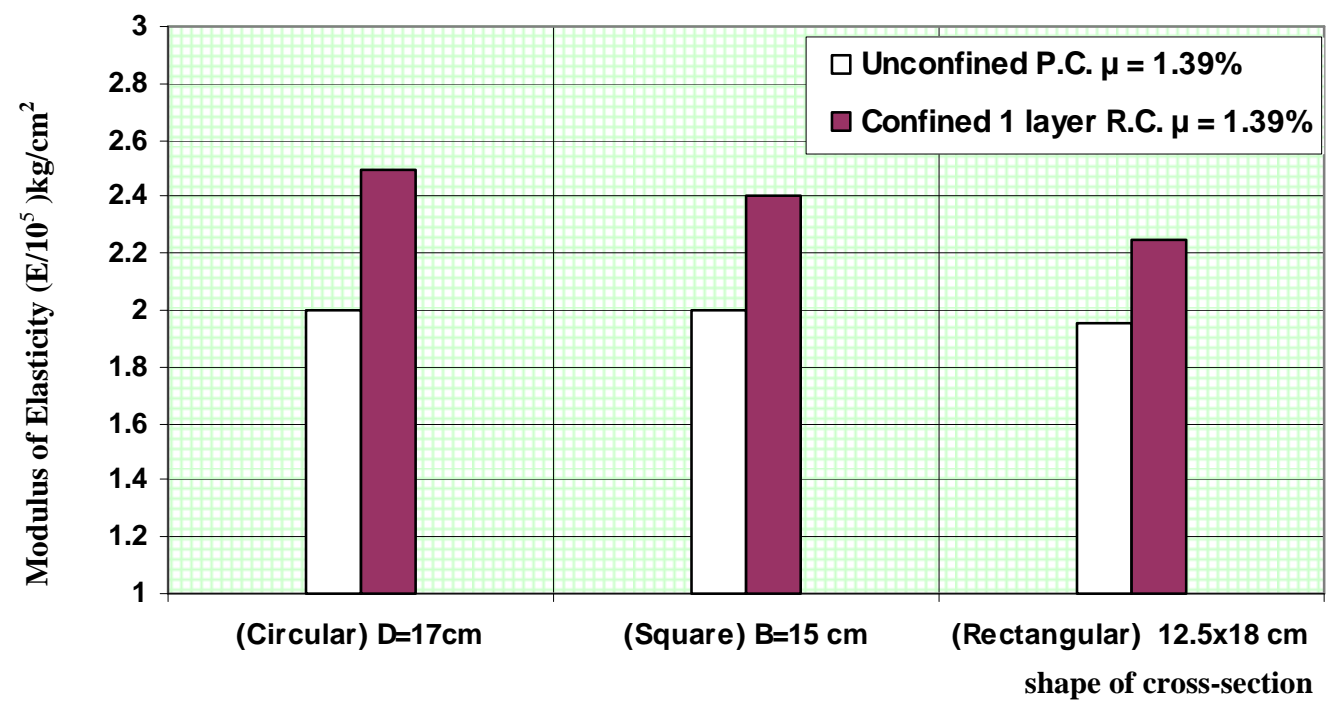

Fig. (43) Comparison between modulus of elasticity ( $E$ ) and shape of cross-section for R.C columns (Group $\boldsymbol{E})$

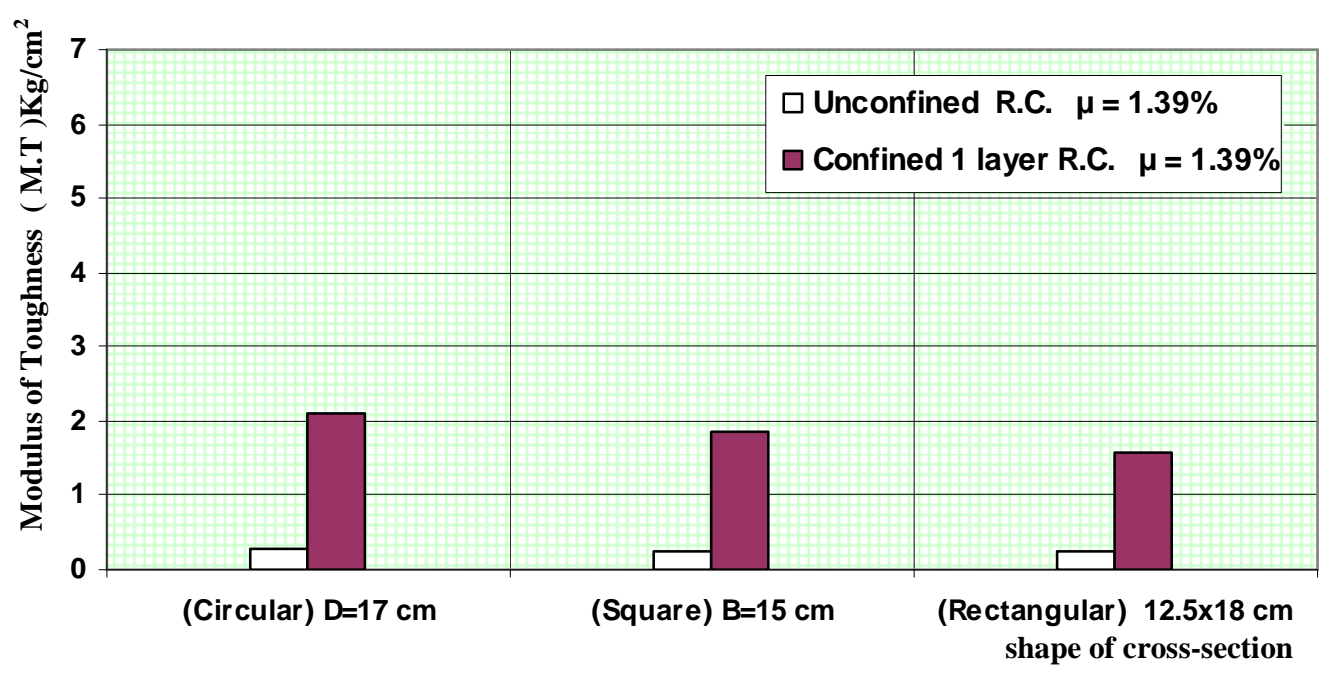

Fig. (44) Comparison between modulus of toughness (M.T) and shape of cross-section for R.C columns (Group E)

It is clear that these properties are higher for confined one layer reinforced concrete columns rather than that for unconfined reinforced concrete as plain concrete. The efficiency values for strength $\left(\zeta_{1}\right),\left(\zeta_{2}\right),\left(\zeta_{3}\right)$ and $\left(\zeta_{4}\right)$ are given in Table (5) as well as in Figs. (45) to (48).

Again, it is clear that such values are higher for circular confined one layer reinforced concrete rather than for both square and rectangular confined one layer. Also these values are higher for square confined one layer reinforced concrete than that for rectangular confined one layer reinforced concrete. 


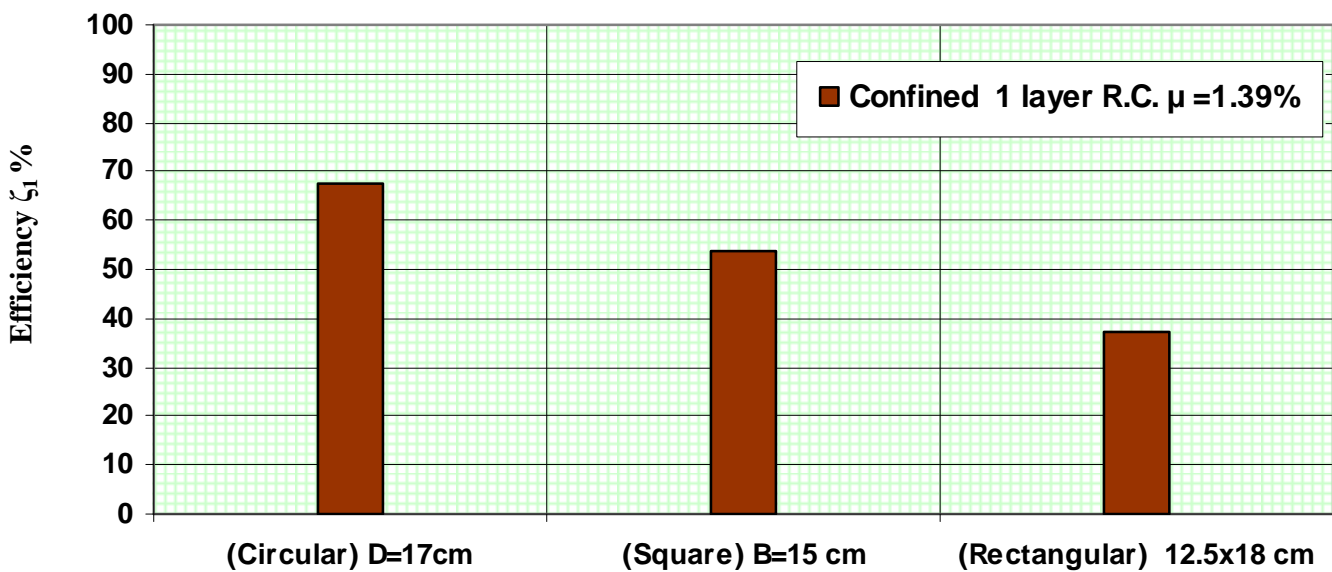

Shape of cross-section

Fig. (45) Comparison between efficiency $\left(\zeta_{l}\right)$ and shape of cross-section for R.C columns (Group E)

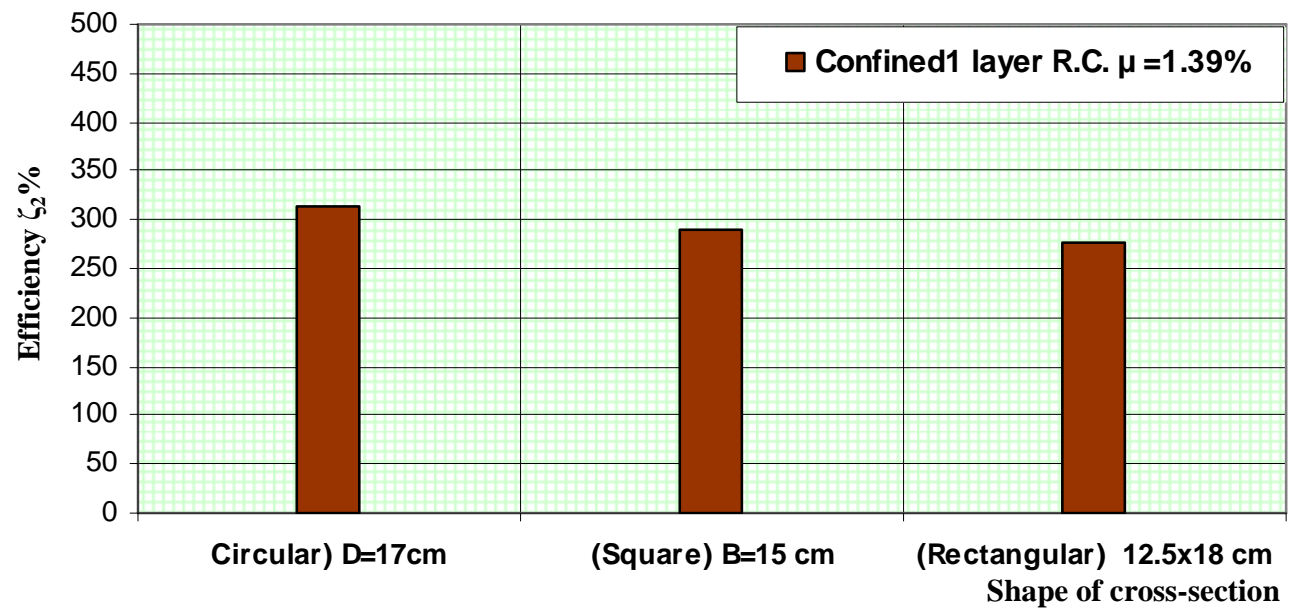

Fig. (46) Comparison between efficiency $\left(\zeta \zeta_{2}\right)$ and shape of cross-section for R.C columns (Group E)

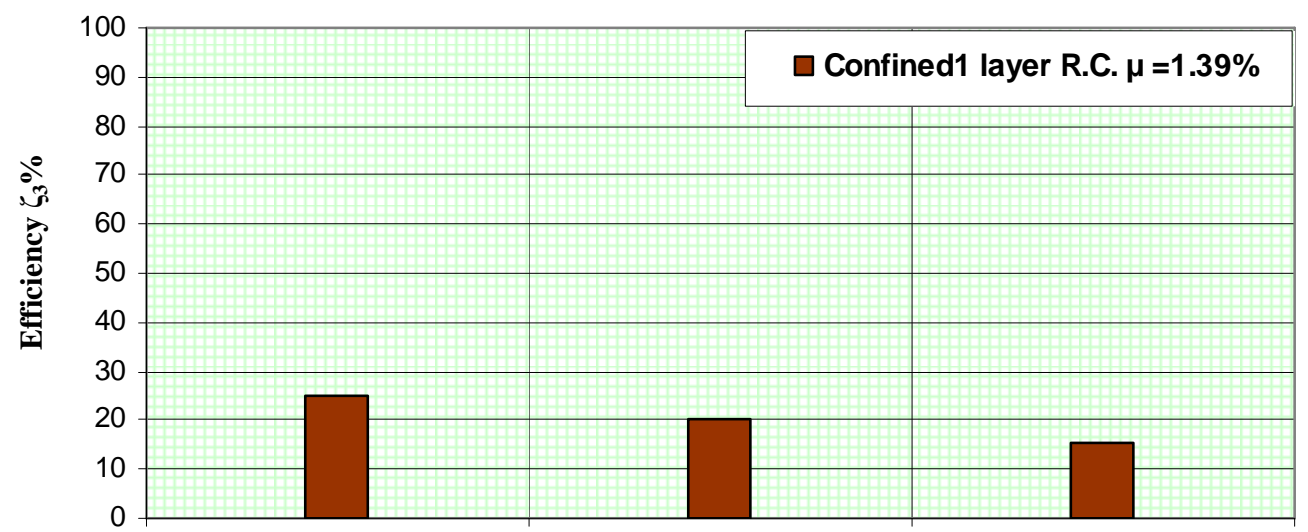

(Circular) $\mathrm{D}=\mathbf{1 7 \mathrm { cm }}$

(Square) $B=15 \mathrm{~cm}$

(Rectangular) $12.5 \times 18 \mathrm{~cm}$

Fig. (47) Comparison between efficiency $\left(\zeta_{3}\right)$ and shape of

Shape of cross-section cross-section for R.C columns (Group E) 


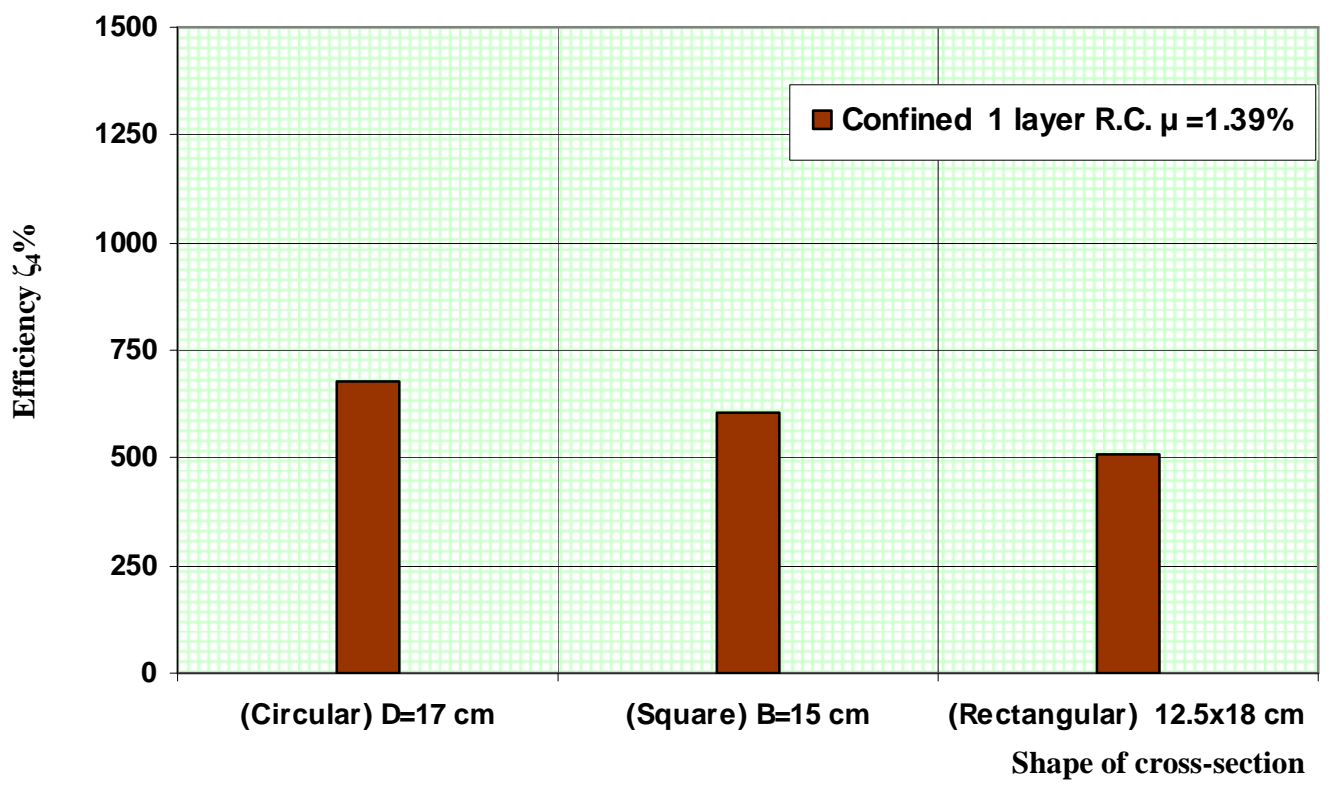

Fig. (48) Comparison between efficiency $\left(\zeta_{4}\right)$ and shape of cross-section for R.C columns (Group E)

Figures (49) to (52) show the relationships between the max. nominal stress $(\sigma)$. the max. nominal strain $(\mathcal{E})$, the value of modulus of elasticity as well as the modulus of toughness (M.T) and corresponding column diameter (D) for both unconfined and confined with one layer plain concrete circular columns with different size .

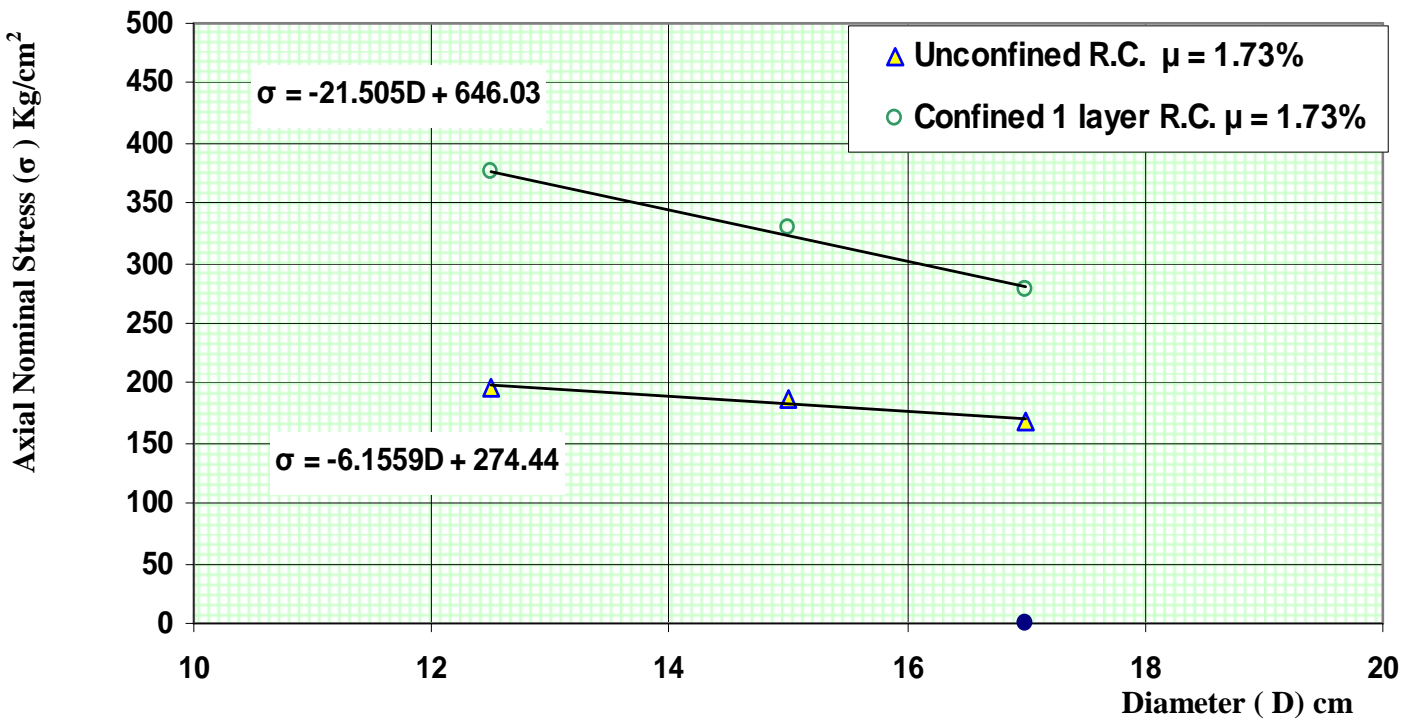

Fig. (49) Relation of nominal stress $(\sigma)$ and diameters $(D)$ for R.C circular columns (Group F) 


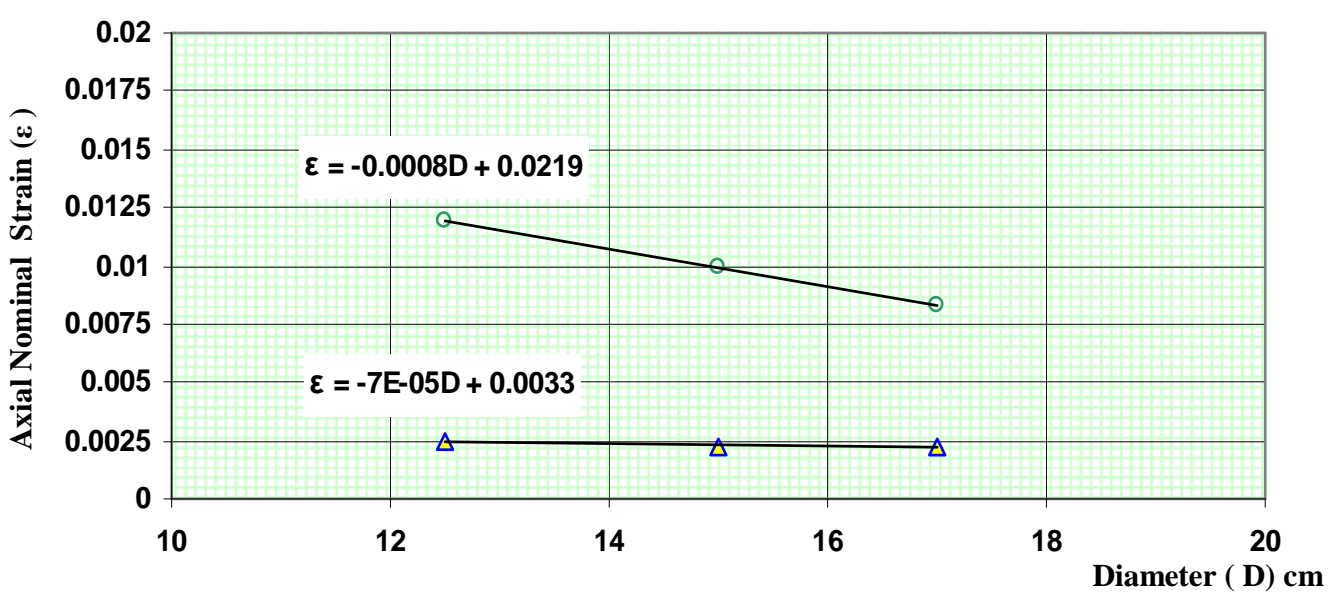

Fig. (50) Relation of nominal axial strain $(\boldsymbol{\mathcal { E }}$ ) and diameters $(D)$ for R.C circular columns (Group F)

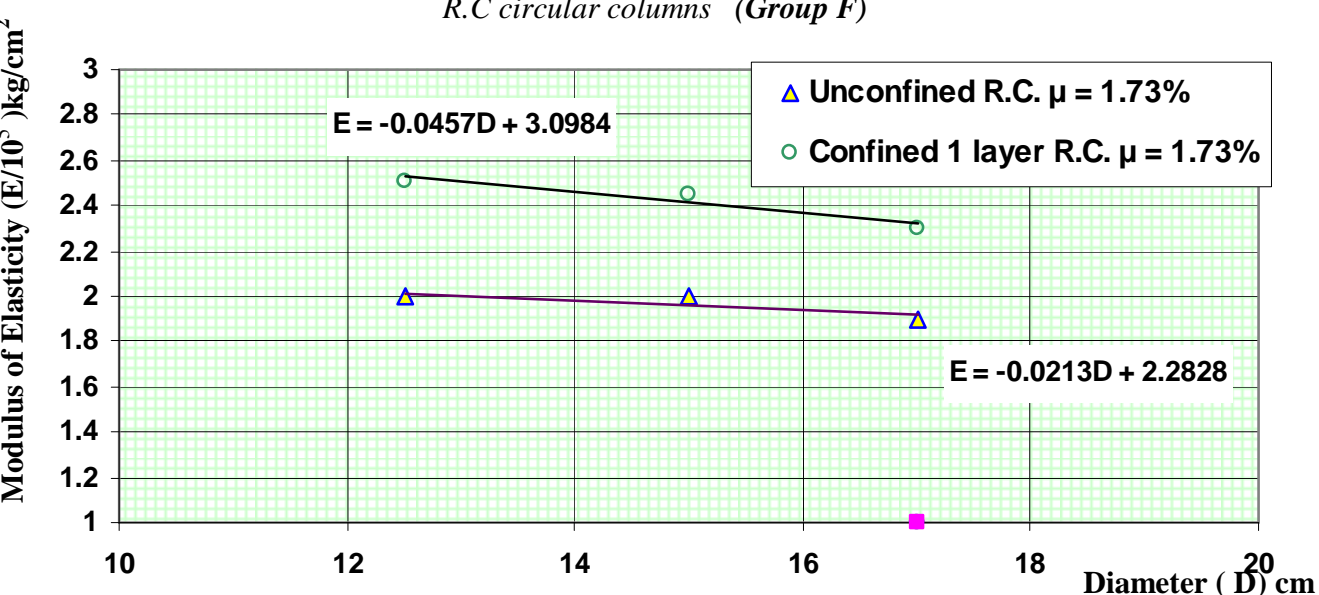

Fig. (51) Relation of modulus of Elasticity ( $E$ ) and diameters $(D)$ for

R.C circular columns (Group F)

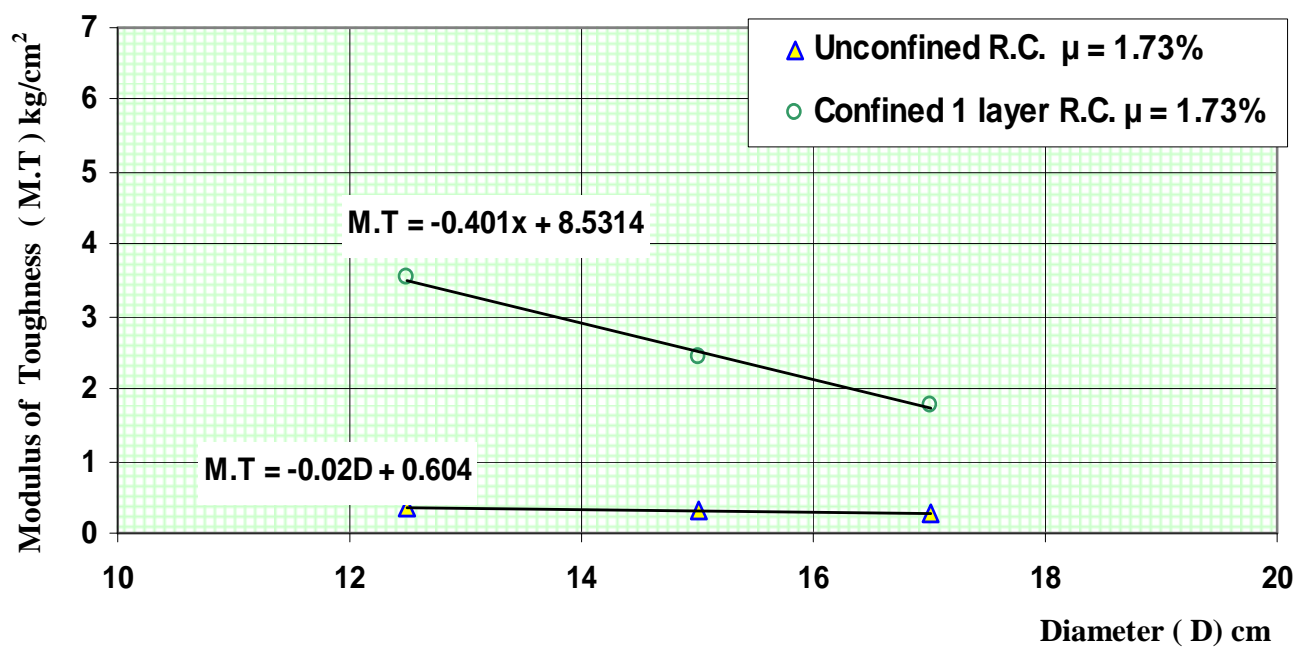

Fig.(52)Relation between modulus of toughness( M.T ) and diameters $(D)$ for R.C circular columns (Group F) 


\section{From Point of View of Strength:}
$\sigma=274.44-6.16 \mathrm{D}$
( for unconfined reinforced concrete)
$\sigma=646.03-21.51 \mathrm{D}$

Comparing this induced maximum stress with grade of used concrete then :

$\frac{\sigma}{f_{\text {cube }}}=1.372-0.0308 \mathrm{D}$

( for unconfined reinforced concrete)

$\frac{\sigma}{f_{\text {cube }}}=3.230-0.107 \mathrm{D}$

On the light of equations (52) and (53) for example for a standard dimension diameter of cylinder of $15 \mathrm{~cm}$, these equations led to the values:

$\frac{\sigma}{f_{\text {cube }}}=0.91$
$\frac{\sigma}{f_{\text {cube }}}=1.625$ ( for unconfined reinforced concrete)

Figure (53) shows the relation between the strength efficiency (ל1) against the diameter (D) of specimen of reinforced concrete.

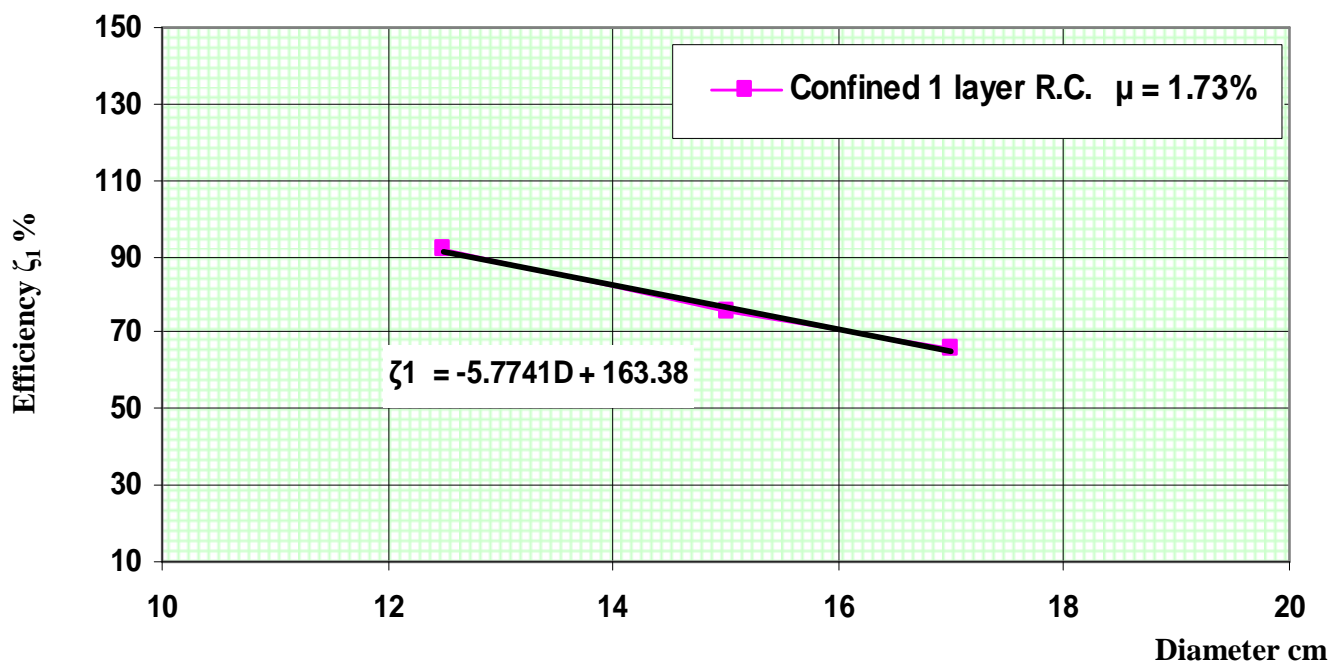

Fig. (53) Relation of efficiency (ל1) and diameters (D) for R.C circular columns (Group F)

This relation indicates that the efficiency $(\zeta 1)$ decreases by the increase of column diameter (D) and can be best represented by the following relation: $\zeta_{1}=163.38-5.7741 \mathrm{D} \ldots(54)$ ( for circular reinforced concrete confined 1 layer)

From the above equation (54) it is seen that the value of $(\zeta 1)$ equals zero when (D) is approximately equals $30 \mathrm{~cm}$. This means that the strength efficiency or the percentage of increase in strength due to confinement of reinforced concrete vanishes when (D) is higher than $30 \mathrm{~cm}$ as the same plain concrete columns. 


\section{From Point of View of Strain :}

$\mathcal{E}=0.0033-7 \times 10^{-5} \mathrm{D}$

( for unconfined reinforced concrete)

$\mathcal{E}=0.0219-0.0008$

$\mathrm{D}$.

...(56) (for confined one layer reinforced concrete )

where $(\mathcal{E})$ is the max. strain in $(\mathrm{cm} / \mathrm{cm})$ and $(D)$ is the diameter with one layer of column in (cms).

Based on the above relations, it is clear that the max. induced axial strains for confined reinforced concrete is considerably higher than that for unconfined concrete and mainly depends on the size of the cross- section as mentioned before .

Concerning the ductility coefficient $\left(\zeta_{2}\right)$, Fig. (54) shows the relation between its value against the diameter for confined with one layer reinforced concrete circular column. The relation can be best fitted by the following equation:

$\zeta_{2}=651.82-21.65 \mathrm{D} \ldots(57)$ for circular reinforced concrete confined 1 layer)

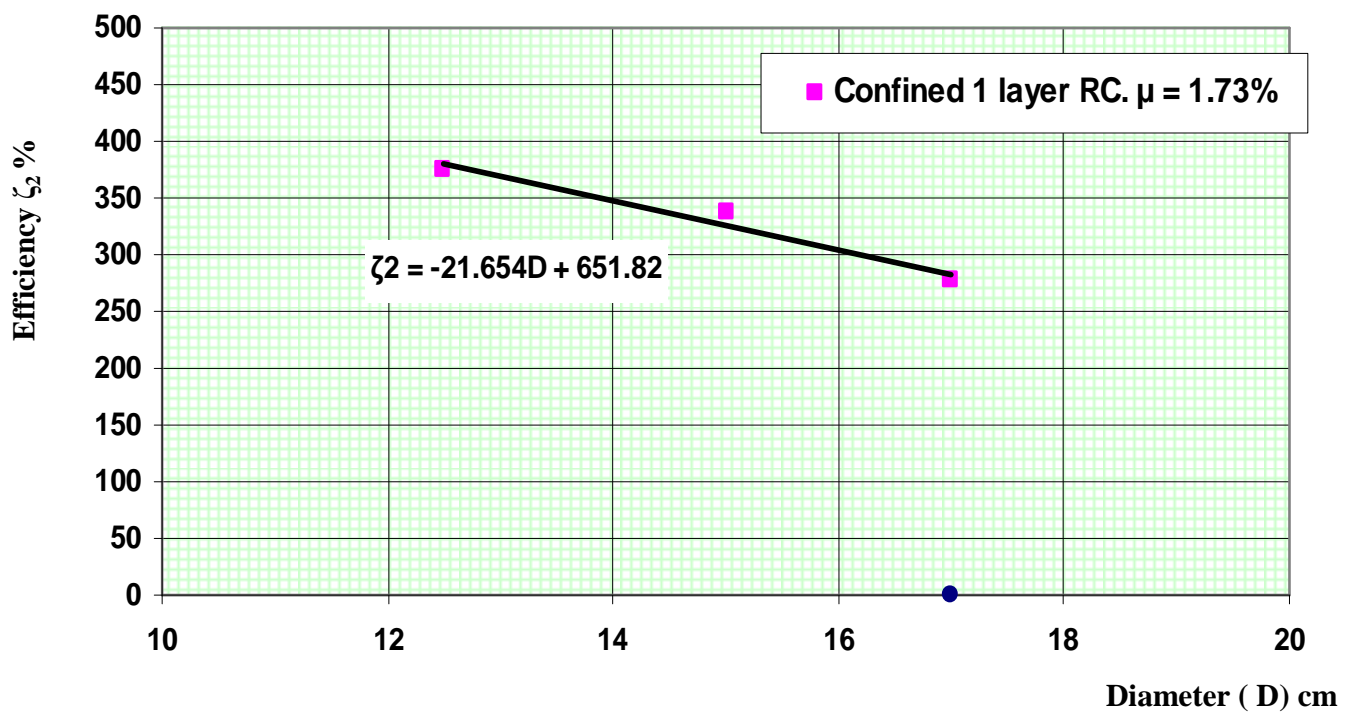

Fig. (54) Relation of efficiency $\left(\zeta_{2}\right)$ and diameters $(D)$ for R.C circular columns (Group F)

Again it is obvious that the ductility coefficient ( $\zeta 2$ ) decreases with the increase of (D) and vanishes when (D) equals $(30.0 \mathrm{~cm})$. This means that the ductility efficiency or the percentage of increase in strain due to confinement of reinforced concrete vanishes when (D) is higher than $30 \mathrm{~cm}$.

\section{From Point of View of Stiffness :}

$\mathrm{E}=2.2828-0.0213$ (D) .... (58) ( for unconfined reinforced concrete)

$\mathrm{E}=3.0984-0.0457$ (D).......(59) (for confined one layer reinforced concrete )

The above relationships can be rewritten in terms of the used cube modulus of elasticity (grade of concrete $\mathrm{C} 200$ ) as follow:

$\frac{E}{\text { E grade }}=1.1535-1.07 \times 10^{-7} \quad \mathrm{D} \quad \ldots .(60) \quad$ ( for unconfined reinforced concrete) 


$$
\frac{E}{E \text { grade }}=1.565-.309 \times 10^{-7} \text { D.........(61) (for confined } 1 \text { layer reinforced concrete) }
$$

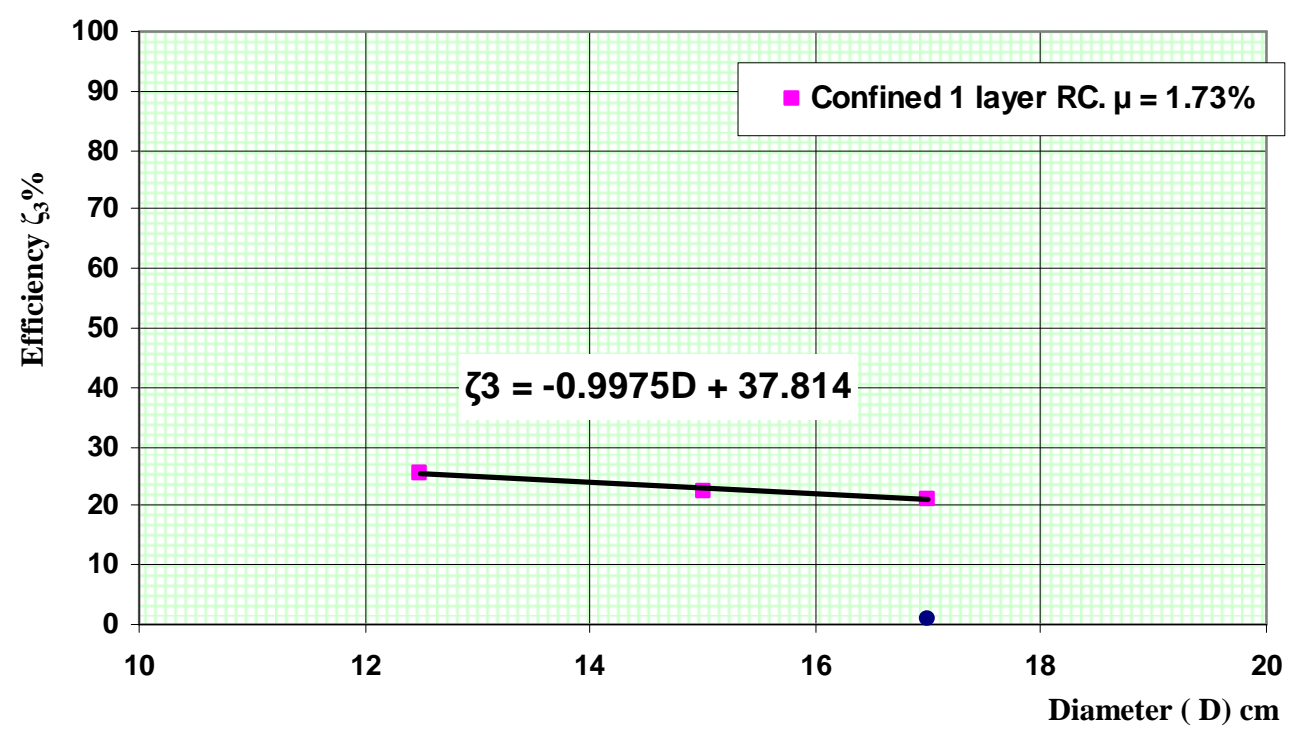

Fig. (55) Relation of efficiency $\left(\zeta_{3}\right)$ and diameters $(D)$ for R.C circular columns (Group $\boldsymbol{F})$

Figure (55) shows the relation between ( $\zeta 3$ ) value and the diameter of confined 1 layer reinforced concrete circular columns of cross- sections, this relation can be written by the following equation:

$\zeta_{3}=37.814-0.9975 \mathrm{D}$...(62) (for confined 1 layer reinforced circular column )

From the above equation (62) it is seen that the value of ( $\zeta 3)$ equals zero when (D)is approximately equals $38 \mathrm{~cm}$. This means that the stiffness efficiency of reinforced concrete circular columns vanishes when $(\mathrm{D})=38 \mathrm{~cm}$.

\section{From Point of View of Total Absorbed Energy:}

M.T $=0.604-0.02 \mathrm{D}$

( for unconfined reinforced concrete)

$\mathrm{M} . \mathrm{T}=8.5314-0.401 \mathrm{D}$

...64) (for confined one layer reinforced concrete )

The value of ( M.T ) for reinforced confined with one layer is higher than that for unconfined reinforced concrete, and both values decreases with the increase of diameter (D), taking into account that the rate of decrease is higher for confined 1 layer reinforced concrete rather than that for unconfined reinforced concrete.

Figure (56) shows the relation between $\left(\zeta_{4}\right)$ against the diameter (D) . It shows how this efficiency $\left(\zeta_{4}\right)$, decreases with the increase of diameter (D), represented by the following equation:

$\zeta_{4}=1842.7-75.298 \mathrm{D}$

(for confined one layer reinforced concrete) 


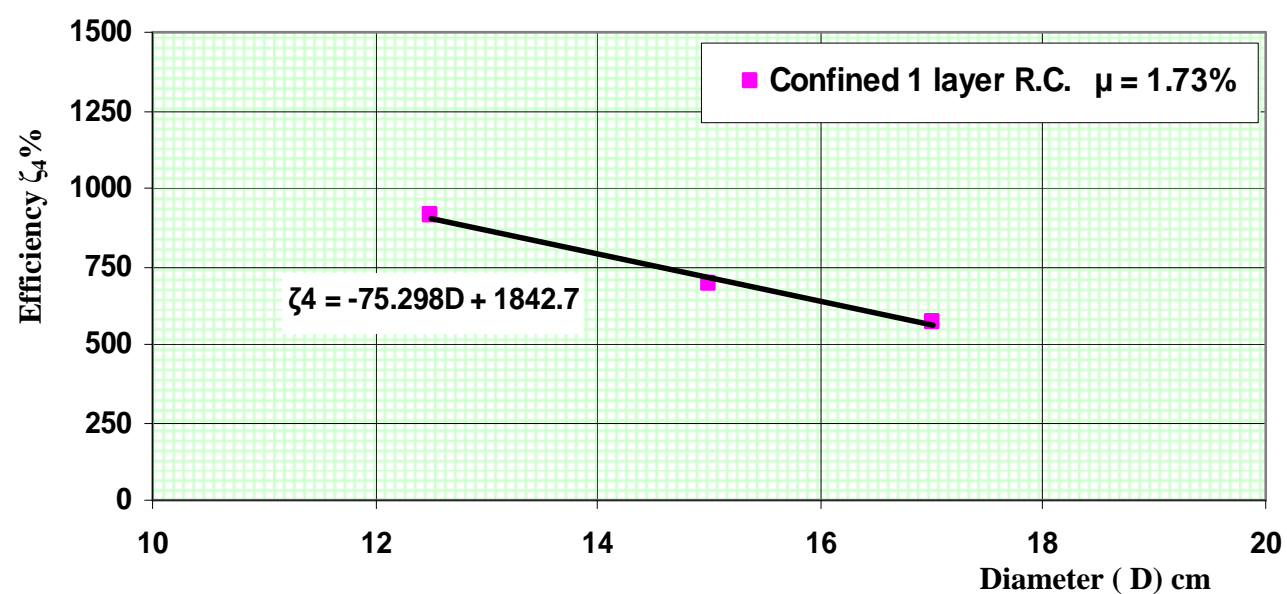

Fig. (56) Relation of efficiency $\left(\zeta_{4}\right)$ and diameters $(D)$ for R.C circular columns confined 1 layer (Group F)

Also this equation shows that the value of the efficiency $\left(\zeta_{4}\right)$ decreases with the increase of diameter ( D) of column. At the same time this increase vanishes when D $=25 \mathrm{~cm}$. i.e there is no increase in modulus of toughness ( M.T) due to confined of reinforced concrete with one layer beyond $\mathrm{D}=25 \mathrm{~cm}$.

\section{4-2-2 Effect of Percentage of Longitudinal Steel}

\section{4-2-2-1 For Constant Shape Circular Concrete Columns With Variable Cross-Section (Group A and F) :}

The values of the maximum induced nominal stresses, maximum nominal strains, modulus of elasticity as well as modulus of toughness for such columns are indicated in Table (4) and Table (5) as well as Figs. (57) to (60) shows the relationships between the max. nominal stress $(\boldsymbol{\sigma})$. the max. nominal strain $(\mathcal{E})$, the value of modulus of elasticity as well as the modulus of toughness (M.T) and corresponding column diameter (D) for both unconfined and confined with one layer reinforced concrete columns.

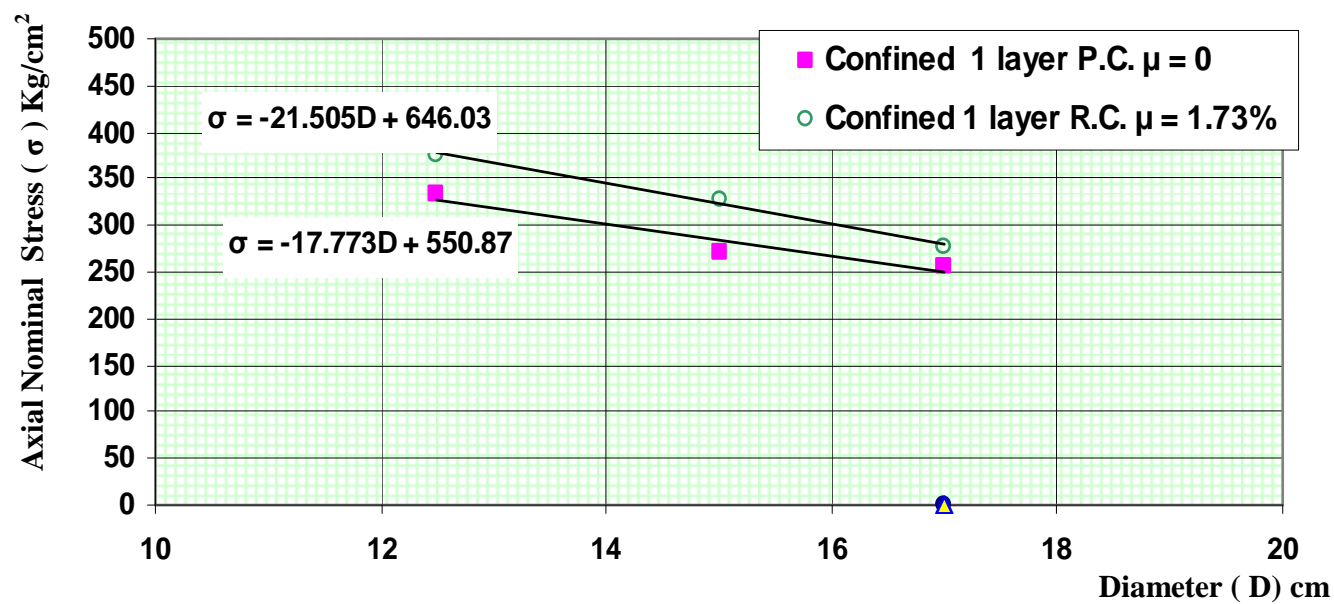

Fig. (57) Relation between axial nominal stress $(\sigma)$ and $(D)$ for both P.C and R.C circular columns confined 1 layer (Group A and F) 


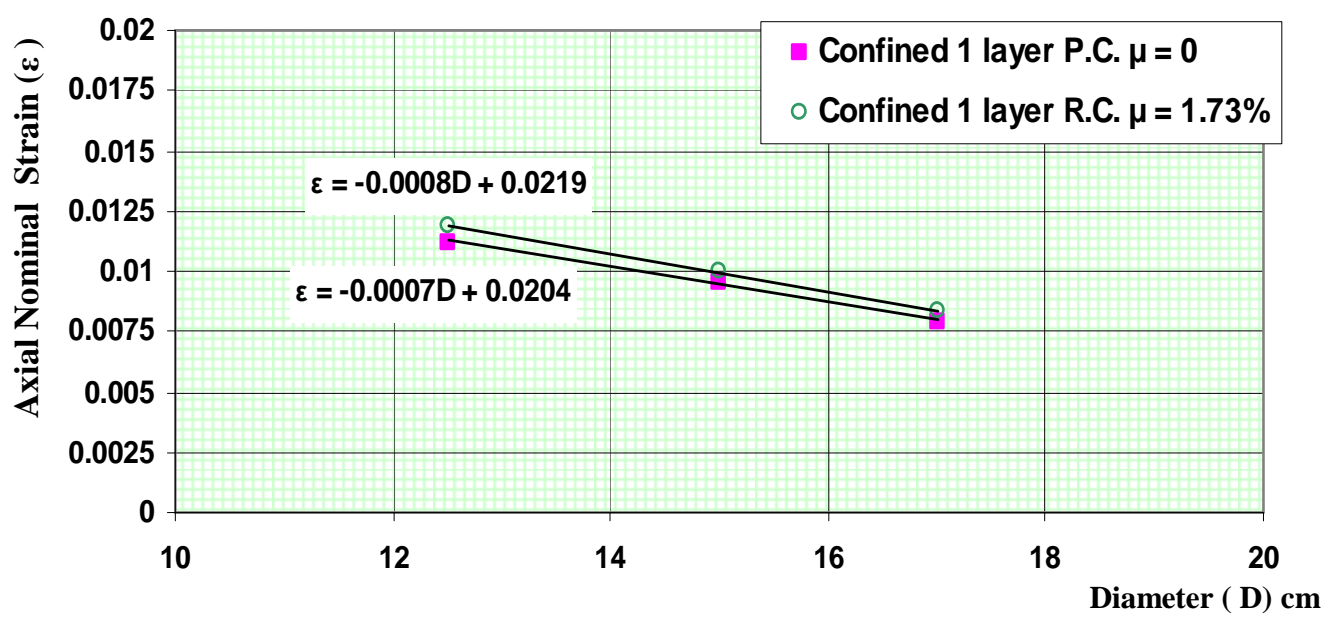

Fig. (58) Relation between nominal axial strain $(\mathcal{E})$ and $(D)$ for both P.C and R.C circular columns confined 1 layer (Group $\boldsymbol{A}$ and $\boldsymbol{F}$ )

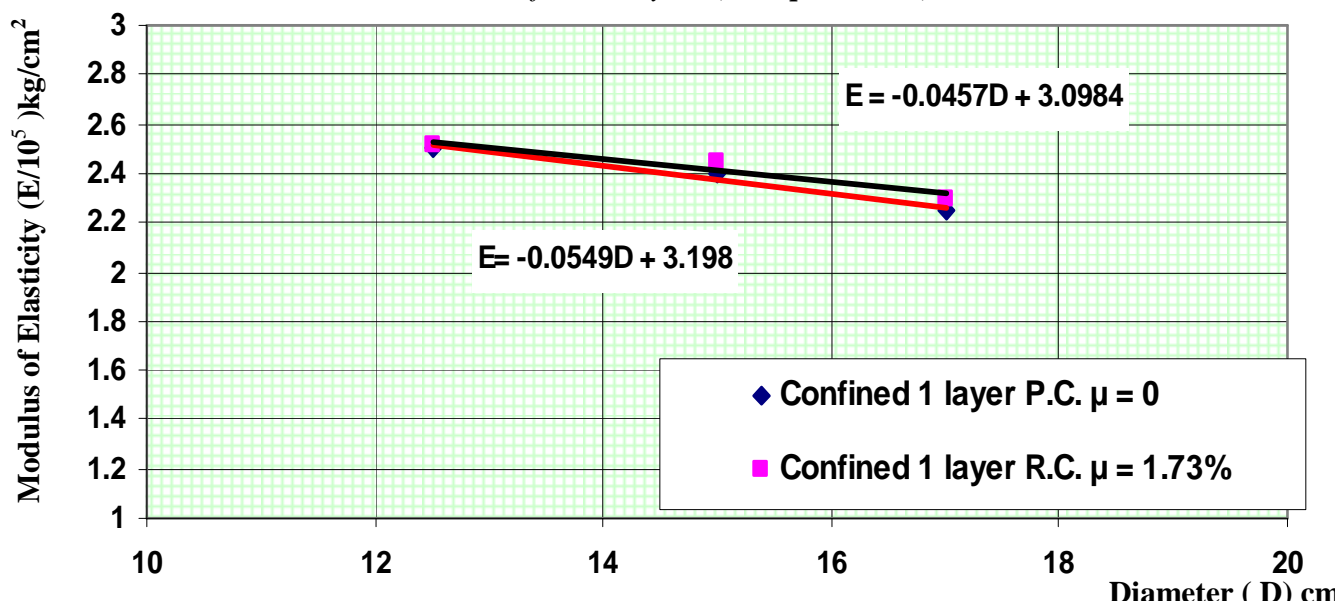

Fig. (59) Relation of modulus of Elasticity (E) and (D) for both P.C and R.C circular columns confined 1 layer (Group A and F)

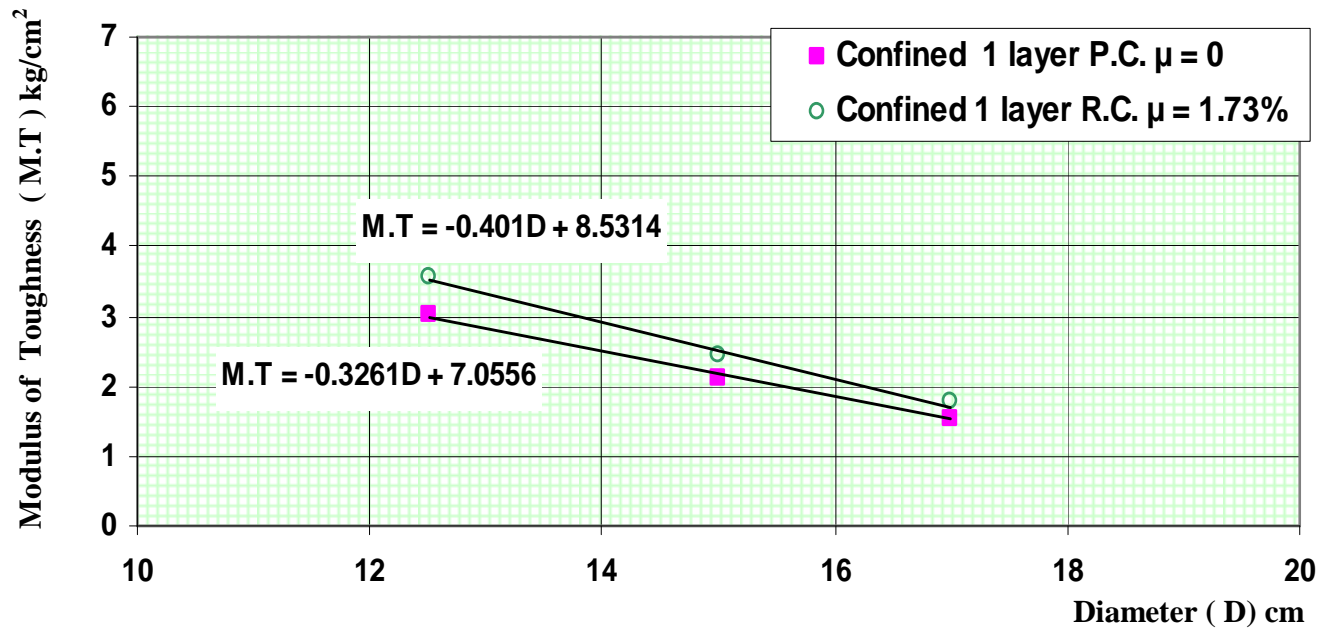

Fig. (60) Relation of modulus of toughness (M.T) and (D) for both P.C and R.C circular columns confined 1 layer (Group A and F) 
These properties are higher slightly for confined one layer reinforced concrete columns rather than for confined plain concrete, as shown in these Figs. Concerning the efficiency values for $\left(\zeta_{1}\right),\left(\zeta_{2}\right),\left(\zeta_{3}\right)$ and $\left(\zeta_{4}\right)$. Table (4) and Table (5) as well as Figs. (61) to (64) give the values of such efficiencies.



Fig.(61) Relation of efficiency (ל1) and (D) for both P.C and R.C circular columns confined 1 layer (Group A and $\boldsymbol{F}$ )

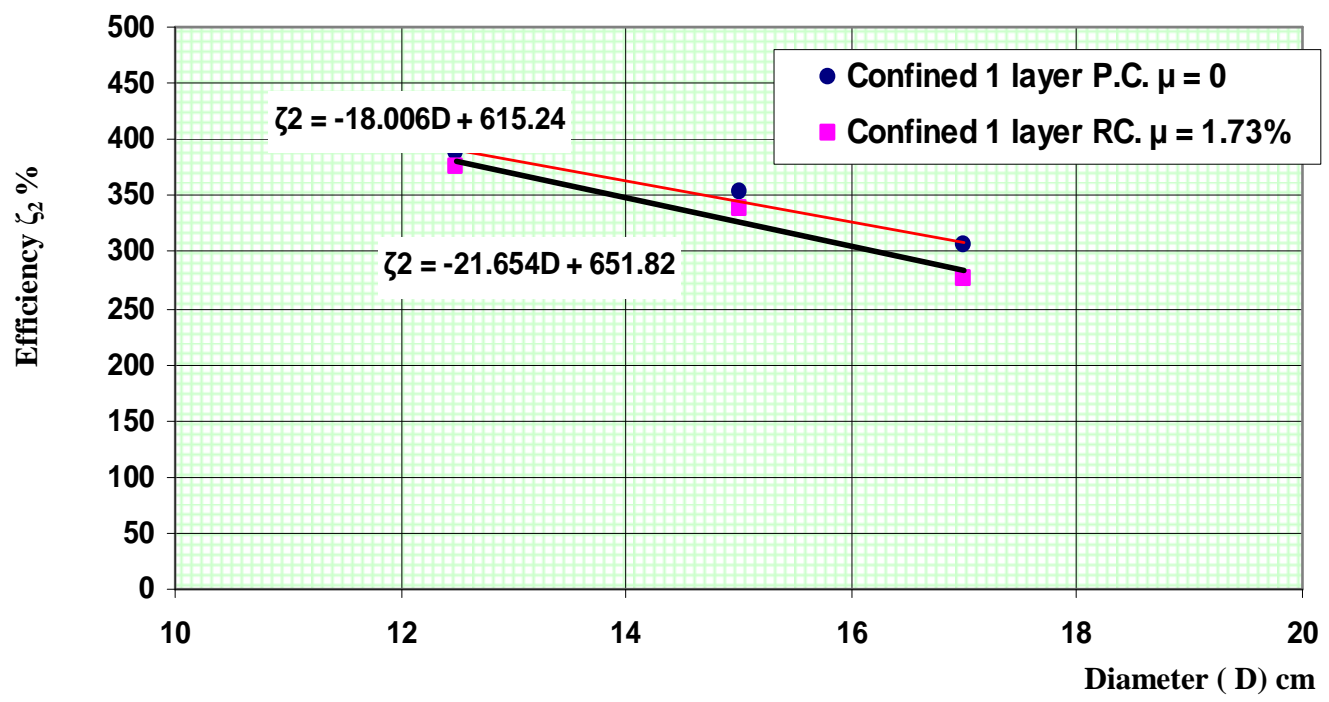

Fig. (62) Relation of efficiency $\left(\zeta_{2}\right)$ and (D) for both P.C and R.C circular columns confined 1 layer (Group $A$ and $F)$ 


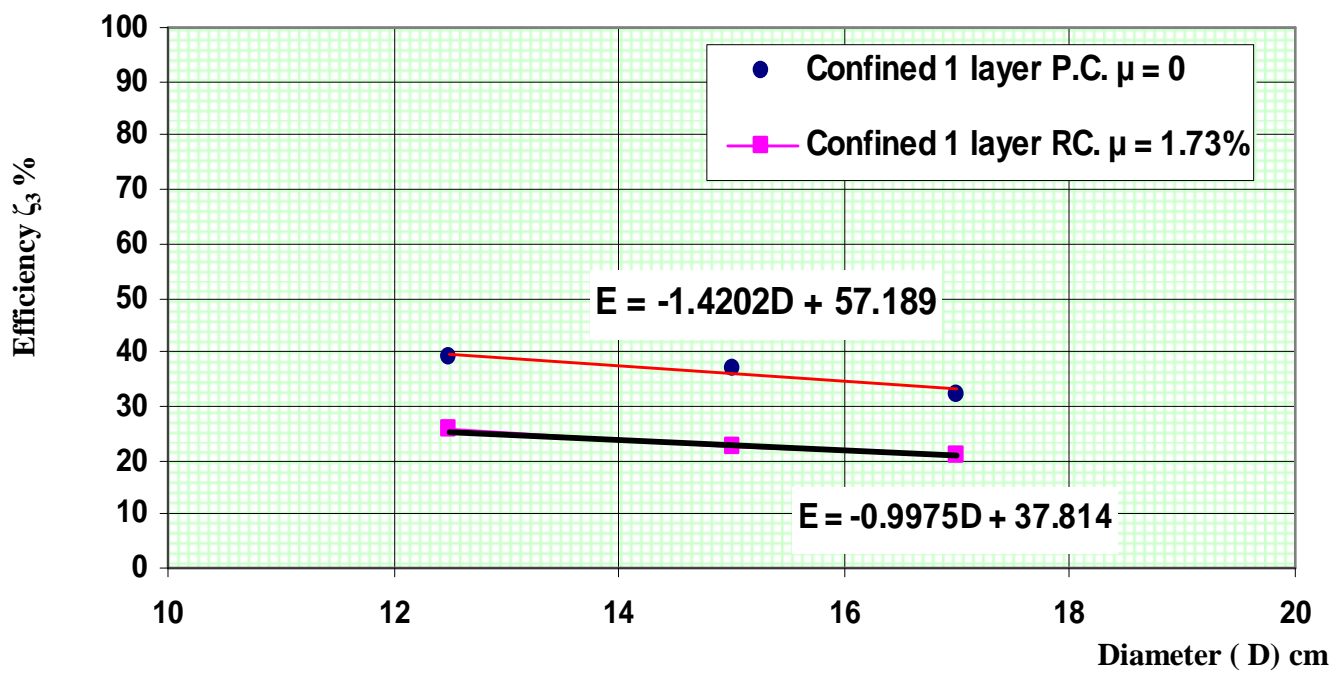

Fig.(63) Relation between efficiency $\left(\zeta_{3}\right)$ and (D) for both P.C and R.C circular columns confined 1 layer (Group $A$ and $F$ )

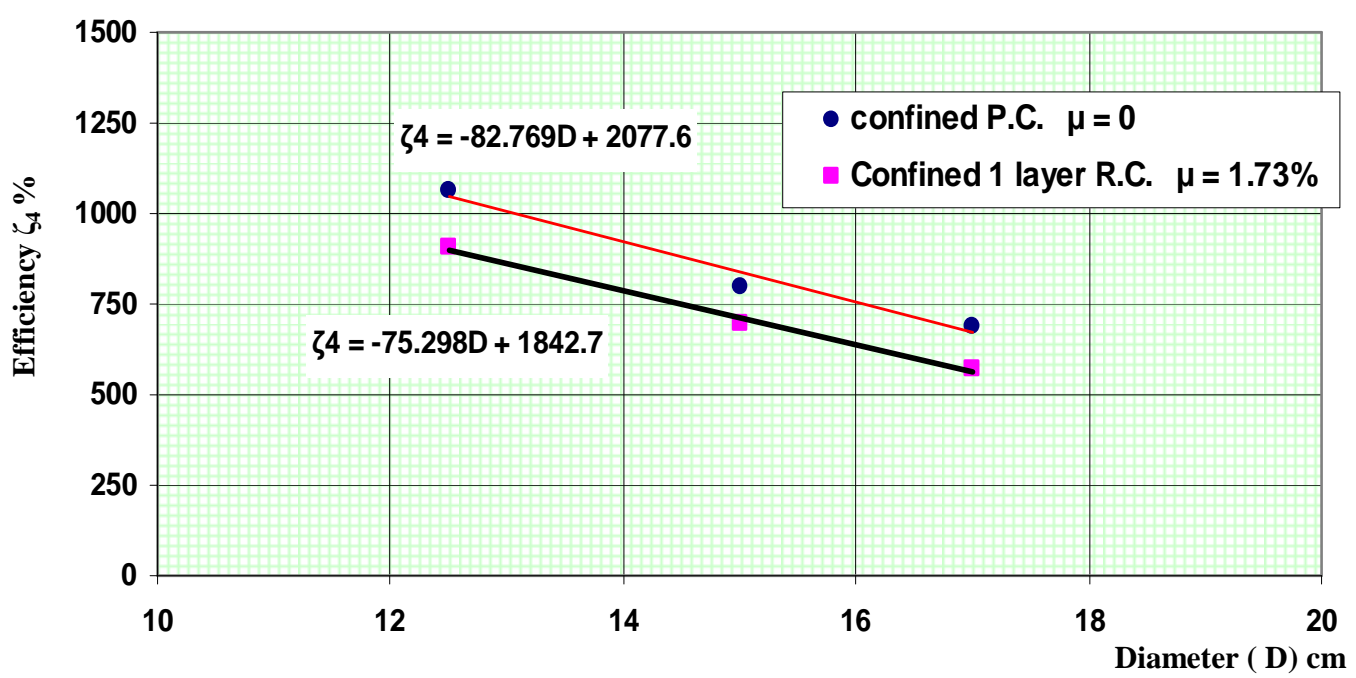

Fig. (64) Relation between efficiency ( $\left.\zeta_{4}\right)$ and $(D)$ for both P.C and R.C circular columns confined 1 layer (Group A and F)

All the efficiencies $\left(\zeta_{1}\right),\left(\zeta_{2}\right),\left(\zeta_{3}\right)$ and $\left(\zeta_{4}\right)$ decrease slightly due to longitudinal reinforcement for circular section, the represented equations for this efficiencies are mentioned before .

\section{4-2-2-2 For Different Shape Concrete Columns With Constant Cross sectional Area $=225 \mathrm{~cm}^{2}$ (Group D and E ):}

The values of the max. induced nominal stresses, max. nominal strains, modulus of elasticity and modulus of toughness for such columns are given in Table (5), as well as Figs. (65) to (68) show the relationships these values and corresponding shape of cross sections for both unconfined and confined with one layer reinforced concrete columns. 




(Circular) $\mathrm{D}=\mathbf{1 7} \mathrm{cm}$

(Square) $B=15 \mathrm{~cm}$

(Rectangular) $12.5 \times 18 \mathrm{~cm}$

Shape of cross-section

Fig. (65) Comparison between axial nominal stress $(\sigma)$ and shape

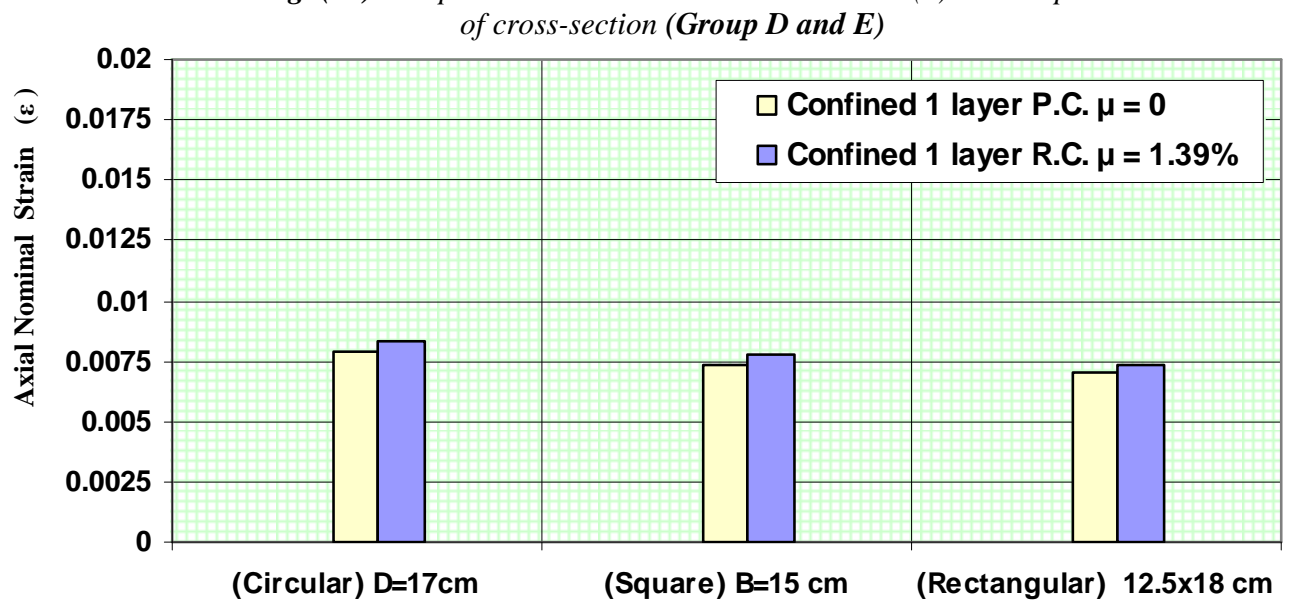

Shape of cross-section

Fig. (66) Comparison between axial nominal strain $(\boldsymbol{E})$ and shape of cross-section (Group D and $\boldsymbol{E}$ )

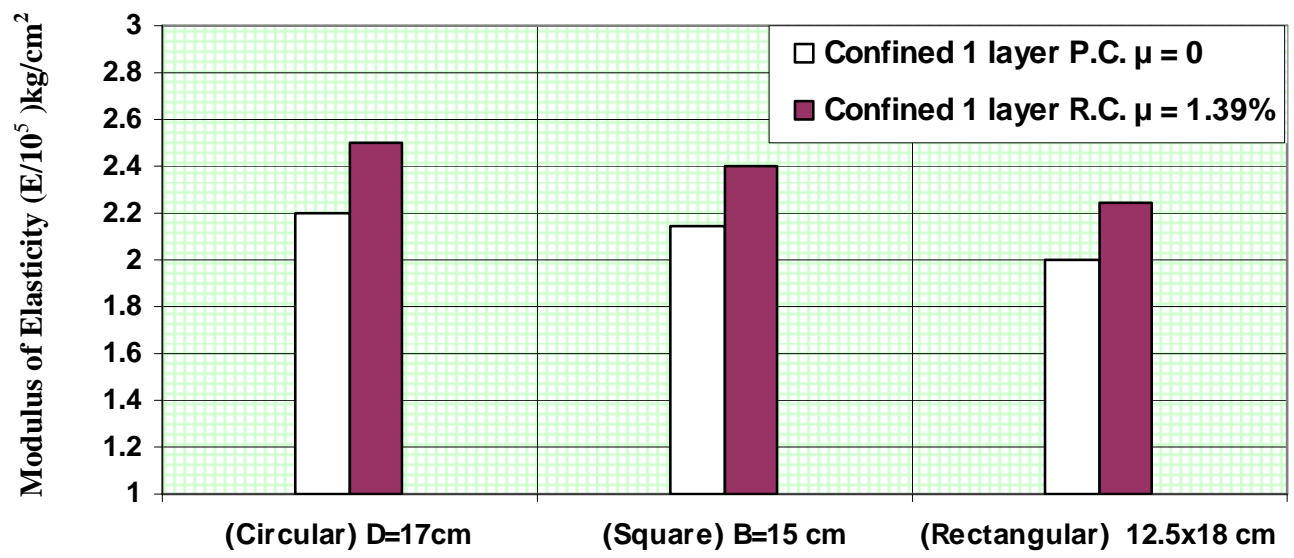

Shape of cross-section

Fig. (67) Comparison between modulus of elasticity (E) and shape of cross-section (Group D and E) 


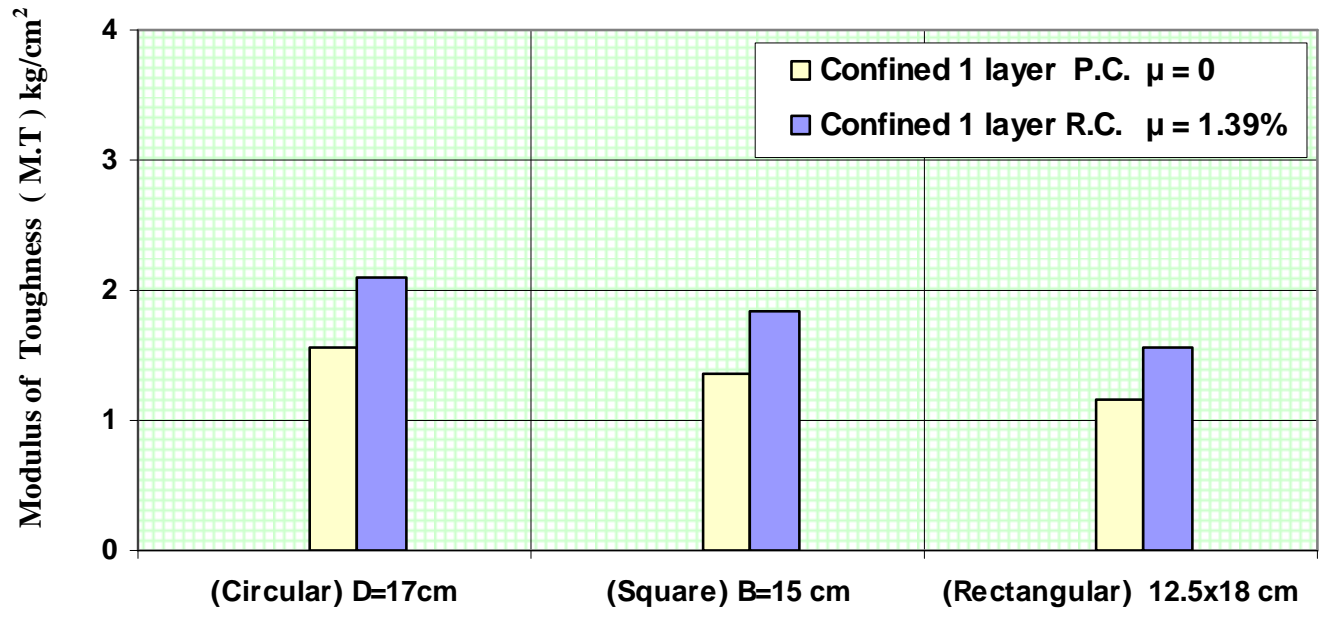

Shape of cross-section

Fig. (68) Comparison between modulus of toughness (M.T) and shape of cross-section (Group D and E)

Again, these properties are higher slightly for confined one layer reinforced concrete columns rather than for confined plain concrete, as shown in these Figs. Concerning the efficiency values for strength $\left(\zeta_{1}\right)$, for ductility $\left(\zeta_{2}\right)$, for stiffness $\left(\zeta_{3}\right)$ and for absorbed energy $\left(\zeta_{4}\right)$. Table (4) and Table (5) as well as Figs. (69) to (72) give the values of such efficiencies.

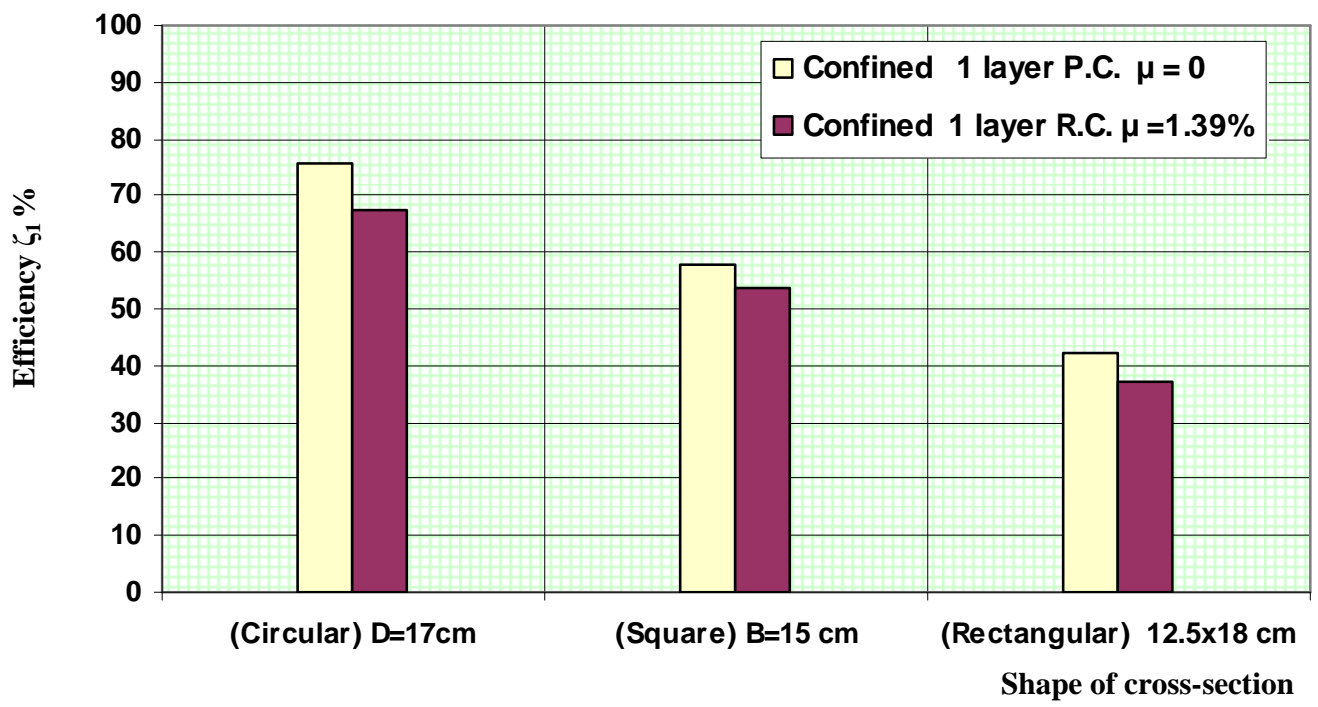

Fig. (69) Relation between efficiency (ל1) and different shape of cross- sections (Group D and E) 




Fig. (70) Relation between efficiency (ל2) and different shape of cross- sections

(Group D and E)

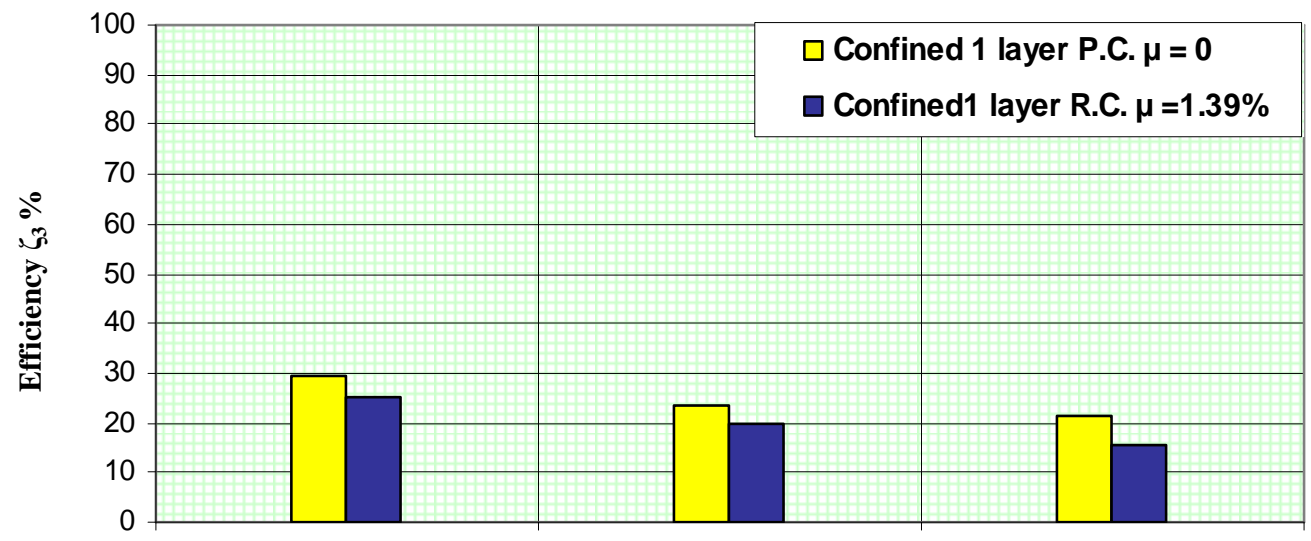

(Circular) $\mathrm{D}=\mathbf{1 7} \mathrm{cm}$

(Square) $B=15 \mathrm{~cm}$

(Rectangular) $12.5 \times 18 \mathrm{~cm}$ Shape of cross-section

Fig. (71) Relation between efficiency ( $\zeta 3)$ and different shape of cross- sections

(Group D and E)

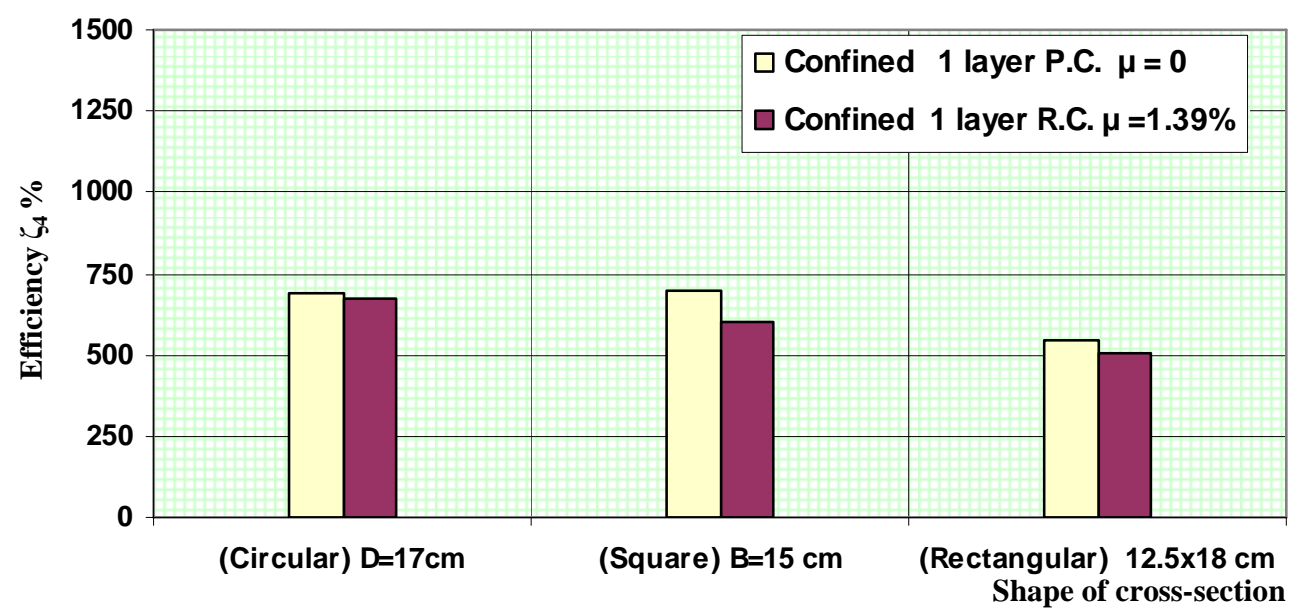

Fig. (72) Relation between efficiency ( $\zeta 4)$ and different shape of cross- sections

(Group D and E) 
Again, all the efficiencies $\left(\zeta_{1}\right),\left(\zeta_{2}\right),\left(\zeta_{3}\right)$ and $\left(\zeta_{4}\right)$ decrease slightly due to longitudinal reinforcement for different shapes of sections, the represented equations for these efficiencies are mentioned before considering the values are higher for circular section than square section, also these values are higher for square section than rectangular section.

\section{4-2-3 Effect of the Percentage of Lateral Reinforcements (Stirrups):}

Figure (40) illustrates the relations between axial nominal stress- axial nominal strain for reinforced circular concrete columns with diameters $\mathrm{D}=17 \mathrm{~cm}$ and longitudinal steel $(\mu=1.73 \%)$ for both different percentages of lateral steel and strengthening technique.

Again the maximum induced axial nominal stress; axial nominal strain, modulus of elasticity as well as modulus of toughness for such tested columns are induced in Table (5). The previous values are plotted against the corresponding values of percentages of lateral steel (stirrups) as shown in Figs.(73) to (76).

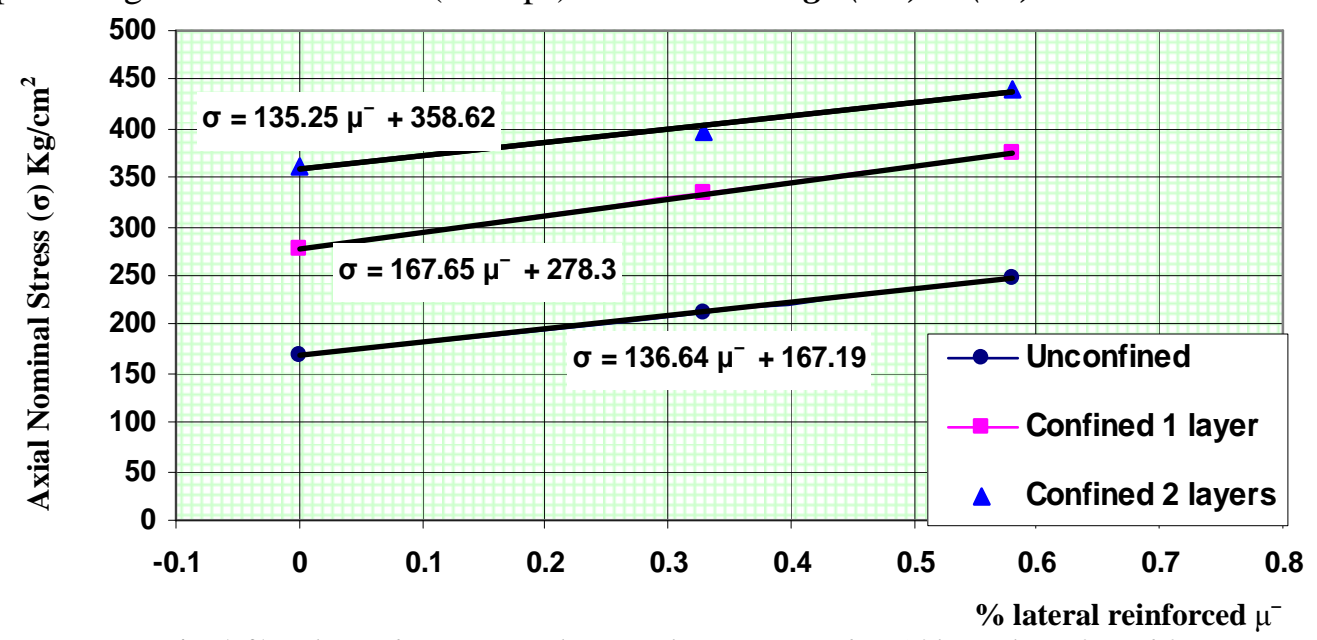

Fig. (73) Relation between axial nominal stress $(\sigma)$ and $\mu^{-} \%$ lateral reinforced for circular section (Group $\boldsymbol{G}$ )

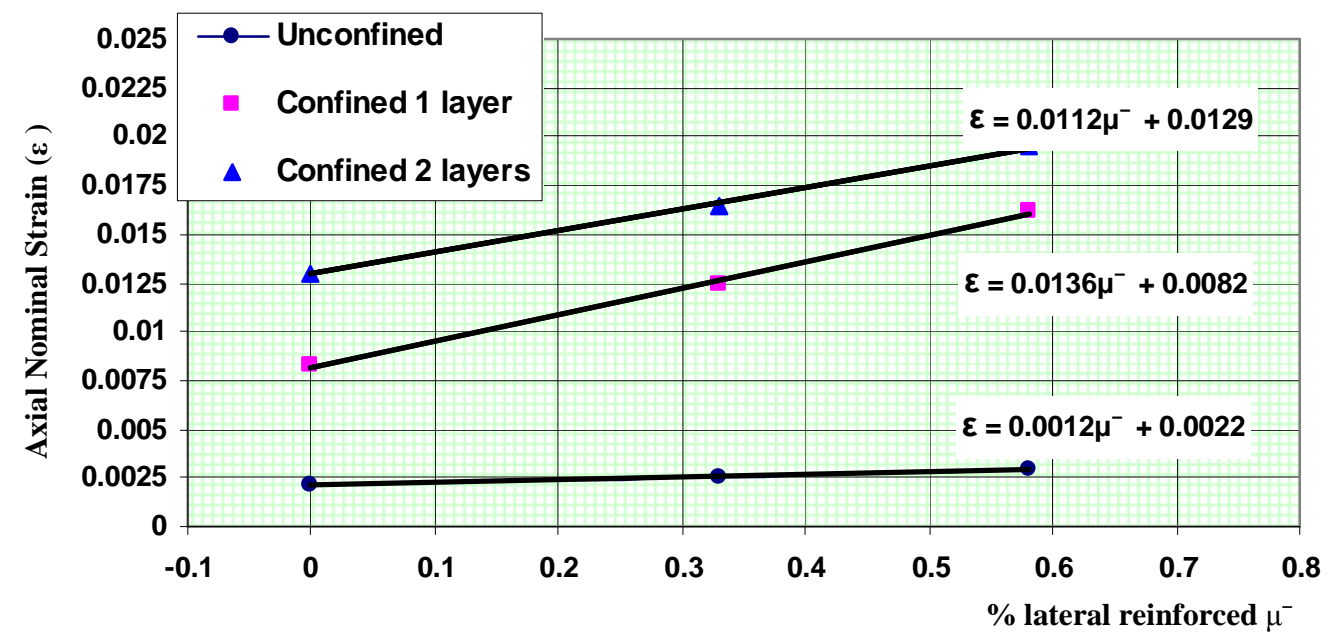

Fig. (74) Relation between axial strain $\left(\mathcal{E}\right.$ ) and $\mu^{-} \%$ stirrups for circular section (Group $\boldsymbol{G}$ ) 


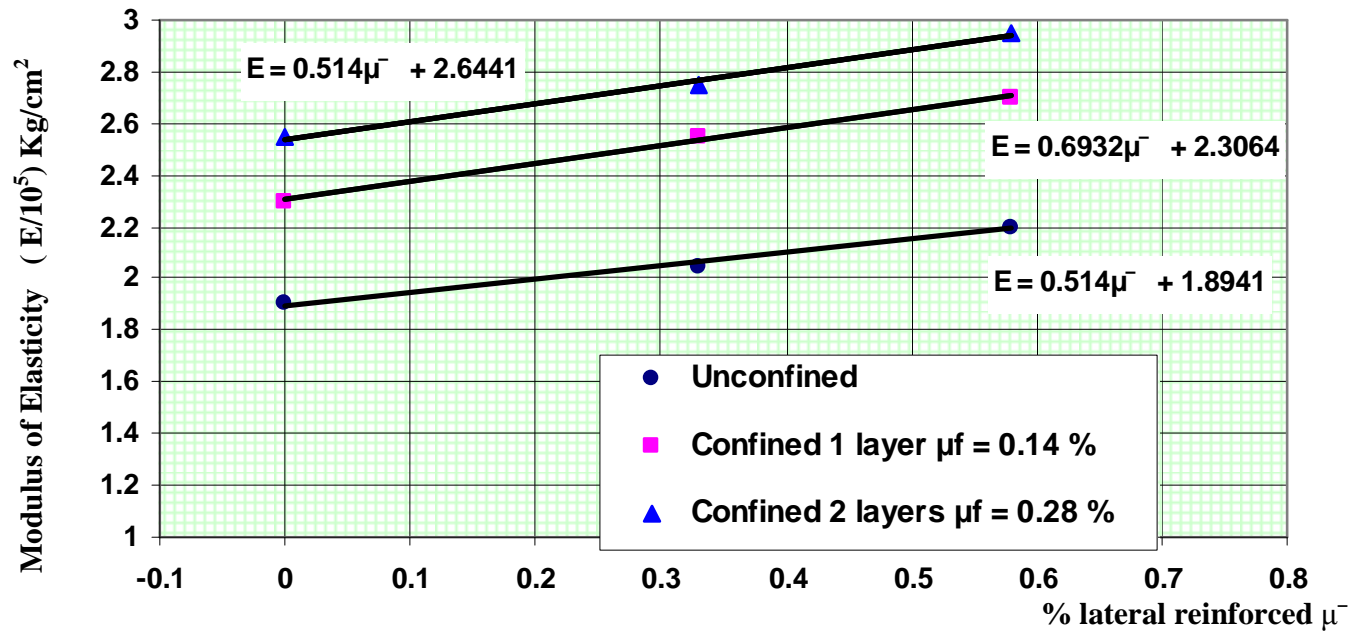

Fig. (75) Relation between modulus of Elasticity (E) and \% stirrups $\mu^{-}$ for circular section (Group $\boldsymbol{G}$ )

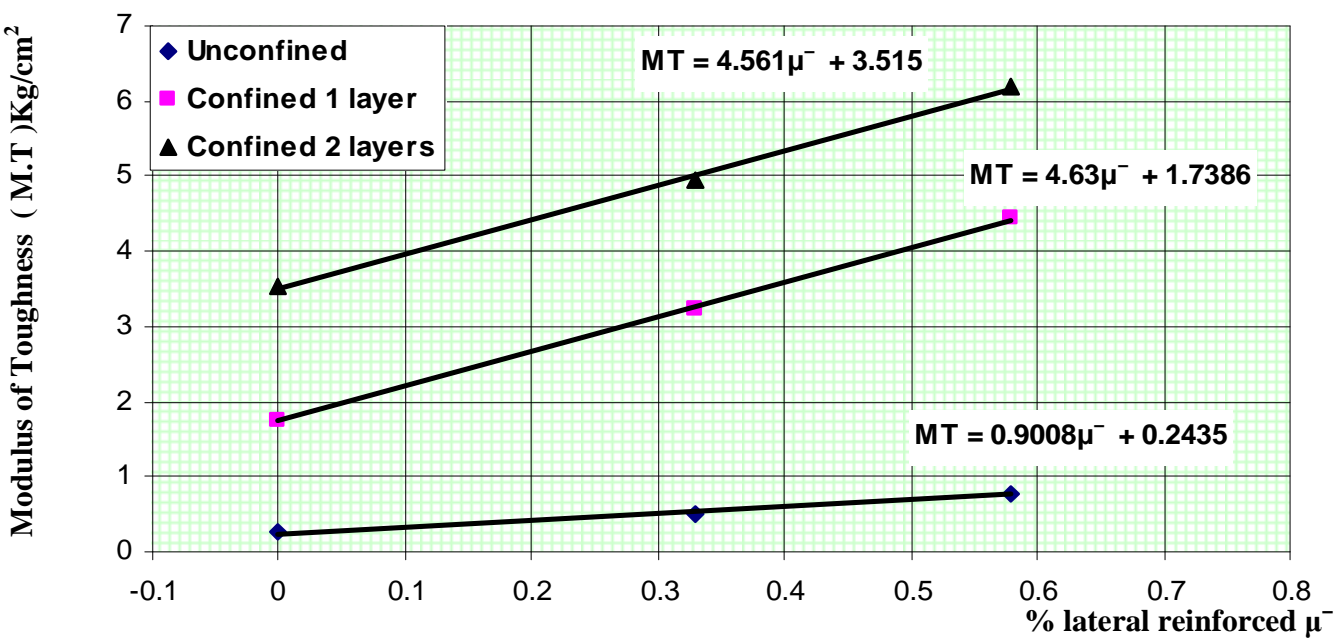

Fig. (76) Relation between modulus of toughness (M.T) and \% stirrups $\mu^{-}$ for circular section (Group $\boldsymbol{G}$ )

As a general rule, as the percentage of lateral steel increases all the above values increase for both unconfined and confined reinforced concrete. The relations between such properties and percentages of lateral steel can be represented as follow:

\section{From Point of View of Strength :}

$\begin{array}{lr}\sigma=167.19+136.84 \mu^{-} \% \ldots \ldots \ldots . .(66) & \text { (for unconfined reinforced concrete) } \\ \sigma=278.30+167.66 \mu^{-} \% \ldots \ldots \ldots .(67) & \text { (for confined 1 layer reinforced concrete) } \\ \sigma=358.62+135.25 \mu^{-} \% \ldots \ldots \ldots \ldots . .(68) & \text { (for confined } 2 \text { layers reinforced concrete) }\end{array}$

The above relationships can be rewritten in terms of the used cube compressive strength ( grade of concrete $\mathrm{C} 200$ ) as follow :

$\frac{\sigma}{f_{\text {cube }}}=0.835+0.864 \mu^{-} \%$

( for unconfined reinforced concrete) 
$\frac{\sigma}{f_{\text {cube }}}=1.391+0.838 \mu-\%$

( for confined 1 layer reinforced concrete)

$\frac{\sigma}{f_{\text {cube }}}=1.791+0.676 \mu-\%$

(for confined 2 layers reinforced concrete)

This equations reflect how the percentage of lateral steel for reinforced circular concrete increases the compressive strength of unconfined and confined one layer or two layers. It is interesting to note that with increasing the percentage of lateral steel, the compressive strength increases. Also, the values of compressive strength is increased with increasing strengthening technique, but it is evitable to note that the increasing of compressive strength for due to confinement by one layer is more affective than the two layers.

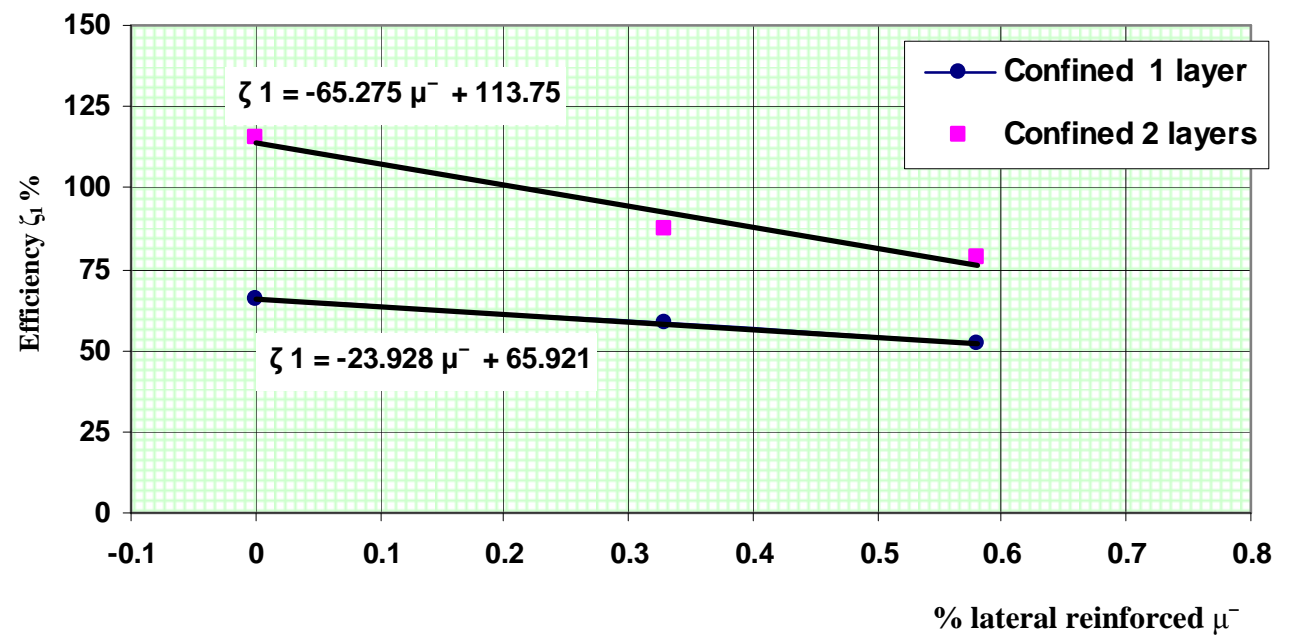

Fig. (78) Relation between efficiency $\left(\zeta_{I}\right)$ and \% stirrups $\mu^{-}$ for circular section (Group $\boldsymbol{G}$ )

Figure (78) shows how the value of $(\zeta 1)$ decreases with increase of the percentage of lateral steel and can be represented by the equation for both confined one layer and two layers:

$$
\begin{aligned}
& \zeta_{1}=113.75-65.28 \mu^{-} \% \ldots . .(72) \\
& \zeta_{1}=65.92-23.93 \mu-\% \ldots . .(73) \\
& \text { ( for confined } 1 \text { layer reinforced concrete) } \\
& \text { (for confined } 2 \text { layers reinforced concrete) }
\end{aligned}
$$

\section{From Point of View of Strain :}

$\mathcal{E}=0.0022+0.0012 \mu^{-} \% \ldots .(74)$

$\mathcal{E}=0.0082+0.0136 \mu^{-} \% \ldots . .(75)$

$\mathcal{E}=0.0129+0.0112 \mu^{-} \% \ldots .(76)$ represented by :

$$
\begin{gathered}
\zeta_{2}=277.36+312.72 \mu-\% \ldots .(77) \\
\zeta_{2}=490.15+140.10 \mu-\% \ldots(78)
\end{gathered}
$$

( for unconfined reinforced concrete) ( for confined 1 layer reinforced concrete)

(for confined 2 layers reinforced concrete) ercentage of lateral steel, see Fig. ( 79 ), can be ( for confined 1 layer reinforced concrete) (for confined 2 layers reinforced concrete) 
It is interesting to note that as the percentage of lateral steel increases the ductility efficiency ( $\zeta 2)$ is increased. The rate of increasing of ductility efficiency ( $\zeta 2$ ) with increasing the percentage of lateral steel for the confined by one layer is higher than that for the confined by two layers .



Fig. (79) Relation between efficiency $\left(\zeta_{2}\right)$ and $\%$ stirrups $\mu^{-}$for circular section with different technique (Group $\mathbf{G})$

\section{From Point of View of Stiffness:}

$\mathrm{E}=1.894 \times 10^{5}+0.514 \mu^{-} \%$

$\mathrm{E}=2.306 \times 10^{5}+0.693 \mu^{-} \% \quad \ldots(80)$

( for unconfined reinforced concrete)

$\mathrm{E}=2.664 \times 10^{5}+0.514 \mu^{-} \%$

( for confined 1 layer reinforced concrete)

The above relatio (grade of concrete C 200) as follow:

$\frac{E}{E \text { grade }}=0.957+2.6 \times 10^{-6} \mu^{-} \%$...(82) (for unconfined reinforced concrete)

$\frac{E}{E \text { grade }}=1.165+3.5 \times 10^{-6} \mu^{-} \% \ldots .(83)$ (for confined 1 layer reinforced concrete) $\frac{E}{E \text { grade }}=1.346+2.6 \times 10^{-6} \mu^{-} \%$....(84) (for confined 2 layers reinforced concrete)

These equations reflect that, as the percentage of lateral steel for reinforced concrete increases, the modulus of elasticity for both cases slightly increases. Figure (80) shows the relation between $\left(\zeta_{3}\right)$ value and the percentage of lateral steel for reinforced concrete for both unconfined and confined with one layer or two layers reinforced concrete circular column and can be represented by the equations for both confined one layers and two layers: 


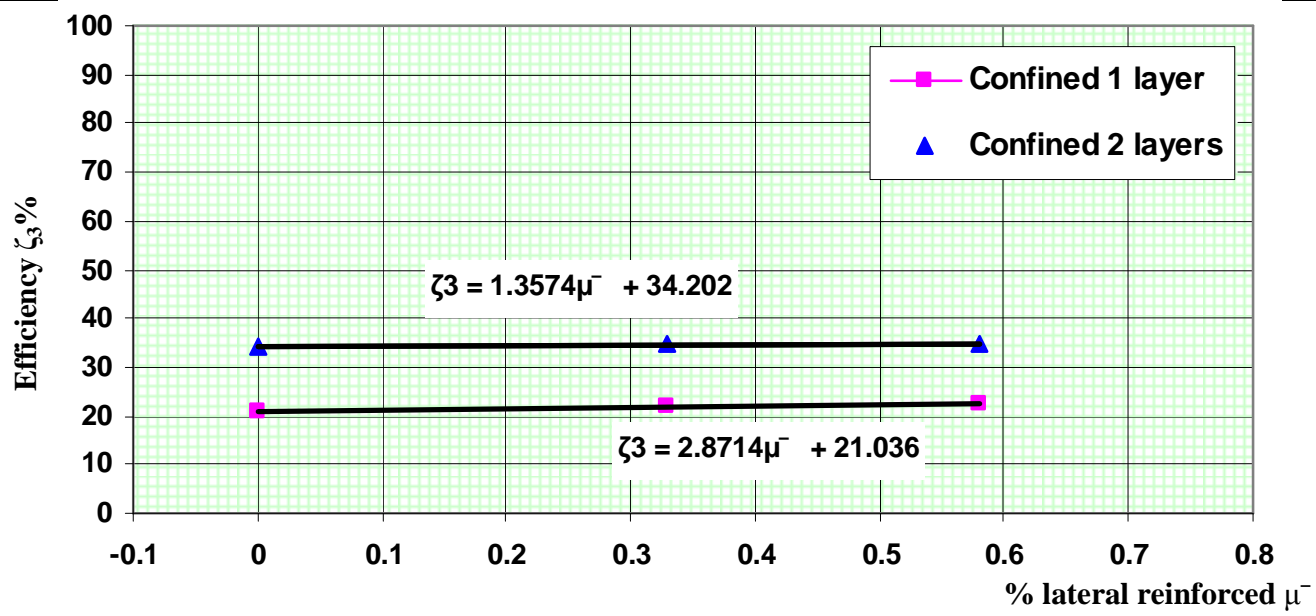

Fig. (80) Relation between efficiency $\left(\zeta_{3}\right)$ and \% stirrups $\mu^{-}$for circular section with different technique (Group G)
$\zeta_{3}=21.036+2.8714 \mu-\% \ldots .(85)$
( for confined 1 layer reinforced concrete)
$\zeta_{3}=34.202+1.3574 \mu^{-} \%$
(for confined 2 layers reinforced concrete)

This relation indicates that as the percentage of lateral reinforced $\mu^{-}$increases, the efficiency $(\zeta 3)$ increase very slightly for both confined 1layer and two layers.

\section{From Point of View of total Absorbed Energy:}

M.T $=0.2435+0.9008 \mu^{-} \% \ldots . .(87)$

M.T $=1.7386+4.63 \mu-\% \ldots \ldots \ldots(88)$

M.T $=3.515+4.561 \mu^{-} \%$
( for unconfined reinforced concrete) ( for confined 1 layer reinforced concrete) (for confined 2 layers reinforced concrete)

Regarding with the efficiency $\left(\zeta_{4}\right)$, see $\mathbf{F i g}$. (81), it is relations with the percentage of lateral $\left(\mu^{-}\right)$are given by the following equations:
$\zeta_{4}=582.65-182.90 \mu-\%$
$\zeta_{4}=1220.90-940.75 \mu^{-\%}$
( for confined 1 layer reinforced concrete)
(for confined 2 layers reinforced concrete)

Equations (90) and (91) indicate that as the \% of stirrups increases, the absorbed energy $\left(\zeta_{4}\right)$ is decrease.

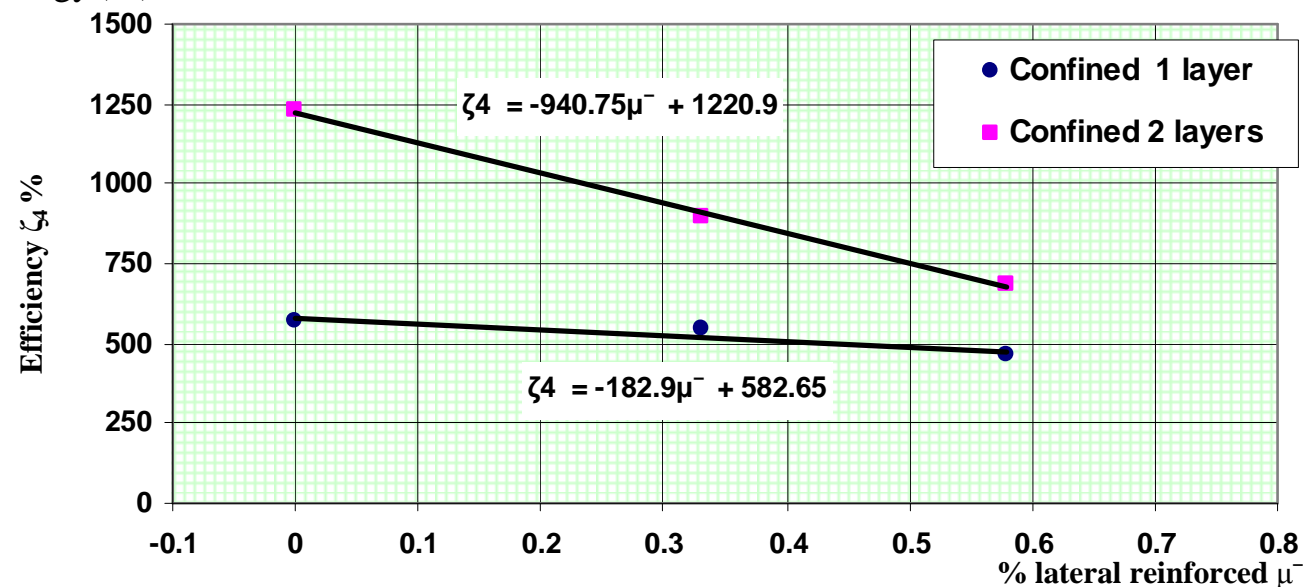

Fig. (81) Relation of efficiency( $\left.\zeta_{4}\right)$ and $\%$ stirrups $\mu^{-}$for circular section with different technique (Group $\boldsymbol{G}$ ) 


\section{4-2-4 Effect of Strengthening Technique :}

Figure (40) illustrate the relations between axial stress-axial strain for reinforced circular concrete columns with $\mathrm{D}=17 \mathrm{~cm} \mu=1.73 \%$ and strengthening technique. The max. induced axial stress, axial strain, modulus of elasticity and modulus of toughness for such tested columns are given in Table (5). These values are plotted against the corresponding strengthening technique as shown in Fig.(82) to Fig. (85).

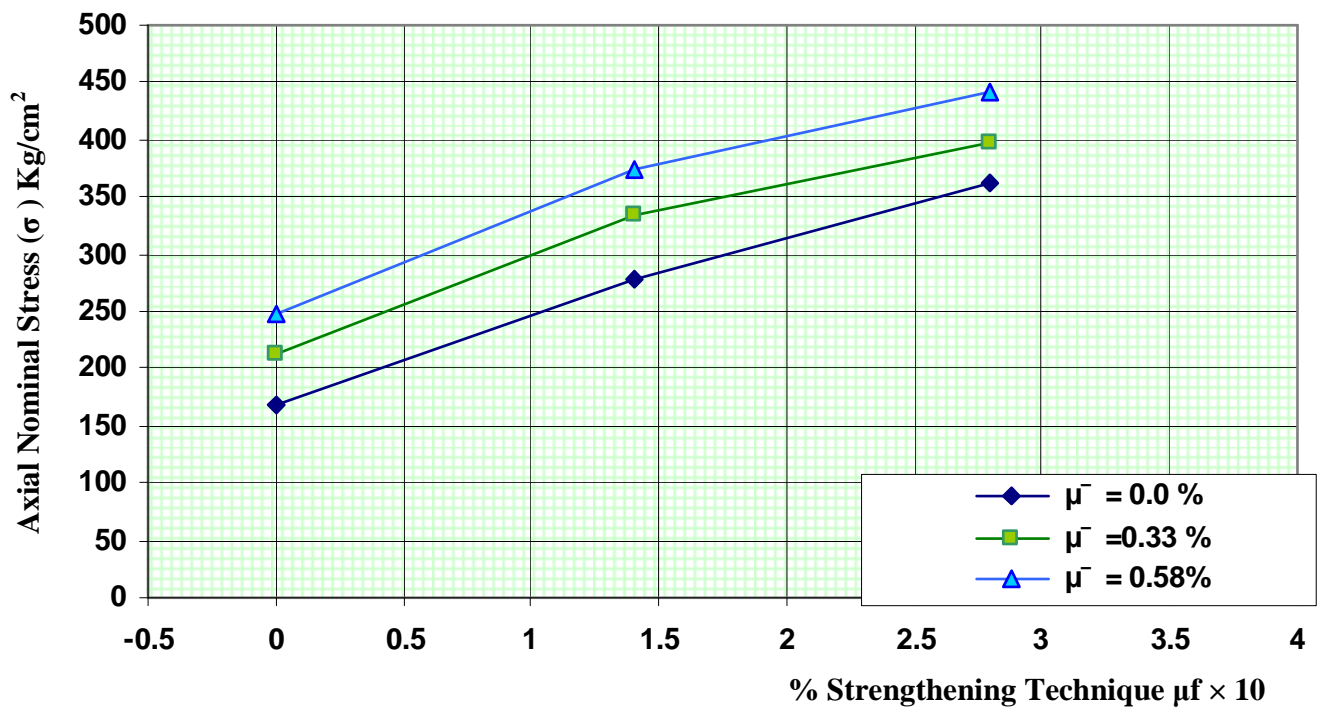

Fig. (82) Relation between axial stress $(\sigma)$ and \% stirrups $\mu^{-}$for circular section with different technique (Group $\boldsymbol{G}$ )

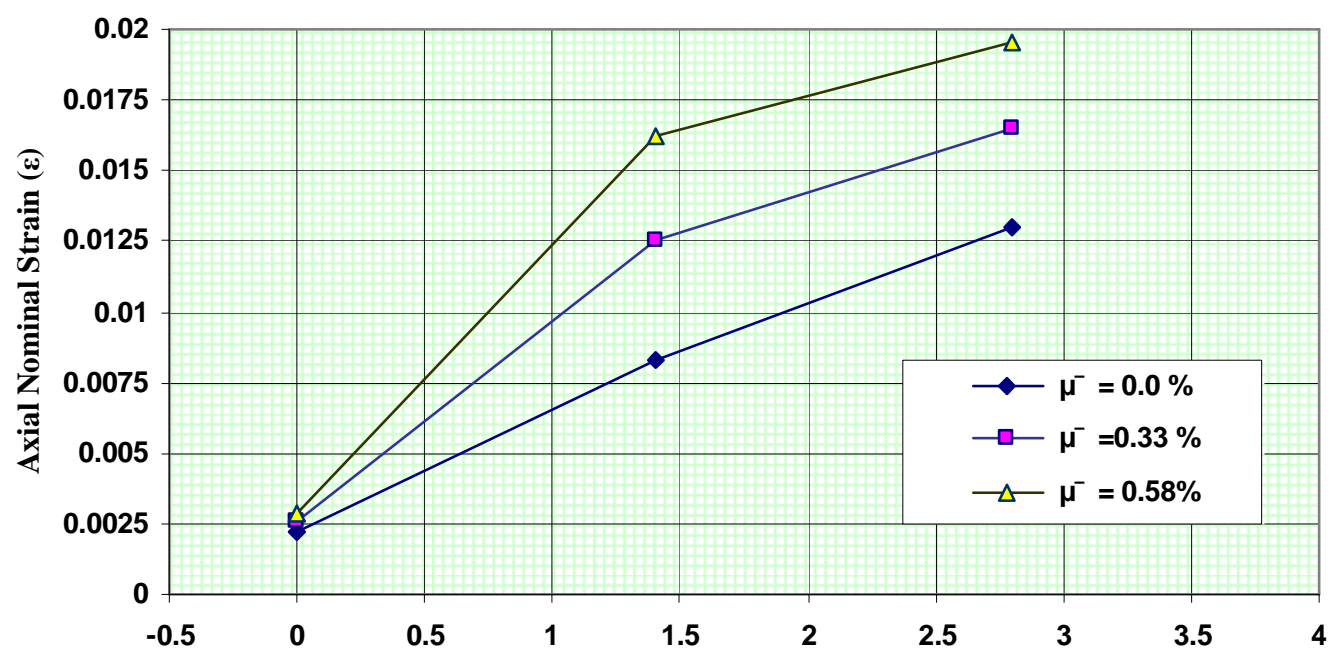

$\%$ Strengthening Technique $\mu_{\mathrm{f}} \times 10$

Fig. (83) Relation between axial nominal strain $(\mathcal{E})$ and strengthening technique for R.C circular section (Group $\boldsymbol{G}$ ) 


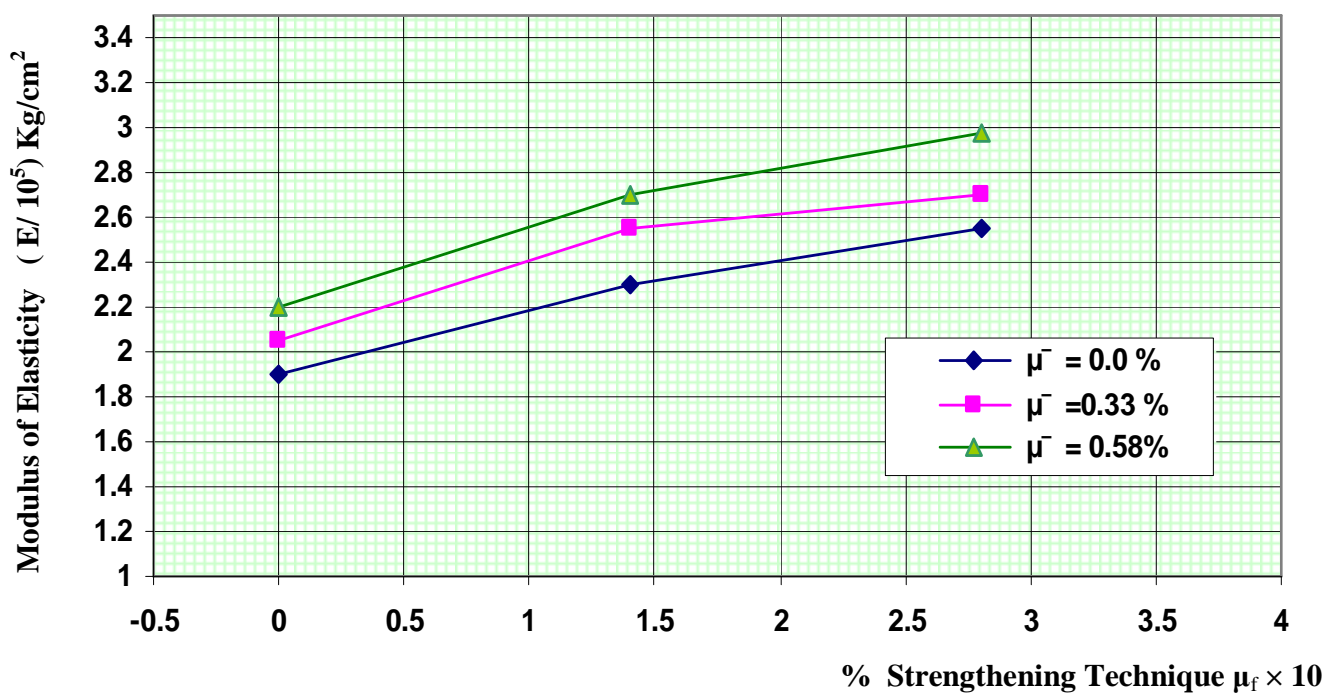

Fig. (84) Relation between modulus of elasticity (E) and strengthening technique for R.C circular section (Group G)



Fig. (85) Relation between modulus of toughness (M.T) and strengthening technique for R.C circular section (Group $\boldsymbol{G}$ )

As a general rule, as the strengthening technique increases all the above values increase for both unconfined and confined 1 layer or two layers reinforced concrete , but it is suitable to note that the increasing of these values for by one layer confinement is more effective than by the two layers corresponding the unconfined concrete columns.

Concerning the efficiency values for strength $\left(\zeta_{1}\right)$, ductility $\left(\zeta_{2}\right)$, stiffness $\left(\zeta_{3}\right)$ and for absorbed energy $\left(\zeta_{4}\right)$. Table (5) as well as Figs. (86) to (89) give the values of such efficiencies where all the efficiencies varied according to the percentage of lateral reinforcement and the used strengthening technique. 


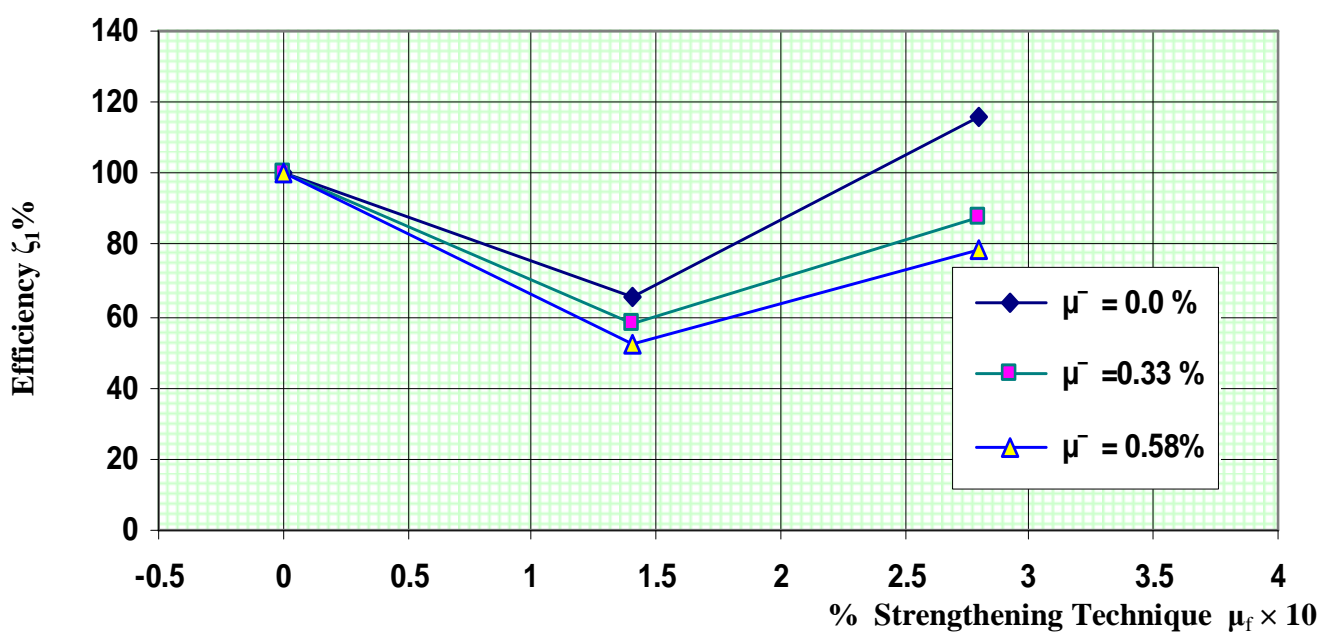

Fig. (86) Relation between $\left(\zeta_{1}\right)$ and strengthening technique for R.C circular section (Group $\boldsymbol{G})$

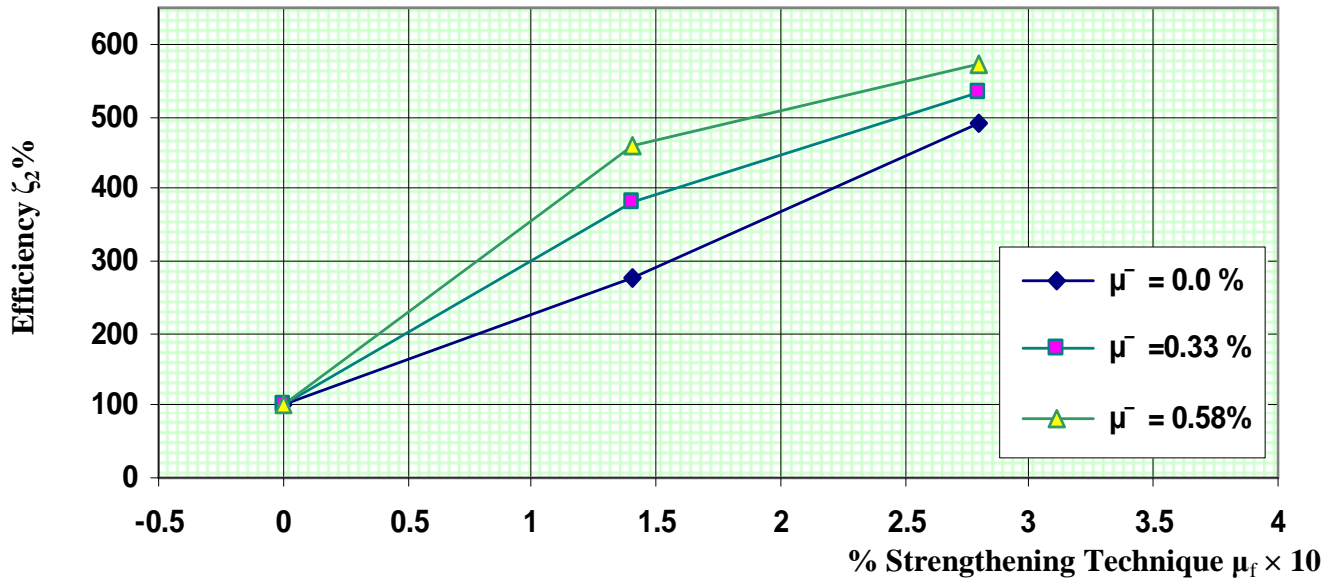

Fig. (87) Relation between $\left(\zeta_{2}\right)$ and strengthening technique for R.C circular section (Group G)

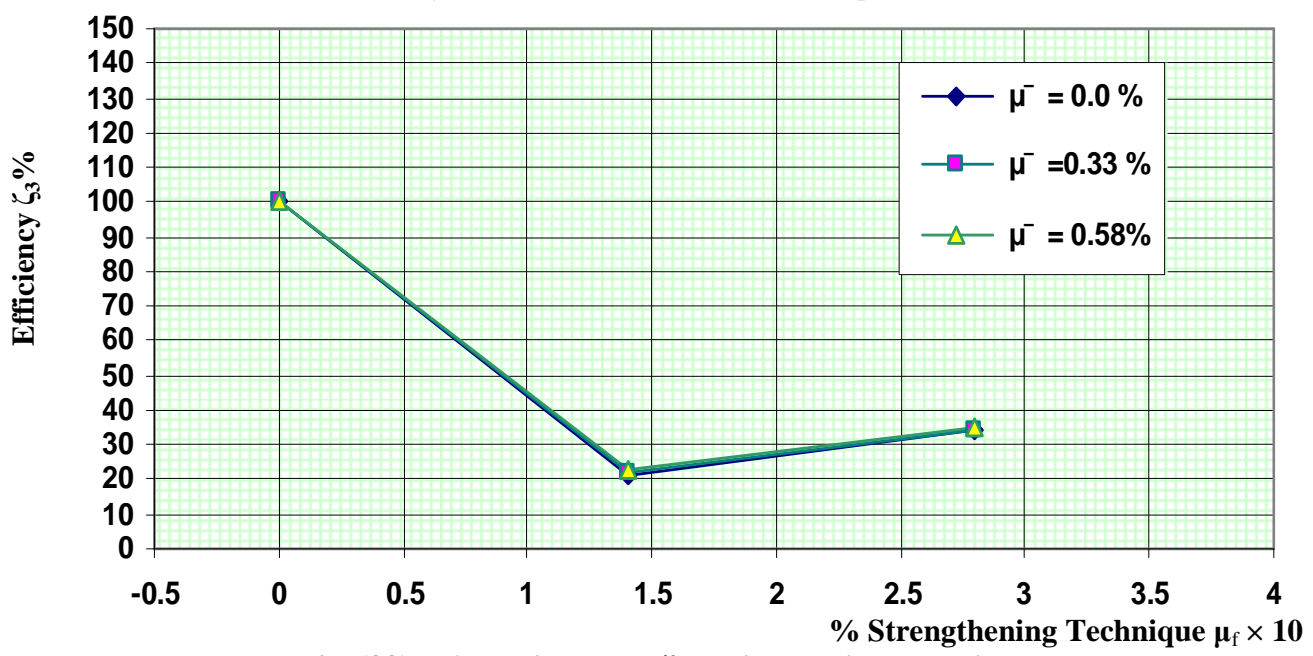

Fig. (88) Relation between $\left(\zeta_{3}\right)$ and strengthening technique for R.C circular section (Group $\boldsymbol{G}$ ) 


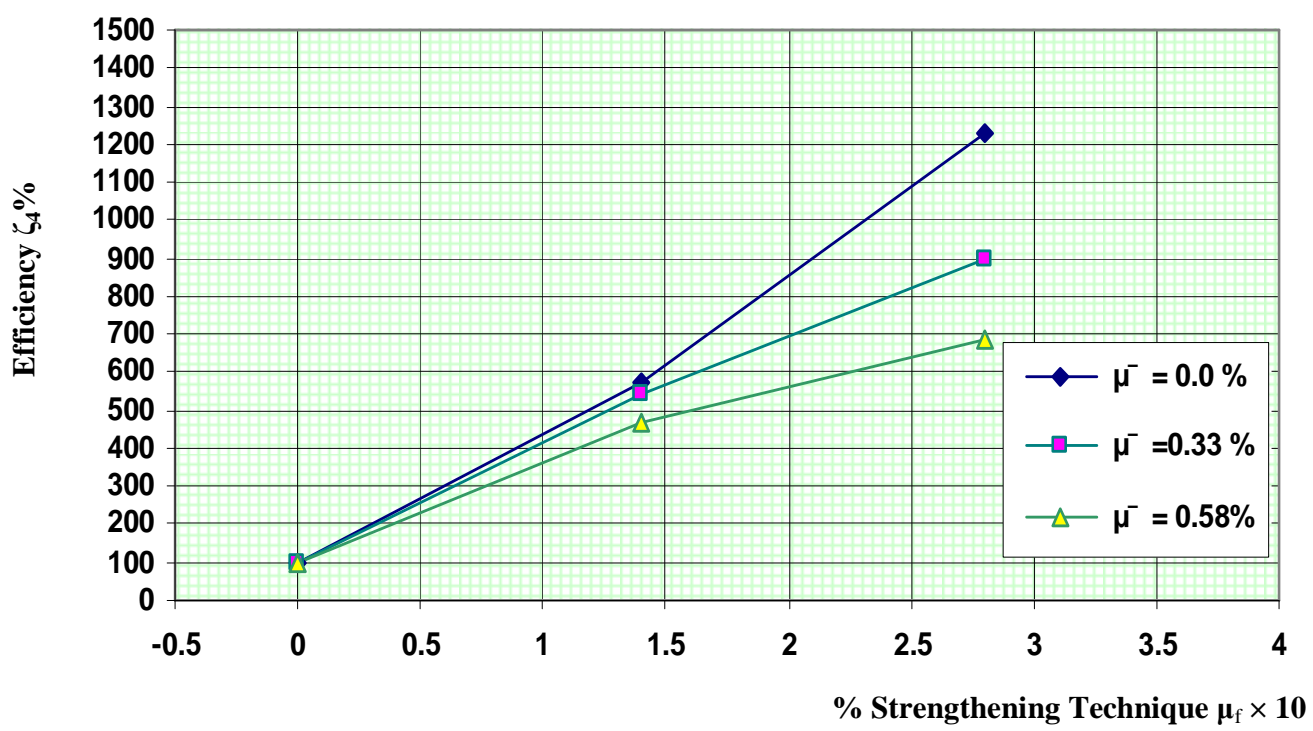

Fig. (89) Relation between $\left(\zeta_{4}\right)$ and strengthening technique for R.C circular section (Group $\boldsymbol{G}$ )

Generally, the values of strength $\left(\zeta_{1}\right)$, ductility $\left(\zeta_{2}\right)$, stiffness $\left(\zeta_{3}\right)$ and of absorbed energy $\left(\zeta_{4}\right)$ are increased by increasing number of layers of CFRP . Taking into consideration that $\left(\zeta_{1}\right)$ and $\left(\zeta_{4}\right)$ values were decreased by increasing the percentage of lateral steel as shown in these Figs.

\section{5 - CONCLUSIONS}

Based on the obtained experimental results the following conclusions are being drown out:

\section{5-1 With Respect to axially loaded Plain Concrete Columns:}

The behavior of such columns under axially static loading mainly depends on the shape of cross section, the size of cross section and the degree and type of lateral confinement as follows:

1- For plain concrete columns circular, square and rectangular sections, the strength efficiency, ductility efficiency, stiffness efficiency and the absorbed energy efficiency are higher for confined 1 layer columns than that for the unconfined columns.

2- For plain concrete columns circular, square and rectangular sections, as the cross section increase strength, ductility, stiffness and the absorbed energy efficiency are decreased.

3- The strength efficiency or the percentage of increase in strength due to confinement of plain concrete with one layer vanishes when diameter of circular column (D) is higher than $30 \mathrm{~cm}$, when size of square column $\mathrm{B}=25 \mathrm{~cm}$ and when $(\mathrm{t} / \mathrm{b})$ ratio for rectangular $=(4.0)$.

4- The ductility efficiency or the percentage of increase of axial nominal strain due to confinement of plain concrete with one layer vanishes when diameter of 
circular column (D) is $=34 \mathrm{~cm}$, when $\mathrm{B}=30 \mathrm{~cm}$ for plain square columns and when $(t / b)=4.0$ for rectangular columns .

5- The stiffness efficiency or the percentage of increase of modulus of elasticity due to confinement of plain concrete with one layer vanishes when diameter of circular column (D) is $=40 \mathrm{~cm}$, when B approximately $=40 \mathrm{~cm}$ for plain square columns and when $(\mathrm{t} / \mathrm{b})$ ratio $=(6)$ for plain rectangular concrete columns.

6- The Absorbed energy efficiency or the percentage of increase of the modulus of toughness due to confinement of plain concrete with one layer vanishes when diameter of circular column (D) is $=25 \mathrm{~cm}$, when $\mathrm{B}=35 \mathrm{~cm}$ for plain square columns and when $(\mathrm{t} / \mathrm{b})$ ratio $=(4.65)$ for $\mathrm{r}$ plain rectangular concrete columns.

7- The shape of cross-section for unconfined plain concrete columns has no significant effect on strength efficiency, ductility efficiency, stiffness efficiency and the absorbed energy efficiency where the shape of cross-section has a significant effect for confined concrete columns.

8- For confined plain concrete columns, strength efficiency, ductility efficiency, stiffness efficiency and the absorbed energy efficiency are higher for circular sections than that for square sections; also later efficiencies of square concrete sections are higher than that for the rectangular concrete sections.

\section{5-2 With Respect to Reinforced Concrete Columns:}

\section{5-2-1 Effect of Size and Shape of Cross- Section:}

The behavior of such R.C short static loading columns mainly depends on : the shape and size of cross section, presence and percentage of longitudinal reinforcement, presence and percentage of lateral reinforcement as well as the strengthening technique as follows:

1- For reinforced concrete columns circular, square and rectangular section, the strength efficiency, ductility efficiency, stiffness efficiency and the absorbed energy efficiency are higher for confined 1 layer than that for unconfined column.

2- For reinforced concrete columns circular sections, as the cross section increase, the strength efficiency, the ductility efficiency, the stiffness efficiency and the absorbed energy efficiency decrease.

3- The strength efficiency or the percentage of increase in strength due to confinement of reinforced concrete with one layer vanishes when diameter of circular column (D) is higher than $30 \mathrm{~cm}$.

4- The ductility efficiency or the percentage of increase of axial nominal strain due to confinement of reinforced concrete with one layer vanishes when diameter of circular column (D) is $=30 \mathrm{~cm}$.

5- The stiffness efficiency or the percentage of increase of modulus of elasticity due to confinement of reinforced concrete with one layer vanishes when diameter of circular column (D) is $=38 \mathrm{~cm}$.

6- The Absorbed energy efficiency or the percentage of increase of the modulus of toughness due to confinement of reinforced concrete with one layer vanishes when diameter of circular column (D) is $=25 \mathrm{~cm}$.

7- The shape of cross-section for unconfined reinforced concrete columns has no significant effect on strength efficiency, ductility efficiency, stiffness efficiency and 
the absorbed energy efficiency where the shape of cross-section for confined concrete columns has a significant effect on such efficiencies.

8- For confined reinforced concrete columns, the strength efficiency, the ductility efficiency, the stiffness efficiency and the absorbed energy efficiency of circular sections are improved than square, also these efficiencies of square concrete columns is higher than that of the rectangular sections.

\section{5-2-2 Effect of the Percentage of Longitudinal Steel:}

1- For confined one layer circular concrete columns with longitudinal reinforcement, the axial nominal stress, the axial nominal strain, the modulus of elasticity and the modulus of toughness increases slightly compared with that confined one layer plain concrete

2- All the efficiencies, strength efficiency, ductility efficiency, stiffness efficiency and the absorbed energy efficiency decrease slightly due to longitudinal reinforcement for different shapes sections.

\section{5-2-3 Effect of the Percentage of Lateral Reinforcement (stirrups):}

1- 1- The axial nominal stress, the axial nominal strain, the modulus of elasticity and the modulus of toughness are increased by increasing the percentage of lateral steel.

2- As the percentage of lateral steel increases, the strength efficiency is decreased; the rate of decreasing of strength efficiency by increasing the percentage of lateral steel for confined one layer is higher than that for the confined two layers columns.

3- 3- As the percentage of lateral steel increases, the ductility efficiency is increased; the rate of increasing of ductility efficiency by increasing the percentage of lateral steel for confined two layers is higher than that for the confined one layer columns.

4- Also as the percentage of lateral reinforcement increases, the stiffness efficiency is increased very slightly for both confined 1layer and two layers columns.

5- As the percentage of lateral steel increases, the absorbed energy is decreased for both confined 1 layer and two layers. The rate of decreasing of confined two layers columns is bigger than that of confined one layer columns.

\section{5-2-4 Effect of the Strengthening Technique:}

1- As a general rule, as the strengthening technique increases, the axial nominal stress, the axial nominal strain, the modulus of elasticity and the modulus of toughness increase for both unconfined and confined one layer or two layers reinforced concrete columns.

2- As the strengthening technique increases, the strength efficiency is decreased; the rate of decreasing of strength efficiency for confined two layers is higher than that of the confined one layer columns.

3- As the strengthening technique increases, the ductility efficiency is increased; the rate of increasing of ductility efficiency for confined one layer is higher than that of the confined two layers columns.

4- Also as the strengthening technique increases, the stiffness efficiency increases very slightly for both confined 1layer and two layers columns. 
5- As strengthening technique increases, the absorbed energy is decreased for both confined 1 layer and two layers. The rate of decreasing of confined two layers is bigger than that of confined one layer columns.

\section{REFERENCES}

1- Bakis E. B. (1993) ; FRP Reinforcement, Materials and Manufacturing in Fiber Reinforced- Plastic (FRP) Reinforcement for Concrete Structure: Properties and Applications, Development in Civil Engineering 42, Ed. A. Nanni, Elsevier Science, Amsterdam, The Netherlands, pp. 13-58.

2- ACI (1996); State-of-the-Art Report on Fiber Reinforced Plastic Reinforcement for Concrete Structure, ACI Report 440R-96, American Concrete Institute, ACI Committes 440, Detroit, Michigan, USA, 153 pp.

3- Fib CEB-FIB (2001); Externally Bonded FRP Reinforcement for RC Structures, Bulletin, 14, July 2001

4- SIKA. (2001); Sika Carbdur System, P.C.26: Specifications for Structural Strengthening with SIKA, CARBODUR System.

5- Stijn Matthys (2000); Structural Behavior and Design of Concrete Members Strengthened with Externally Bonded FRP Reinforcement, pp. 51- 60.

6- Shaw J.D.N, (1982); A Review of Resin used in Construction, Type of Resins Application - Case Histories , Int. Journal Adhesion and Adhesive, April 1982.pp 77-83.

7- CEN (1999); Products and System for The Protection and Repair of Concrete Structure Definition - Requirement - Quality Control and Evaluation of Conformity, Part 4 : Structural Bonding, prEN 1504-4, Comite Europen de Normalisation (CEN), Brussels, Belgium, $18 \mathrm{pp}$.

8- Samaan M., Mirmiran A., Shahawy M. (1999); Model of Concrete Confined by Fiber Composites, ASCE Journal of Structural Engineering, Vol. 124, No. 9,pp. 1025-1031.

9- Mirmiran A., Kargahi M., Samaan M. and Shahawy M. (1996 ); Composite FRPConcrete Column with Bi-direction External Reinforcement, Proceeding 1 st. Int. Conf. on Composite in Infrastructure, Eds. H. Saadatmanesh and M. R. Ehasni, Tucson, Arizona. USA,pp.888-902.

10- Matthys S. (1997); Proceeding 4National Congres over Theoretische en Toegepast Mechanica, Leuven, Belgium, pp. 445-448.

11- Mark J. Masia, Trevor N. Gale, and Nigal. Shrive (2004) ; Size Effects in Axially Loaded Square-Section Concrete Prisms Strengthened Using Carbon Fiber Reinforced Polymer Wrapping , NRC Research.

12- M. Reza Esfahani, And M. Reza Kianouh (2004); Axial Compressive Strength of Reinforced Concrete Columns Wrapped with FRP, $1{ }^{\text {st }}$ Conference on Application of FRP. Composites in Construction and Rehabilitation of Structures, Tehran, Iran.

13- SIKA (1998); Technical Report Strengthening of Struture with CFRP Lemanites, July 1998. 


\section{بعض العوامل الرئيسية التي تؤثر على كفاعة التقوية الخارجية للأعمدة الخرسانية

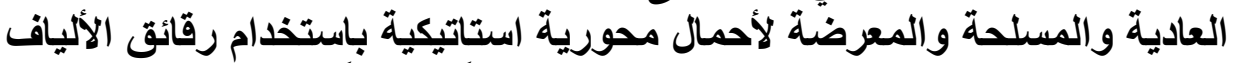 الكربونية الملصوقة عرضياً وجزئياً}

في هذا البحث تم بعمل دراسة معملية لعدد 37 عمود خرساني لبيان مدى كفاءة التقوية باستخدام رقائق

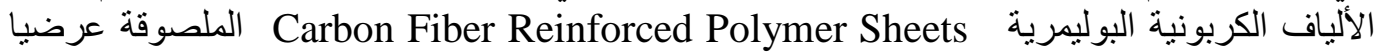

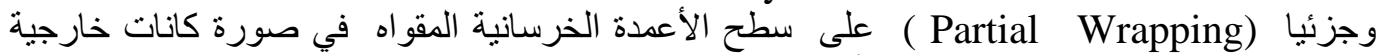

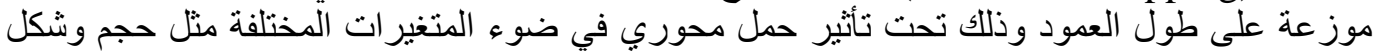

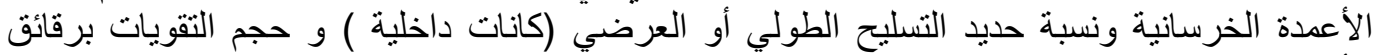

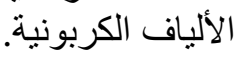

في هذا البحث تم دراسة مساهمة شر ائح الألياف الكربونية في تحسين كل من المقاومة لتتحمل الأحمال



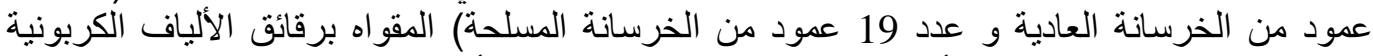

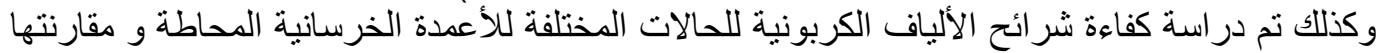

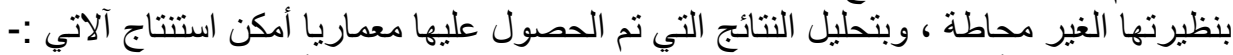

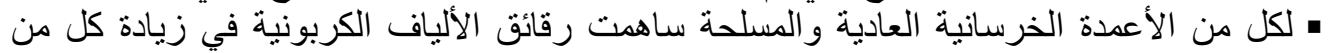

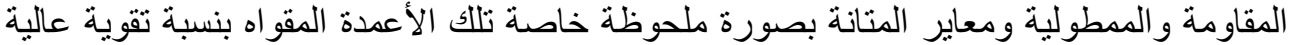

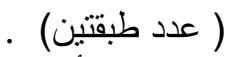
• لكل من الأعمدة الخرسانية العادية والمسلحة ساهمت رقائق الألياف الكربونية في زيادة معامل

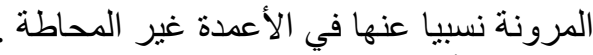

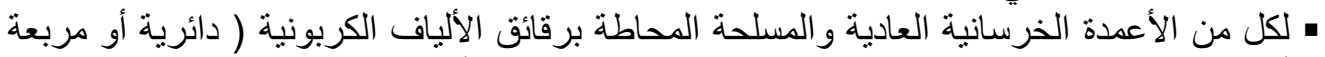

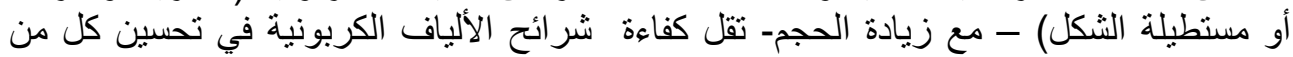

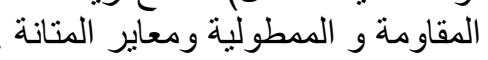

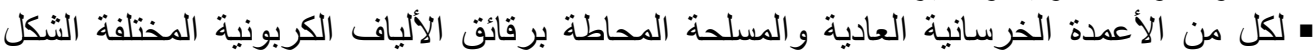

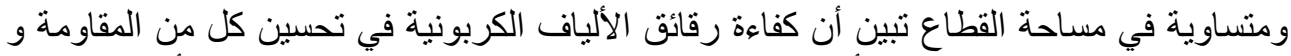

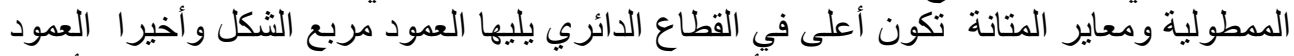

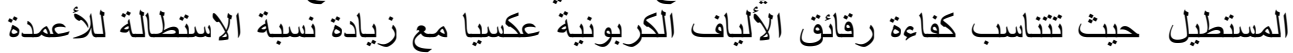

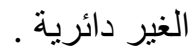

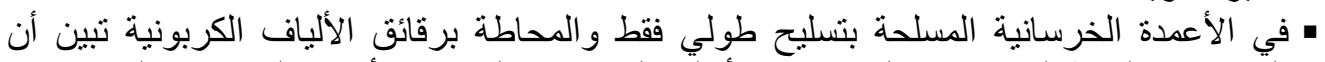

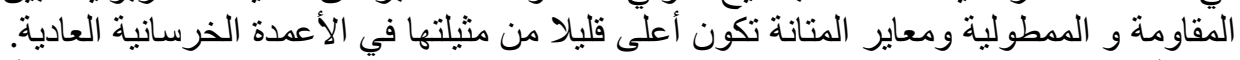

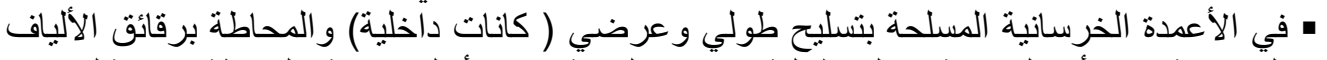

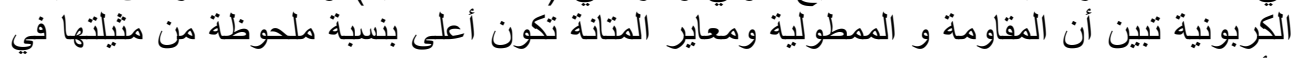

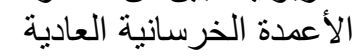

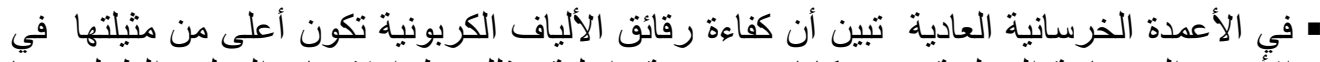

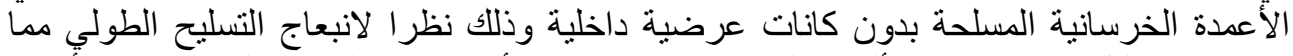

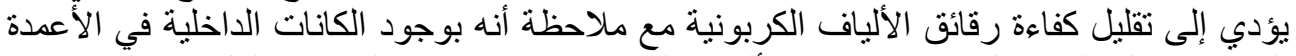

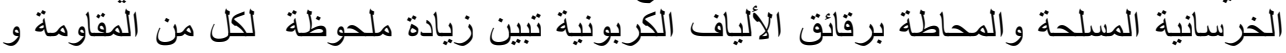

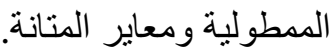

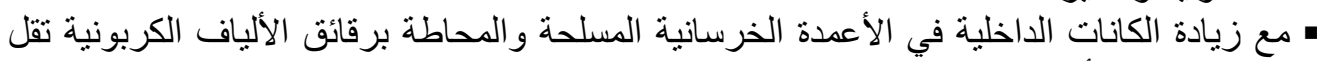

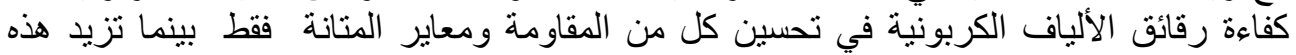

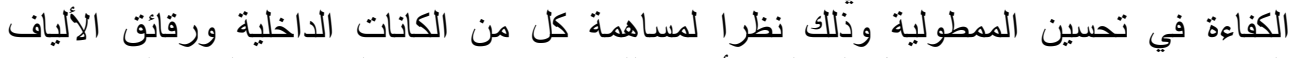

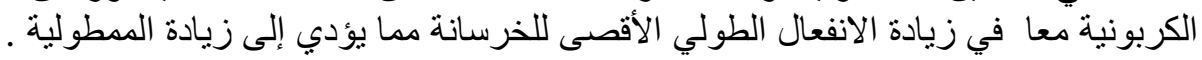




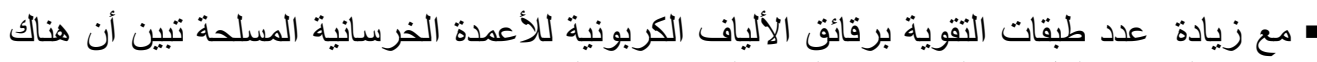

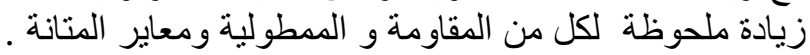

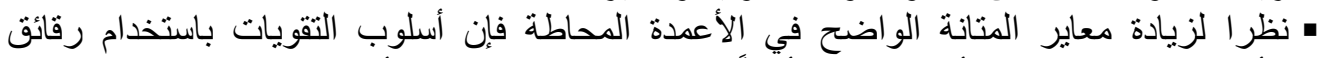

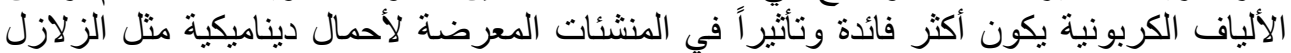

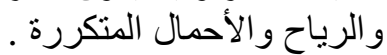

